Maicon Gouvêa de Oliveira

\title{
Integração do technology roadmapping (TRM) e da gestão de portfólio para apoiar a macro-fase de pré- desenvolvimento do PDP: estudo de caso em uma pequena empresa de base tecnológica
}

Dissertação apresentada à Escola de Engenharia de São Carlos, da Universidade de São Paulo, para obtenção do título de Mestre em Engenharia de Produção

Área de concentração: Gestão de projetos e desenvolvimento de produtos Orientador: Prof. Tit. Henrique Rozenfeld 

TRABALHO, POR QUALQUER MEIO CONVENCIONAL OU ELETRÔNICO, PARA FINS DE ESTUDO E PESQUISA, DESDE QUE CITADA A FONTE.

Ficha catalográfica preparada pela Seção de Tratamento da Informação do Serviço de Biblioteca - EESC/USP

$048 i$

\section{Oliveira, Maicon Gouvêa de}

Integração do technology roadmapping (TRM) e da gestão de portfólio para apoiar a macro-fase de prédesenvolvimento do PDP : estudo de caso em uma pequena empresa de base tecnológica / Maicon Gouvêa de Oliveira ; orientador Henrique Rozenfeld. -- São Carlos, 2009.

Dissertação (Mestrado-Programa de Pós-Graduação e Área de Concentração em Engenharia de Produção) -- Escola de. Engenharia de São Carlos da Universidade de São Paulo, 2009 .

1. Desenvolvimento de produto. 2. Pré-desenvolvimento. 3. Technology roadmapping. 4. Gestão de portfólio.

5. Planejamento estratégico de produtos. . Tátulo. 
Candidato: Engenheiro MAICON GOUVÊA DE OLIEVEIRA

Dissertação defendida e julgada em 16/04/2009 perante a Comissão Julgadora:
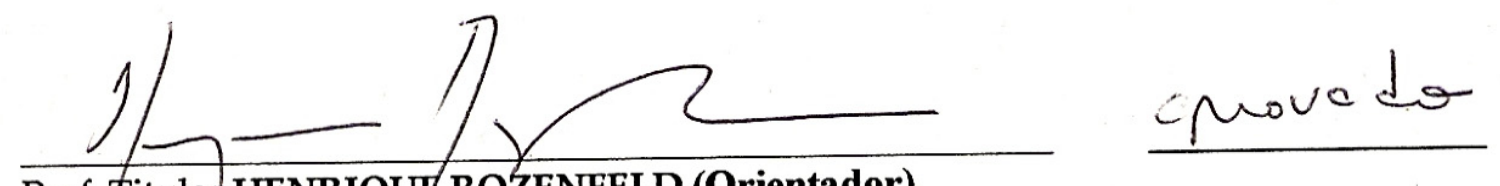

Prof. Titular HENRIQUE ROZENFELD (Orientador)

(Escola de Engenharia de São Carlos/USP)

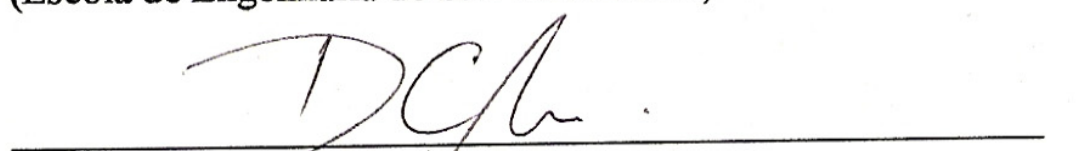

$$
\text { APNOVADO }
$$

Prof. Dr. DANIEL CAPALDO AMARAL

(Escola de Engenharia de São Carlos/USP)

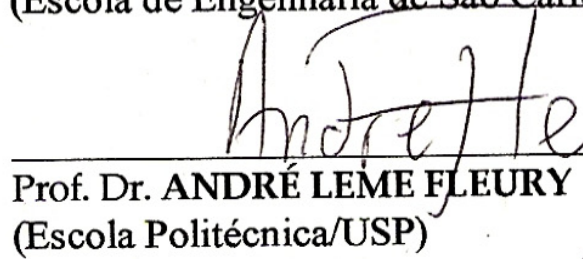

(Escola Politécnica/USP)
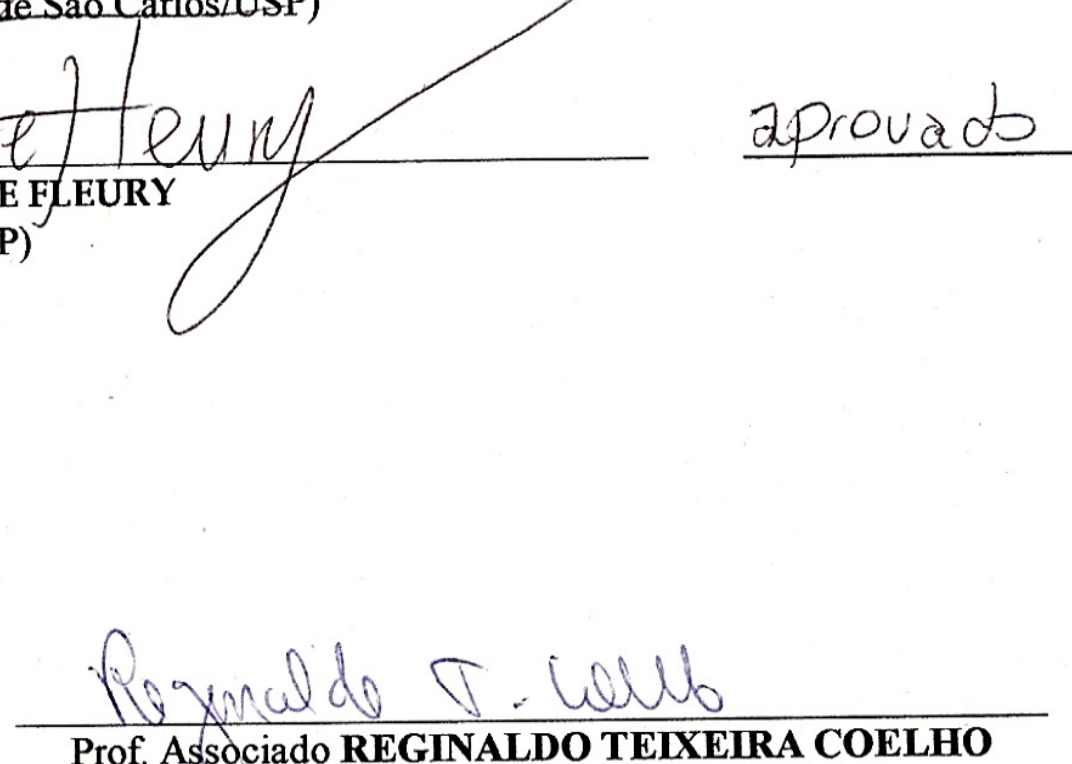

Prof. Associado REGINALDO TEIXEIRA COELHO

Coordenador do Programa de Pós-Graduação em

Engenharia de Produção

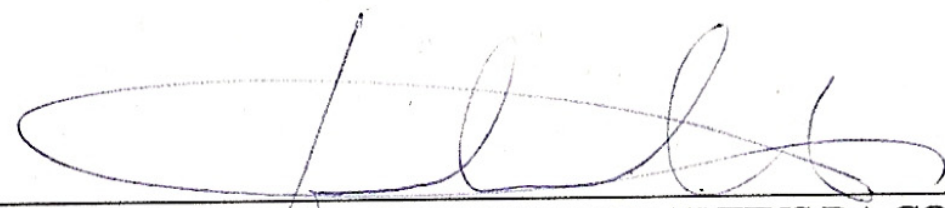

Prof. Associado GERALDO ROBERTO MARTINS DA COSTA

Presidente da Comissão da Pós-Graduação da EESC 


\section{Agradecimentos}

Agradeço primeiramente aos meus pais, Ana Rosa e Geraldo, pelo apoio incondicional na minha vida e na minha educação.

À minha namorada Natália, companheira de todos os momentos, que amo tanto.

Ao meu irmão Guilherme, meus avós José e Aorildes, minha tia Ana Paula, pela amizade sempre presente.

Ao meu orientador, Prof. Henrique Rozenfeld, pela amizade e oportunidade ímpar de aprendizado.

Aos amigos do NUMA (Janaína, Sayuri, Vitor, Prof. Daniel, Eduardo) e especialmente ao amigo Edivandro pela amizade, dicas e contribuições no trabalho.

E aos participantes da empresa Nanox (Leandro, Daniel, Gustavo, Maurício e André) pela contribuição essencial nos resultados da pesquisa

Á Fundação de Amparo à Pesquisa do Estado de São Paulo (FAPESP), pelo fomento disponibilizado para o desenvolvimento da pesquisa 


\section{Sumário}

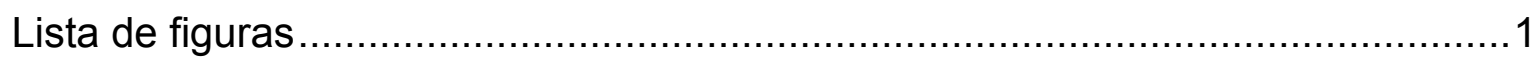

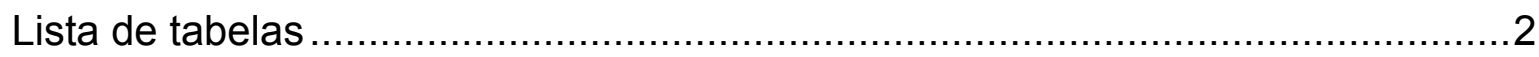

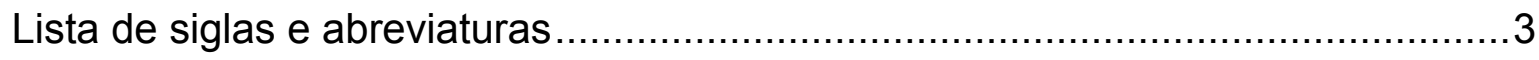

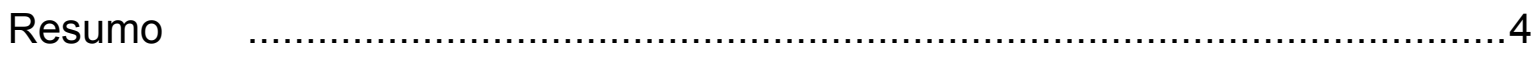

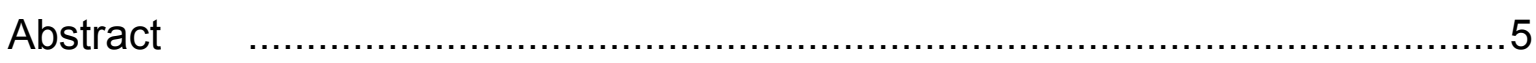

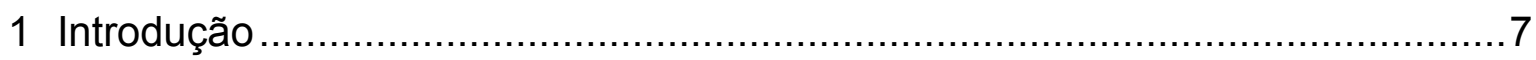

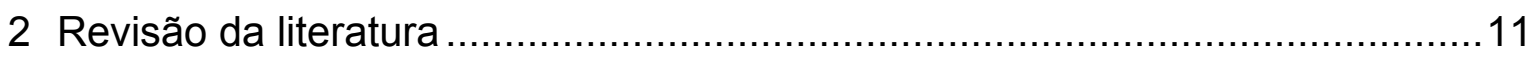

2.1 Gestão de desenvolvimento de produtos (GDP) …............................................... 11

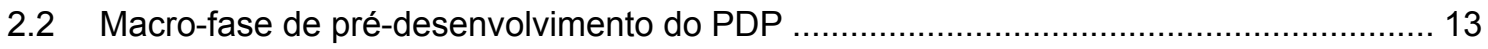

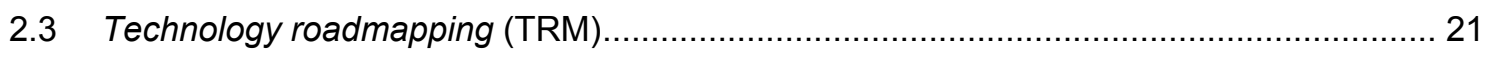

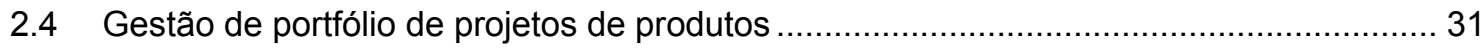

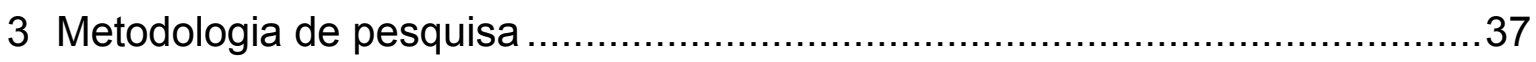

3.1 Classificações da pesquisa e métodos científicos ...................................................... 37

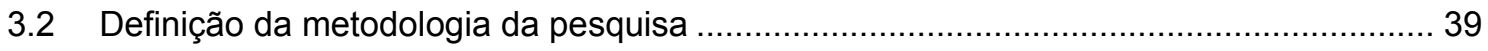

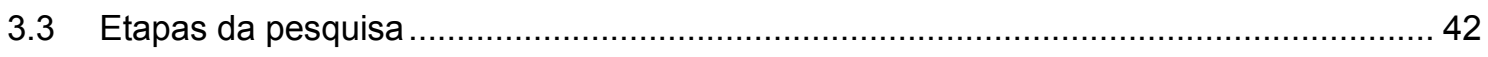

4 Método ITG: planejamento estratégico do portfólio de projetos de produtos ....47

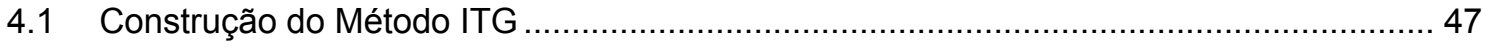

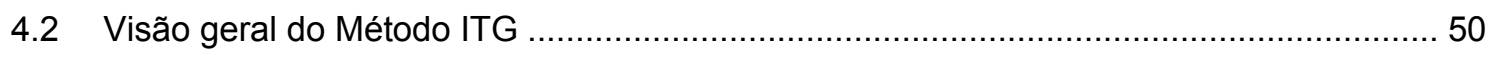

4.3 Atividade 1 - Definição da unidade de análise ............................................................ 52

4.4 Atividade 2 - Análise das estratégias do negócio..................................................... 54

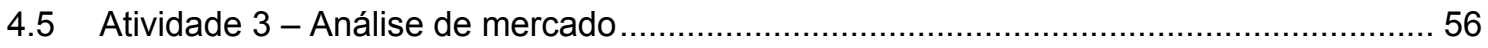

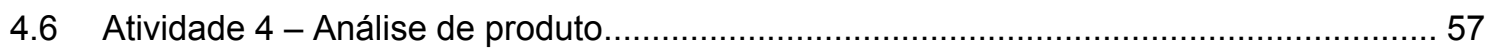

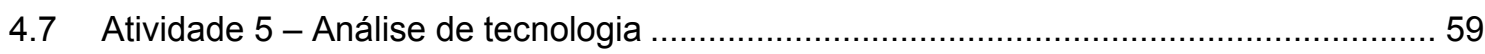

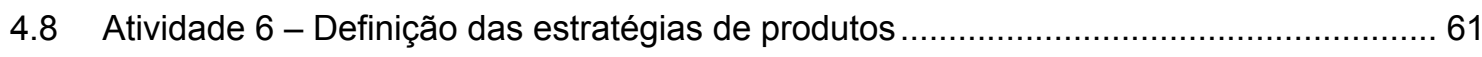

4.9 Atividade 7 - Proposição de projetos de novos produtos ................................................. 63 
4.10 Atividade 8 - Avaliação financeira de projetos.

4.11 Atividade 9 - Avaliação da probabilidade de sucesso de projetos .........................68

4.12 Atividade 10 - Avaliação do potencial estratégico dos projetos ............................72

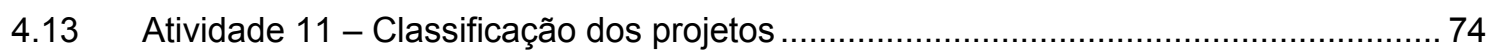

4.14 Atividade 12 - Análise do relacionamento entre os projetos ............................. 76

4.15 Atividade 13 - Seleção de projetos de produto para desenvolvimento ..................... 78

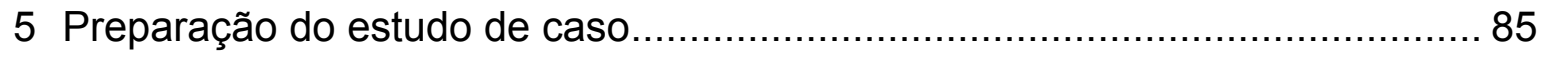

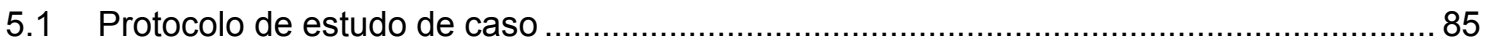

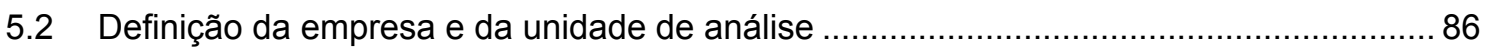

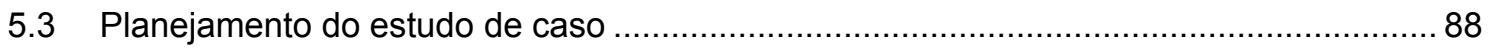

6 Resultados e avaliação do estudo de caso em uma pequena empresa de base

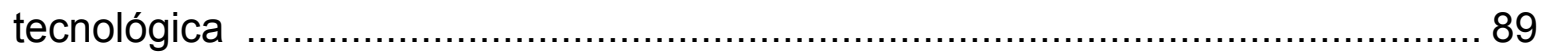

6.1 Atividade 1 - Definição da unidade de análise .............................................. 89

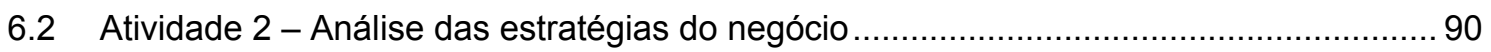

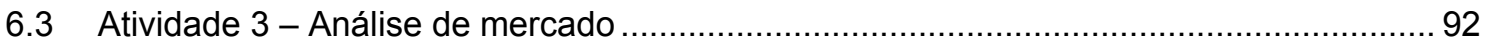

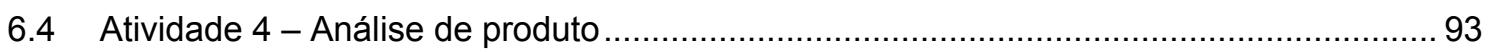

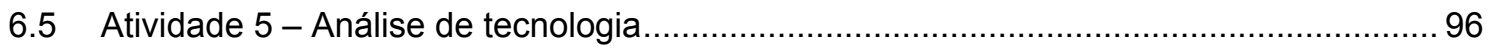

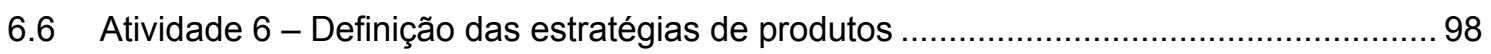

6.7 Atividade 7 - Proposição de projetos de novos produtos ................................... 101

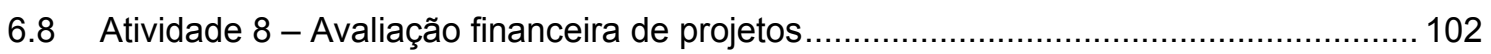

6.9 Atividade 9 - Avaliação da probabilidade de sucesso do projeto ............................. 102

6.10 Atividade 10 - Avaliação do potencial estratégico do projeto .............................. 103

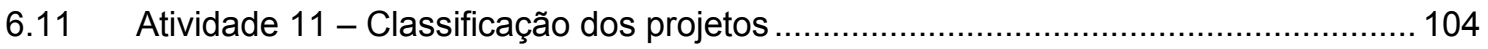

6.12 Atividade 12 - Análise do relacionamento entre os projetos ............................. 106

6.13 Atividade 13 - Seleção de projetos de produto para desenvolvimento .................... 107

6.14 Avaliação dos resultados do estudo de caso ............................................. 110

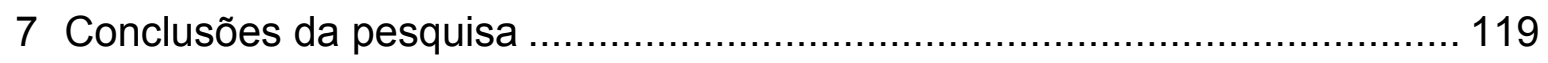

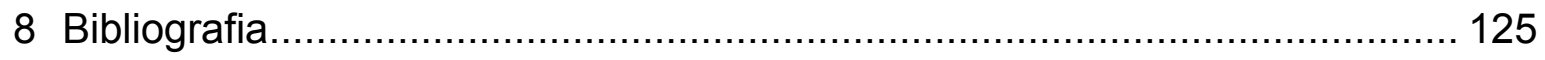


9 Apêndice

129

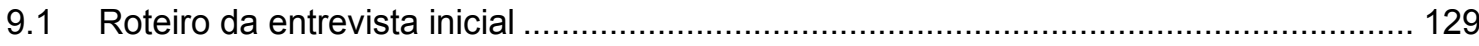

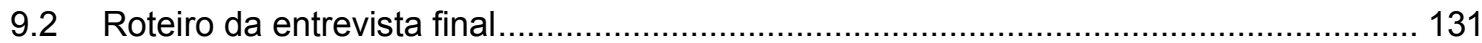

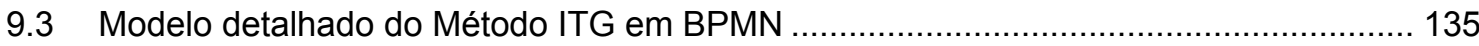




\section{Lista de figuras}

Figura 1 - Modelo das fases e Gates do PDP de Crawford e Benedetto (2006). Adaptado da fonte. 17 Figura 2 - Modelo das atividades da fase de identificação e seleção de oportunidades de produtos. Adaptado de Crawford e Benedetto (2006).

Figura 3 - Modelo das atividades da fase de geração de conceito de produto. Adaptado de Crawford e Benedetto (2006). 19

Figura 4 - Modelo das atividades da fase de avaliação de conceito e projeto de produto. Adaptado de Crawford e Benedetto (2006).

Figura 5 - Classificação do TRM segundo Kappel (2001). Adaptado da fonte.................................. 26

Figura 6 - Formato de roadmap proposto por EIRMA (1997). Adaptado de Phaal (2004)................. 27

Figura 7 - Processo de aplicação do TRM proposto pelo T-Plan. Adaptado de Phaal (2004)........... 29

Figura 8 - Processo de gestão de portfólio de Cooper et al. (1998). Adaptado da fonte..................... 34

Figura 9 - Processo de gestão de portfólio de Archer e Ghasemzadeh (1999). Adaptado da fonte. .. 35

Figura 10 - Processo de gestão de portfólio de Bitman (2005). Adaptado da fonte............................ 36

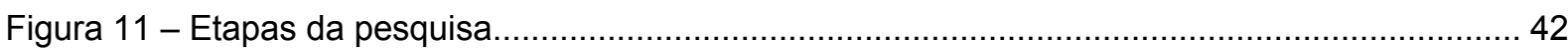

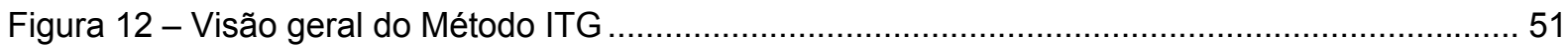

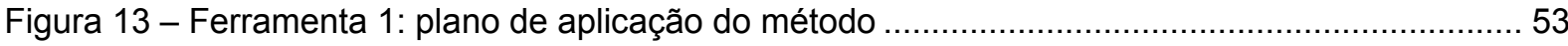

Figura 14 - Dimensões de desempenho do produto. Adaptado de Phaal et al. (2001)....................... 54

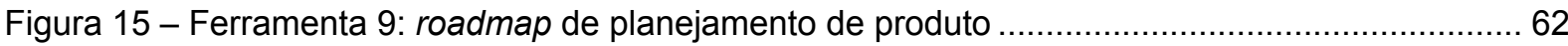

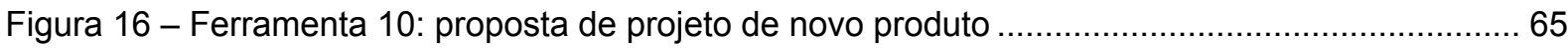

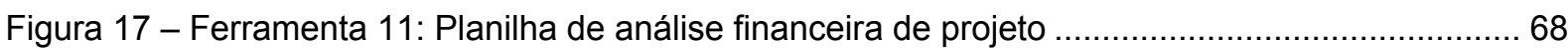

Figura 18 - Ferramenta 16: planilha de análise dos relacionamentos entre os projetos .................... 78

Figura 19 - Ferramenta 17: planilha de análise de cestas de investimento ........................................ 80

Figura 20 - Ferramenta 19: planilha de verificação do equilíbrio do portfólio de projetos ................... 83

Figura 21 - Versão inicial do roadmap de planejamento do produto do caso Nanox ........................... 99

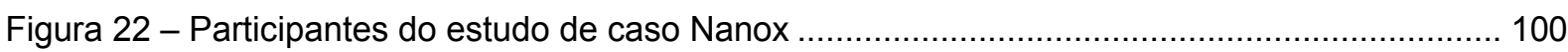

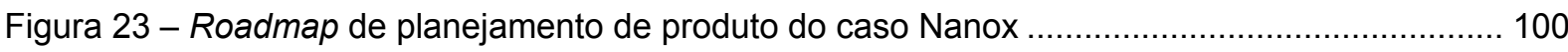

Figura 24 - Propostas de projetos de novos produtos do caso Nanox ........................................... 101

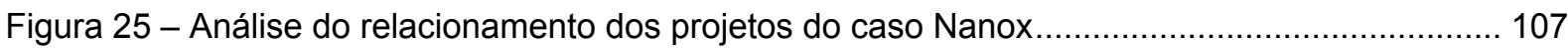

Figura 26 - Gráfico de bolhas dos projetos selecionados do caso Nanox ....................................... 108

Figura 27 - Comparação entre o mini-roadmap e o roadmap de planejamento .................................. 109

Figura 28 - Membros da empresa durante atividade de seleção de projetos ................................... 109

Figura 29 - Contribuição do technology roadmapping nas atividades do pré-desenvolvimento ........ 113

Figura 30 - Contribuição da gestão de portfólio nas atividades do pré-desenvolvimento .................. 113

Figura 31 - Mudanças ocasionadas pelo método nas atividades do pré-desenvolvimento............... 114 


\section{Lista de tabelas}

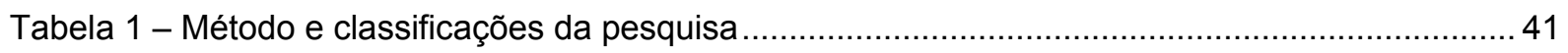

Tabela 2 - Ferramenta 2: planilha de dimensões de desempenho do produto ..................................... 56

Tabela 3 - Ferramenta 3: planilha de direcionadores do negócio .....................................................56

Tabela 4 - Ferramenta 4: planilha de direcionadores de mercado..................................................... 57

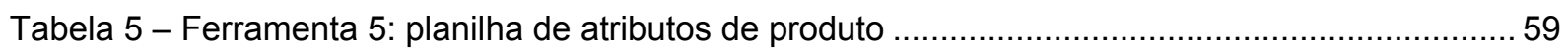

Tabela 6 - Ferramenta 6: planilha de avaliação impacto dos atributos de produto nos direcionadores 59

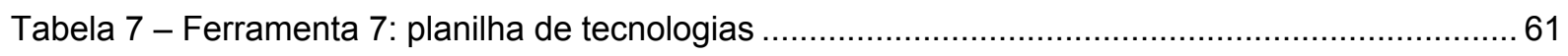

Tabela 8 - Ferramenta 8: planilha de avaliação do impacto das tecnologias nos atributos de produto .61

Tabela 9 - Ferramenta 12.1: lista padrão de riscos técnicos......................................................... 70

Tabela 10 - Ferramenta 12.2: lista padrão de riscos comerciais ..................................................... 71

Tabela 11 - Ferramenta 12.3: planilha de avaliação da probabilidade de sucesso do projeto ............. 72

Tabela 12 - Ferramenta 13.1: lista padrão de critérios estratégicos ................................................ 73

Tabela 13 - Ferramenta 13.2: cálculo do potencial estratégico do projeto ........................................ 73

Tabela 14 - Ferramenta 14: planilha de banco de dados dos projetos ............................................. 75

Tabela 15 - Ferramenta 15: planilha de classificação dos projetos ................................................. 76

Tabela 16 - Ferramenta 18: planilha de análise de alocação de recursos críticos ............................... 80

Tabela 17 - Dimensões de desempenho de produto do caso Nanox .................................................90

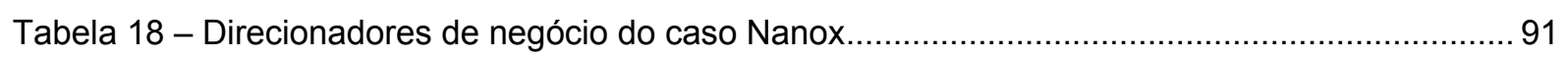

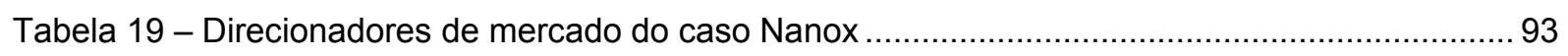

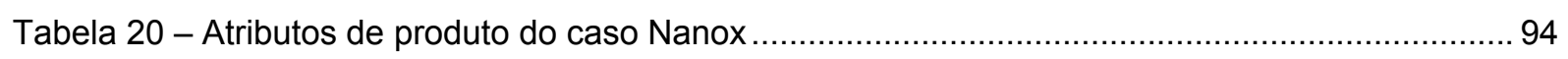

Tabela 21 - Avaliação do impacto dos atributos de produto nos direcionadores do caso Nanox ....... 95

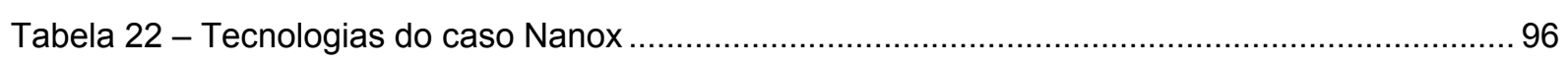

Tabela 23 - Avaliação do impacto das tecnologias nos atributos de produto do caso Nanox ............. 97

Tabela 24 - Indicadores financeiros das propostas de projetos do caso Nanox............................... 102

Tabela 25 - Avaliação de probabilidade de sucesso de projetos do caso Nanox ............................... 103

Tabela 26 - Resultados da avaliação do potencial estratégico dos projetos do caso Nanox ............. 104

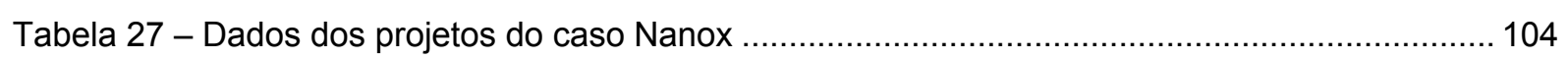

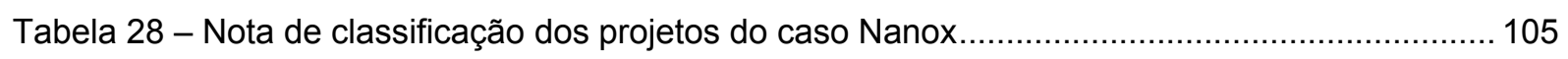




\title{
Lista de siglas e abreviaturas
}

\author{
EIRMA - European industrial research management association \\ EITIM - European institute for technology and innovation management \\ PDP - Processo de desenvolvimento de produtos \\ PDT - Processo de desenvolvimento de tecnologias \\ QFD - Quality function deployment \\ $\mathrm{ROI}$ - Return of investment \\ TIR - Taxa interna de retorno \\ TMA - Taxa mínima de atratividade \\ TRM - Technology roadmapping \\ VCE - Valor comercial esperado \\ VPL - Valor presente líquido
}




\section{Resumo}

Embora as atividades do pré-desenvolvimento sejam essenciais para 0 sucesso no desenvolvimento dos produtos, elas têm sido pouco efetivas no alcance dos seus objetivos. Uma das oportunidades para melhorá-las é a integração dos métodos usados no pré-desenvolvimento, os quais têm sido aplicados de forma isolada. Uma revisão bibliográfica mostrou que o technology roadmapping (TRM) e a gestão de portfólio se destacam entre os métodos usados no pré-desenvolvimento. Esse contexto motivou a investigação da pergunta de pesquisa: "A aplicação integrada do technology roadmapping e da gestão de portfólio contribui com a realização das atividades do pré-desenvolvimento do PDP?". Assim este trabalho avalia o potencial dessa integração a partir de um estudo de caso em uma pequena empresa de base tecnológica. O estudo de caso utilizou um método desenvolvido pela pesquisa para aplicação integrada do technology roadmapping e da gestão de portfólio, o Método ITG. Os resultados obtidos mostraram que a integração beneficiou o pré-desenvolvimento neste caso específico. Entre as contribuições notadas estão: aumento da eficácia do pré-desenvolvimento e o alinhamento das propostas de novos projetos de produtos com as estratégias do negócio, necessidades do mercado e capacidades tecnológicas. Portanto, a integração dos métodos parece constituir um tema com potencial para ajudar as empresas na realização das atividades do pré-desenvolvimento. 


\begin{abstract}
Although the front-end activities are critical to the success of NPD, they are in fact almost ineffective in practice. One opportunity to improve them is the integration of methods used in front-end, which have been applied stand-alone. A bibliographical review showed that technology roadmapping (TRM) and portfolio management are stand out methods for the front-end of NPD. This finding motivated the research question of our work: Can the integration of TRM and portfolio management contribute to improve the front-end of NPD? Hence, this work evaluates the potential of this integration based on a case study at a small technology-based company. The study applied a method built in research for integrated application of technology roadmapping and portfolio management, the ITG Method. In this specific case, the front-end of NPD benefited from the integration. Among the contributions are: the rising of front-end effectiveness and the alignment of new product project proposals with business strategies, market wants and technological capabilities. Therefore, the methods integration appears to constitute a productive field to help companies in the activities of the NPD front-end.
\end{abstract}




\section{Introdução}

As atividades iniciais do processo de desenvolvimento de produtos (PDP) formam a macro-fase denominada de pré-desenvolvimento. Essa macro-fase do PDP é responsável pela definição dos produtos da empresa e corresponde às atividades realizadas antes do desenvolvimento dos projetos dos produtos. De acordo com modelo de PDP proposto por Crawford e Benedetto (2006), o prédesenvolvimento envolve a identificação e seleção de oportunidades para produtos, a geração de idéias e conceitos de produtos e a avaliação de conceitos e projetos de produtos.

Embora as atividades do pré-desenvolvimento sejam essenciais para 0 sucesso no desenvolvimento dos produtos, alguns estudos mostram que essas têm sido pouco efetivas no alcance dos seus objetivos (GRIFFIN, 1997; COOPER, 2001; COOPER et al., 2004). Como consequência desse alerta, têm surgido trabalhos que buscam ajudar as empresas na realização das atividades do pré-desenvolvimento. Entre eles destacam-se: Clark e Wheelwright (1993), Gil et al. (1996), Cooper et al. (2001), Koen et al. (2002) e Crawford e Benedetto (2006).

Estudos recentes mostram que ainda existem oportunidades capazes de contribuir com as empresas na melhoria da realização do pré-desenvolvimento (JETTER, 2003; ALBRIGHT e NELSON, 2004; PHAAL et al., 2005; LEE et al., 2008). Uma delas é a aplicação integrada dos métodos usados no prédesenvolvimento. Essa oportunidade de melhoria está baseada no fato que tais métodos são normalmente aplicados de forma isolada, o que impossibilita uma ação completa e alinhada da empresa nas atividades dessa macro-fase do PDP (PHAAL et al., 2005). 
A exploração das oportunidades que envolvem a integração dos métodos utilizados no pré-desenvolvimento é ampla, portanto é preciso delimitar um escopo entre os métodos existentes para que seja possível investigá-la. Um caminho inicial seria selecionar aqueles que se destaquem individualmente e então avaliar o potencial da aplicação integrada para melhorar o pré-desenvolvimento.

Dentre os vários métodos usados no pré-desenvolvimento, foram selecionados o technology roadmapping e a gestão de portfólio, pois são considerados fatores de sucesso no desenvolvimento de produtos (COOPER et al., 2004), são complementares e porque juntos abrangem grande parte das atividades do prédesenvolvimento. O technology roadmapping é um método usado para o planejamento estratégico de produtos. Ele permite que o planejamento dos produtos considere as necessidades e tendências do mercado e as possibilidades tecnológicas. Já a gestão de portfólio auxilia na seleção dos projetos de produtos, permitindo que o portfólio definido atenda aos objetivos estratégicos do negócio.

Desse modo, o escopo definido para explorar as oportunidades mencionadas está na avaliação da capacidade da aplicação integrada do technology roadmapping e da gestão de portfólio para contribuir com a realização das atividades do prédesenvolvimento.

Antes de avançar nessa direção realizou-se uma pesquisa bibliográfica para averiguar a existência de estudos sobre esse tema. Foram encontradas duas referências que mencionavam a utilização do technology roadmapping para a seleção e planejamento de projetos de produtos: Lee et al. (2008) e Albright e Nelson (2002). Esses autores não se aprofundam na integração dos métodos, mas mostram como o technology roadmapping poderia ser usado para auxiliar no planejamento do portfólio de projetos. Esses resultados confirmam a escolha da 
integração entre o technology roadmapping e a gestão de portfólio como um tema viável para pesquisa.

Assim, confirmado o escopo da pesquisa, a questão que pretende ser respondida é: "A aplicação integrada do technology roadmapping e da gestão de portfólio contribui com a realização das atividades do pré-desenvolvimento do PDP?". Para responder essa pergunta, o trabalho tem como objetivo avaliar a capacidade da aplicação integrada do technology roadmapping e da gestão de portfólio para apoiar a realização do pré-desenvolvimento em um caso real.

A metodologia de pesquisa adotada para atingir esse objetivo baseia-se no estudo de caso. Dessa forma elabora-se um protocolo de pesquisa que define como o estudo pretende ser realizado, especifica o ambiente, planeja sua execução, desenvolve o caso e avalia os resultados. A pesquisa propôs o Método ITG para a realização do estudo de caso, o qual foi elaborado para guiar a aplicação integrada do technology roadmapping e da gestão de portfólio. Por fim, com base nas informações obtidas, consegue-se concluir sobre a contribuição da aplicação integrada dos métodos para o pré-desenvolvimento.

Este documento é dividido em sete capítulos:

No “Capítulo 1 - Introdução" foi apresentada uma visão geral da pesquisa.

No "Capítulo 2 - Revisão da literatura" são descritos os fundamentos teóricos usados no desenvolvimento da pesquisa.

No "Capítulo 3 - Metodologia de pesquisa" é explicada a metodologia cientifica adotada pela pesquisa e são detalhadas as etapas do trabalho.

No "Capítulo 4 - Método ITG" é mostrado o método proposto neste trabalho para guiar a aplicação integrada do technology roadmapping e da gestão de portfólio. 
No "Capítulo 5 - Preparação do estudo de caso" são descritos os resultados da definição do protocolo de pesquisa, definição da empresa e planejamento do estudo de caso.

No "Capítulo 6 - Resultados e avaliação do estudo de caso em uma pequena empresa de base tecnológica" são apresentados os resultados do estudo de caso, no qual foi realizada a aplicação integrada do technology roadmapping e da gestão de portfólio, e também a avaliação dos resultados, que foi feita de acordo com a estratégia de avaliação definida no protocolo de pesquisa.

No "Capítulo 7 - Conclusões finais da pesquisa" o pesquisador conclui sobre a capacidade da integração do technology roadmapping e da gestão de portfólio para apoiar a realização das atividades do pré-desenvolvimento do PDP. 


\section{Revisão da literatura}

A revisão da literatura examinou quatro temas: gestão de desenvolvimento de produtos, macro-fase de pré-desenvolvimento do PDP, technology roadmapping e gestão de portfólio de projetos de produtos. Para cada um desses temas foram analisados os conceitos que permitiriam atender ao objetivo definido para a pesquisa.

\subsection{Gestão de desenvolvimento de produtos (GDP)}

As mudanças ocorridas no mercado mundial nas últimas décadas acarretaram o surgimento de novas abordagens para a gestão do desenvolvimento de produtos. Dentre essas mudanças, podem ser destacadas: o crescimento da competição entre as empresas, o dinamismo dos mercados e tecnologias, a redução do ciclo de vida dos produtos, a globalização dos mercados, o aumento das exigências dos consumidores e a busca por produtos personalizados (CLARK e WHEELWRIGHT, 1993; GRIFFIN, 1997).

Entre as abordagens emergentes nessa época estão: o desenvolvimento de produtos como um processo de negócio (CLARK e FUJIMOTO, 1991), a engenharia simultânea (CLAUSING, 1994; PRASAD, 1996), o funil de desenvolvimento de produtos (CLARK e WHEELWRIGHT, 1993) e o modelo em fases do processo de desenvolvimento de produtos (COOPER, 1993).

Atualmente continuam a surgir abordagens que contribuem com a melhoria do desenvolvimento de produtos. Duas dessas novas abordagens são: o Design for Six Sigma (CREVELING, 2002), que inclui técnicas estatísticas para garantir a qualidade dos produtos e o Lean Design (MASCITELLI, 2004; MORGAN e LIKER, 2006), que 
promove aspectos relacionados à agregação de valor ao produto, melhoria contínua dos processos e valorização do conhecimento e das pessoas.

Crawford e Benedetto (2006) definem o processo de desenvolvimento de produtos como uma combinação de passos, atividades, decisões e objetivos que, se bem realizados, irão produzir os novos produtos da empresa. As suas principais características são: participação de diversas áreas funcionais da organização, grande quantidade de informações, informações incertas e dinâmicas, e a constante necessidade de tomada de decisão (ROZENFELD et al., 2006).

Visando sistematizar as melhores práticas do desenvolvimento de produtos e facilitar o controle dos projetos, foram desenvolvidos modelos de referência divididos em fases para o processo de desenvolvimento de produtos. Cada uma dessas fases delimita um conjunto de atividades com objetivos distintos. Crawford e Benedetto (2006) e Cooper (2001) apresentam em seus modelos de PDP três grandes fases ou macro-fases: pré-desenvolvimento, desenvolvimento e lançamento.

A macro-fase de pré-desenvolvimento corresponde às atividades feitas antes do desenvolvimento do projeto do produto. Essa fase define as estratégias a serem seguidas pelos produtos, identifica idéias de novos produtos e gerencia a entrada de novos projetos de produtos no funil de desenvolvimento. Uma dificuldade para a realização dessas atividades é a forte dependência de informações dos mercados, das tecnologias, das estratégias e dos recursos da organização.

A macro-fase de desenvolvimento engloba as atividades do desenvolvimento do projeto do produto. Ela inicia com o escopo do projeto e com os requisitos primários do produto. Em seguida, durante suas atividades, são detalhados os requisitos, o conceito, as especificações técnicas e o processo de produção do produto. Por fim, os protótipos são testados para verificar a qualidade do produto e o 
atendimento aos requisitos. O resultado final dessa macro-fase consiste nas especificações do produto, em conjunto com todas as informações necessárias para sua fabricação e lançamento no mercado.

A macro-fase de lançamento contempla as atividades necessárias para disponibilizar o produto para venda no mercado. Ela envolve a preparação dos processos relacionados com a produção do produto, o fornecimento de materiais, a assistência técnica, o atendimento dos clientes e as vendas.

\subsection{Macro-fase de pré-desenvolvimento do PDP}

A macro-fase de pré-desenvolvimento tem recebido a atenção de vários autores da gestão de desenvolvimento de produtos. Alguns dos motivos responsáveis por essa importância são: alto impacto na probabilidade de sucesso do desenvolvimento de produtos, dificuldade de sistematização de suas atividades, alto grau de incertezas em suas informações e baixa eficácia quando comparada com as outras partes do PDP (GRIFFIN, 1997, COOPER et al., 2001).

Um dos primeiros trabalhos a tratar dessa macro-fase com mais detalhes foi o de Clark e Wheelwright (1992). Nessa obra, os autores introduzem a idéia do funil de desenvolvimento de produtos. Esse conceito mostra a importância de considerar os objetivos estratégicos do negócio, os requisitos do mercado e as possibilidades tecnológicas na definição dos projetos de produtos.

Gil et al. (1996) e Rozenfeld et al. (2006) definem o pré-desenvolvimento como a ligação entre o planejamento estratégico da corporação e o processo de desenvolvimento de produto. Com outra visão, Cheng (2000) afirma que o prédesenvolvimento é uma tentativa de articular as necessidades do mercado, as soluções de tecnologia e os recursos disponíveis de modo que se permita a continuidade do negócio da empresa. 
Koen et al. (2002) discutem sobre a necessidade de criar uma terminologia comum sobre o pré-desenvolvimento, a fim de possibilitar um alinhamento das ações de melhoria. Ele também explica como essa macro-fase do PDP se integra com o processo de desenvolvimento de tecnologias (PDT). Essa integração tem atraído a atenção das pesquisas devido ao aumento do desenvolvimento de produtos baseados em novas tecnologias. Porém, como esse assunto não pertence ao escopo desse trabalho, adotou-se uma visão simplificada desse relacionamento, na qual as tecnologias necessárias para os produtos já foram desenvolvidas e estão disponíveis.

\subsubsection{Modelos de referência de atividades da macro-fase de pré- desenvolvimento}

Existem dois tipos de publicações que apresentam modelos de referência das atividades do pré-desenvolvimento. O primeiro tipo são aquelas que mostram esses modelos como parte de um modelo do processo de desenvolvimento de produto, enquanto que o segundo tipo aborda apenas o pré-desenvolvimento. Este trabalho avaliou em ambos quais eram os modelos mais citados e quais possuíam um maior detalhamento das atividades do pré-desenvolvimento. $O$ resultado dessa avaliação escolheu seis modelos para serem estudados pela pesquisa: Clark e Wheelwright (1993), Gil et al. (1996), Cooper (2001), Koen et al. (2002), Crawford e Benedetto (2006) e Rozenfeld et al. (2006).

A realização da pesquisa dependia da adoção de um modelo de prédesenvolvimento como referência. Para tanto, cada um dos seis modelos foi analisado qualitativamente, seguindo como critério para a escolha a descrição detalhada das três fases principais do pré-desenvolvimento: definição de estratégias 
de produtos, geração de idéias de novos produtos e gestão da entrada de novos projetos de produto no portfólio de projetos em execução.

A partir dessa análise foi escolhido o modelo de Crawford e Benedetto (2006) como referência para a pesquisa. A seguir são descritos os resultados que apoiaram essa decisão:

- Clark e Wheelwright (1993): esse modelo representa um dos primeiros modelos desenvolvidos para o PDP com ênfase no pré-desenvolvimento. Ele foca na definição das estratégias de produtos e atende parcialmente à gestão da introdução de novos produtos no portfólio. As atividades da geração de idéias de novos produtos são pouco mencionadas neste modelo.

- Gil et al. (1996): esse modelo detalha as atividades envolvidas na definição das estratégias de produtos. No entanto ele é superficial quando trata das outras fases do pré-desenvolvimento. Um aspecto interessante desse modelo é o uso do technology roadmapping na definição das estratégias de produtos.

- Cooper (2001): esse modelo não atendeu às necessidades da pesquisa, pois o pré-desenvolvimento proposto por esse autor inicia-se na geração de idéias de novos produtos e desconsidera a definição das estratégias de produtos. O próprio autor cita a importância dessa fase, mas ele apenas a discute em um capítulo adicional desvinculado do seu modelo de PDP.

- Koen et al. (2002): esse modelo foi considerado superficial na descrição das atividades como um todo. Seu forte está na apresentação de melhores práticas e na descrição dos métodos e ferramentas utilizados na macro-fase. Essa característica é explicada pelo fato desse modelo ter sido construído para unificar os conceitos de várias empresas em relação ao pré-desenvolvimento. 
- Crawford e Benedetto (2006): esse modelo mostrou-se mais completo quando comparado com os outros. Ele descreve detalhadamente as três principais fases do pré-desenvolvimento: estratégias de produtos, geração de idéias de novos produtos e gestão do portfólio de novos projetos de produto. Além disso, ele apresenta melhores práticas, métodos e ferramentas usadas pelas atividades de cada uma dessas fases.

- Rozenfeld et al. (2006): esse modelo mostrou-se limitado em relação à definição de estratégias de produtos e à geração de idéias de novos produtos, pois não entra em detalhes sobre as atividades dessas fases. Já para a gestão da introdução de novos projetos de produtos, ele apresenta um conjunto detalhado de atividades.

Uma vez definido o modelo de Crawford e Benedetto (2006) como referência para a pesquisa, a próxima seção o descreve em detalhes.

\subsubsection{Modelo de pré-desenvolvimento de Crawford e Benedetto (2006)}

O modelo de referência para o processo de desenvolvimento de produtos proposto por Crawford e Benedetto (2006) é dividido em cinco fases: identificação e seleção de oportunidades para produtos, geração de conceitos de produtos, avaliação de conceito e projeto de produto, desenvolvimento do projeto do produto e lançamento do produto no mercado.

Além dessas fases, o modelo também propõe a realização de Gates entre cada uma delas, a fim de avaliar a evolução do projeto do produto. A macro-fase de prédesenvolvimento é representada nesse modelo pelas três primeiras fases. A Figura 1 apresenta o modelo das fases e Gates do PDP de Crawford e Benedetto (2006). 


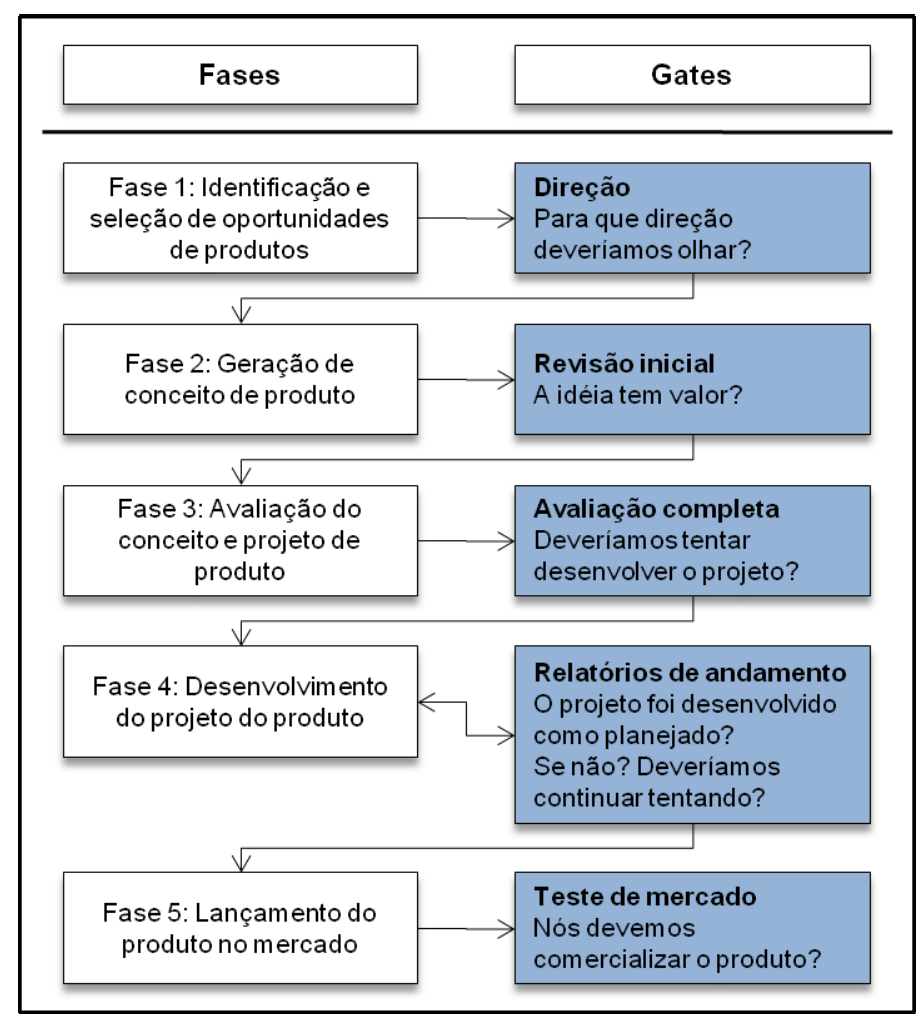

Figura 1 - Modelo das fases e Gates do PDP de Crawford e Benedetto (2006). Adaptado da fonte.

A seguir é apresentada a descrição e o modelo de atividades das três fases que formam o pré-desenvolvimento do PDP:

- Fase 1 - Identificação e seleção de oportunidades de produtos (planejamento estratégico de novos produtos): nessa fase são realizadas as atividades de identificação de oportunidades de novos produtos nas operações do negócio, nas sugestões advindas de fontes internas e externas da organização, nas alterações no plano de mercado, nas alterações nos recursos e nas novas necessidades do mercado. Além disso, essa fase detalha, avalia e classifica as oportunidades identificadas. O modelo das atividades dessa fase está apresentado na Figura 2. 


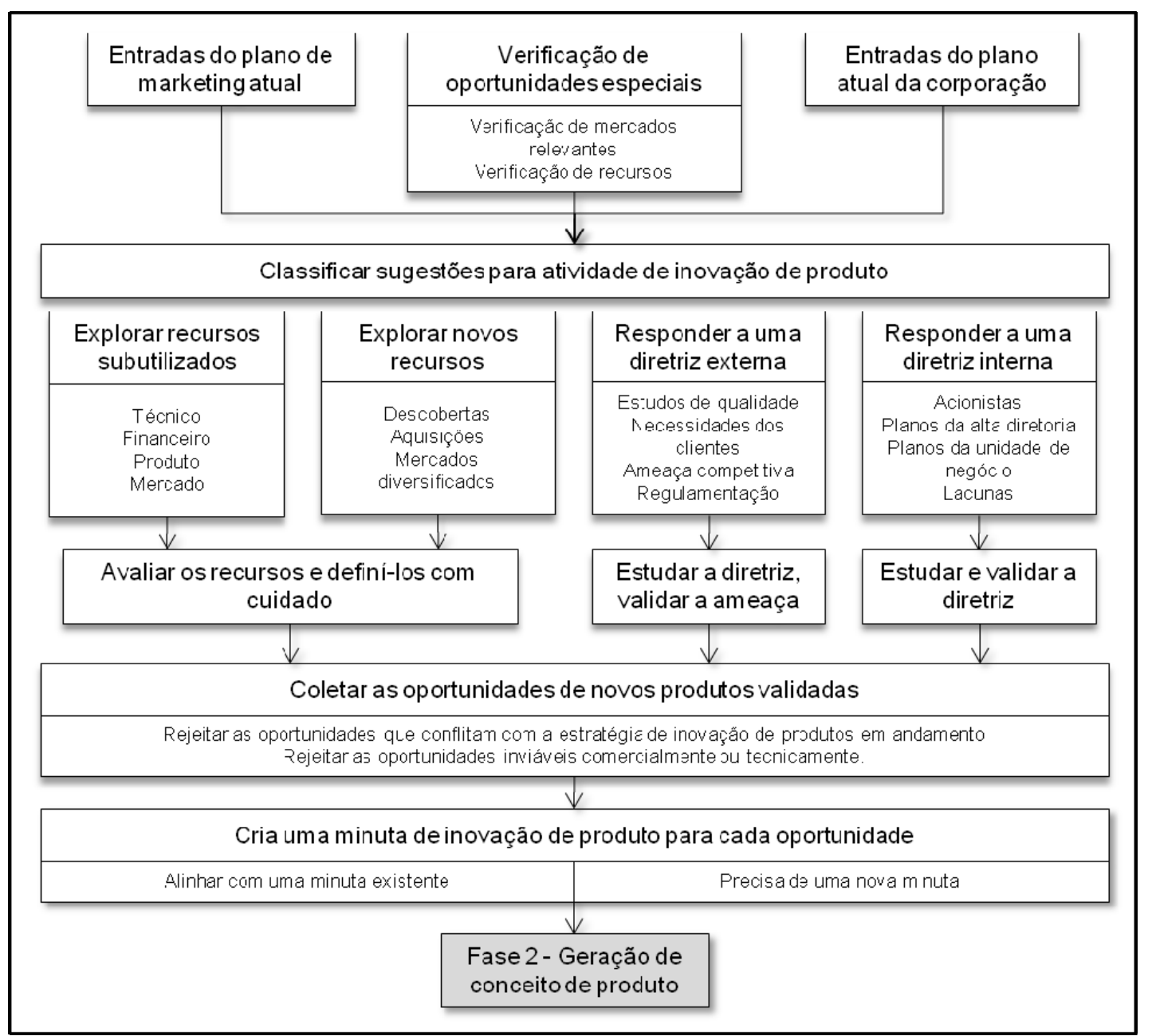

Figura 2 - Modelo das atividades da fase de identificação e seleção de oportunidades de produtos. Adaptado de Crawford e Benedetto (2006).

- Fase 2 - Geração de conceitos de produtos: nessa fase são desenvolvidas idéias e conceitos de produtos para as oportunidades identificadas na fase anterior. Ela também reúne idéias e conceitos provenientes de outras fontes internas ou externas da organização. A Figura 3 mostra o modelo das atividades dessa fase. 


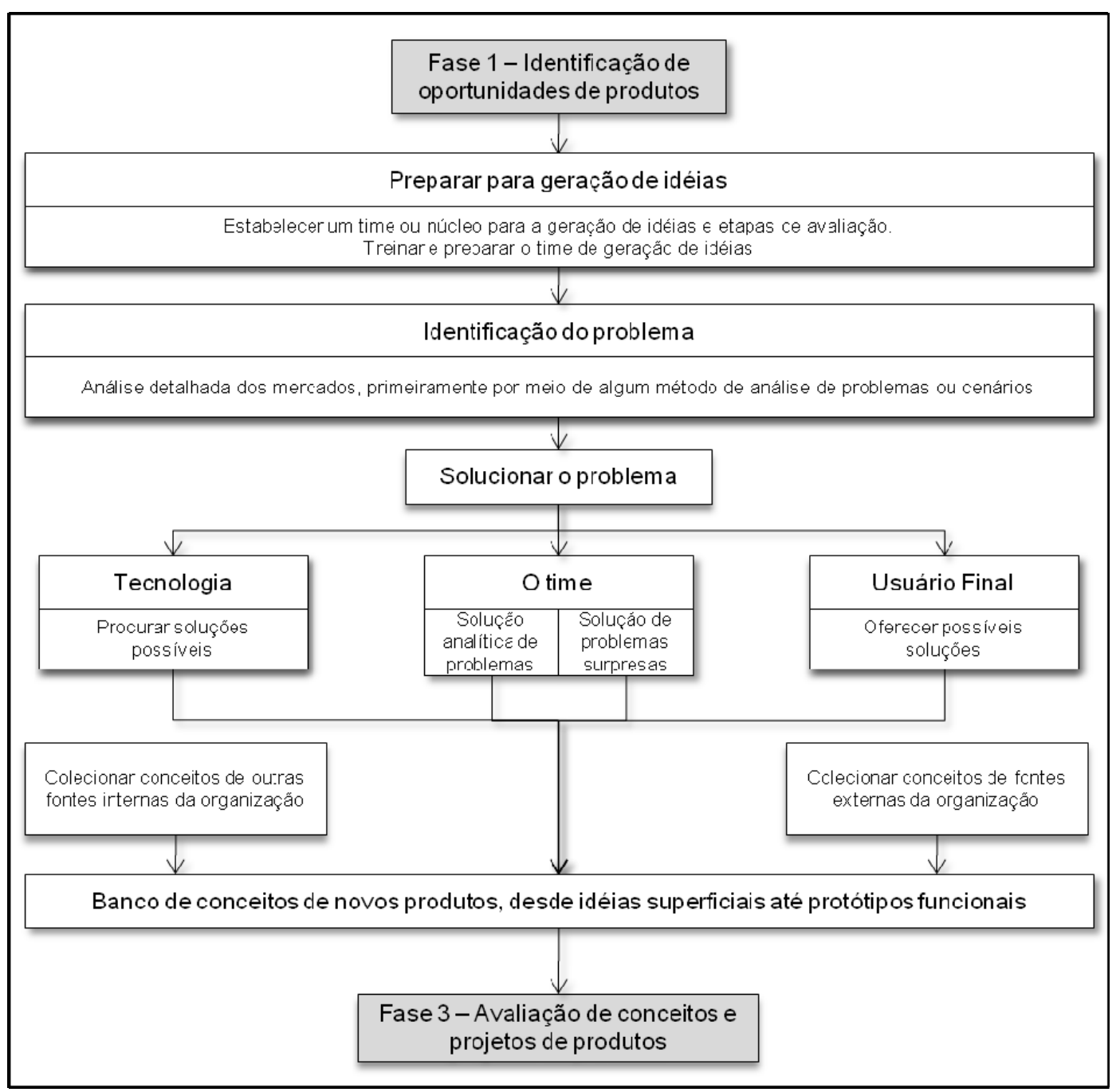

Figura 3 - Modelo das atividades da fase de geração de conceito de produto. Adaptado de Crawford e Benedetto (2006).

- Fase 3 - Avaliação de conceito e projeto de produto: nessa fase os conceitos e projetos de produtos são avaliados por meio de critérios técnicos, comerciais e financeiros. A partir dos resultados dessa avaliação, os conceitos e projetos são classificados, e os melhores são selecionados para serem desenvolvidos. A Figura 4 mostra o modelo das atividades dessa fase. 


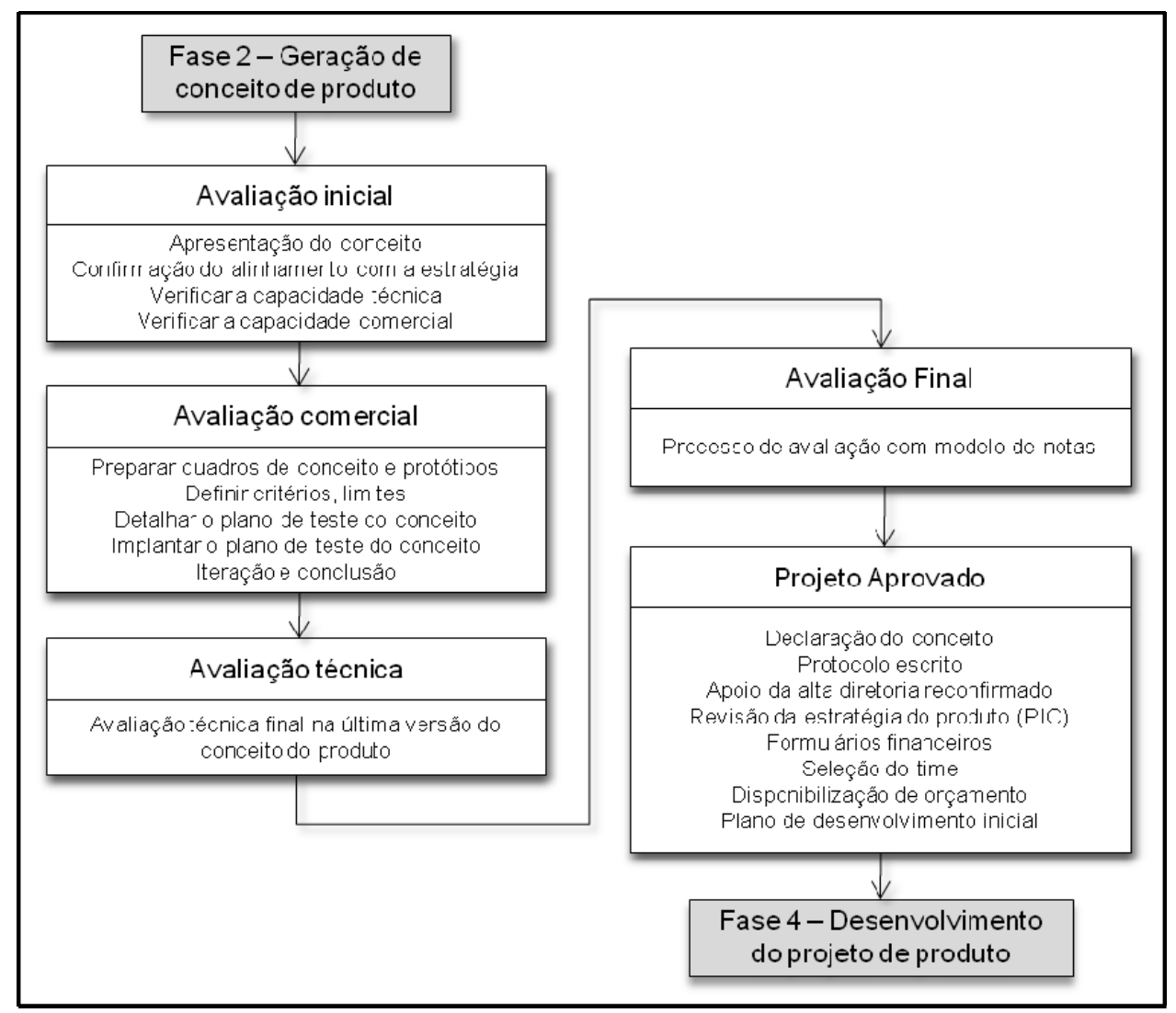

Figura 4 - Modelo das atividades da fase de avaliação de conceito e projeto de produto. Adaptado de Crawford e Benedetto (2006).

O trabalho não detalhou as duas últimas fases apresentadas na Figura 1, pois essas não fazem parte da macro-fase de pré-desenvolvimento.

A realização do estudo de caso adotará como referência o modelo de prédesenvolvimento apresentado nessa seção. 


\subsection{Technology roadmapping (TRM)}

O technology roadmapping é considerado um método da gestão de tecnologia. Assim, os significados usados para os termos gestão de tecnologia e tecnologia precisam ser explicados a fim de esclarecer seu contexto de aplicação.

A gestão de tecnologia, segundo o EITIM ${ }^{1}$, considera a identificação, seleção, aquisição, desenvolvimento, exploração e proteção das tecnologias (produto, processo e infra-estrutura) necessárias para manter uma posição de mercado e um desempenho de negócio que atendam aos objetivos da empresa.

Willyard e McClees (1987) explicam que o termo tecnologia foi usado no nome technology roadmapping em seu contexto mais amplo, no qual significa a aplicação de ciência para resolução de problemas de capacidade de desenvolvimento, de mercado, de competição e de desempenho.

O roadmapping e o roadmap são outras nomenclaturas utilizadas no método que precisam ser explicadas. O roadmapping se refere ao procedimento ou processo de aplicação do método, ou seja, o modo como as atividades são organizadas, o envolvimento dos participantes, o fluxo de informações, as ferramentas usadas e o ambiente organizacional envolvido. O roadmap corresponde ao resultado na forma de mapa que é gerado ao final do processo de aplicação do método.

Esclarecidas as nomenclaturas, a pesquisa adota os termos technology roadmapping para mencionar o método, roadmapping para o seu processo de aplicação e roadmap para o resultado na forma de mapa. Além de seguir os significados apresentados para os termos gestão de tecnologia e tecnologia.

1 EITIM - European Institute for Technology and Innovation Management http://www.eitim.org/. Acessado em dezembro de 2008. 
A definição do technology roadmapping varia de acordo com o ambiente de aplicação e o propósito. Nesta pesquisa, o TRM é utilizado na macro-fase de prédesenvolvimento do PDP para contribuir com o planejamento estratégico de produtos.

Nesse ambiente e propósito mencionados, o TRM é definido como um método que descreve o mercado, planeja o desenvolvimento de produtos e processos, estabelece capacidades tecnológicas e analisa recursos. Dessa forma ele possibilita que a empresa determine se suas prioridades estão corretas e apropriadas (Willyard e McClees, 1987).

Outra definição do TRM para esse mesmo contexto é apresentada por Kappel (2001). Segundo o autor o método mostra as prioridades entre os parâmetros de mercado, produto e tecnologia, além de encontrar objetivos interligados através deles. Como conseqüência da aplicação do technology roadmapping a empresa consegue justificar seus investimentos e ainda aprimorar a coordenação dos esforços para que os seus objetivos sejam alcançados.

Pelo lado organizacional, Probert e Radnor (2003) definem o technology roadmapping como um método que induz ao aprendizado dentro de um grupo, ajudando os seus membros descobrir novas oportunidades para o negócio. Em seguida ela auxilia na criação de uma visão unificada que permite que o grupo delineie os novos caminhos e explique como atravessá-los.

A partir das definições apresentadas, esse trabalho propõe uma nova definição que reúne as anteriores e os seus objetivos:

"O technology roadmapping apóia o desenvolvimento de um planejamento estratégico de produtos voltado para os objetivos do negócio e para as 
necessidades e tendências do mercado, ao mesmo tempo em que considera as restrições e evoluções das tecnologias."

\subsubsection{Melhores práticas do processo de aplicação do technology roadmapping}

As melhores práticas referentes ao processo de aplicação do TRM descrevem fatores que devem ser considerados durante a aplicação do método. A verificação desses fatores assegura que os resultados do método atendam às expectativas da empresa. A seguir são apresentadas oito melhores práticas obtidas na literatura sobre o tema:

1) O sucesso do technology roadmapping nas empresas depende do apoio de um patrocinador influente. Essa pessoa tem o papel de manter a alocação de recursos necessária para a aplicação do método e defender sua importância para a empresa (STRAUSS e RADNOR, 2004; GARCIA e BRAY, 1997; PHAAL, 2004).

2) A probabilidade de sucesso do método é influenciada pela presença de especialistas ou facilitadores no processo de aplicação. Esses atuam na condução do time, coordenam o trabalho, esclarecem dúvidas no processo e direcionam os esforços de acordo com as necessidades da empresa (ALBRIGHT e KAPPEL, 2003; GARCIA e BRAY, 1997; PHAAL, 2004).

3) O roadmapping é um processo multifuncional (ALBRIGHT e NELSON, 2004). Portanto, a participação de representantes de áreas distintas e relacionadas ao contexto a ser analisado é considerado fator primordial (GARCIA e BRAY, 1997).

4) Phaal (2004) afirma que em alguns casos é necessário trazer especialistas relacionados com campos de tecnologia, mercados ou indústrias externos à empresa. Assim é adquirida uma visão mais ampla das oportunidades e ameaças.

5) Os participantes que compõem o time, além de prover os conhecimentos, também devem acreditar nos resultados do método para que ele tenha maiores 
chances de sucesso (PHAAL, 2004). Um caminho para criar esse comprometimento é sua aplicação em áreas críticas da empresa (KAPPEL, 2001).

6) Para que a comunicação dos resultados seja eficaz, Albright e Nelson (2004) destacam a importância de existir uma linguagem (vocabulário e sintaxe) comum na empresa. O que facilitaria a troca de informações entre as áreas funcionais.

7) Probert e Radnor (2003) e Phaal (2004) mostram que devido aos diversos ambientes e objetivos onde o TRM pode ser aplicado, existe uma grande necessidade de customização associada à sua aplicação. A partir dessa customização é possível atingir uma melhor eficácia do método para cada caso específico.

8) O processo de aplicação é considerado o principal responsável pela agregação de valor do TRM (WILLYARD e MCCLEES, 1987; PROBERT e RADNOR, 2003; PHAAL, 2004), portanto esse deve ser valorizado pela empresa.

9) O horizonte temporal de planejamento é um fator importante (PHAAL, 2004). A presença do tempo é reconhecida como um dos diferenciais do TRM quando esse é comparado com outros métodos (ALBRIGHT e NELSON, 2004). Assim o horizonte de tempo deve ser cuidadosamente definido pela empresa.

\subsubsection{Aplicações do technology roadmapping e formatos de roadmap}

Existem vários usos para o technology roadmapping, assim como também podem ser encontrados vários formatos de roadmap. Portanto, os autores 0 classificam de acordo com o seu propósito. O trabalho considerou as classificações do technology roadmapping criadas por Phaal (2004), Kappel (2001) e Albright e Nelson (2004). 
A classificação proposta por Phaal (2004) demonstra que o uso do TRM pode incluir outros objetivos além do planejamento de produtos. Ele propõe oito aplicações para o método: planejamento de produto, planejamento de serviço/capacidade, planejamento estratégico, planejamento de longo prazo, planejamento de programa de projetos, planejamento de processo e planejamento de integração. Em conjunto com sua classificação, Phaal (2004) também descreve os formatos de roadmaps utilizados em cada uma dessas aplicações.

Kappel (2001) combina dois critérios para classificar o uso do technology roadmapping. No primeiro ele verifica a amplitude do negócio para entender se o método é aplicado no contexto de uma única empresa ou em um setor industrial. No segundo ele define se o objetivo do método é posicionar o negócio no ambiente onde atua ou estabelecer uma trajetória a ser percorrida. Essa classificação resulta em quatro possíveis aplicações para o technology roadmapping:

- TRM de Ciência ou Tecnologia: visa compreender melhor o futuro, identificando tendências específicas e gerando previsões mais consistentes sobre as tecnologias para uma indústria.

- TRM de Setor Industrial: tem como objetivo estabelecer as expectativas de desenvolvimento das tecnologias em relação ao setor industrial.

- TRM de Produto-Tecnologia: busca alinhar as decisões de desenvolvimento de produtos e tecnologias com as tendências de uma empresa.

- TRM de Produto: articula a estratégia e a evolução de um produto e/ou famílias de produtos de uma empresa.

A Figura 5 mostra o gráfico desenvolvido por Kappel (2001) para representar as possíveis classificações do technology roadmapping. O eixo horizontal avalia o negócio no qual o método é aplicado e o eixo vertical define o objetivo buscado. 


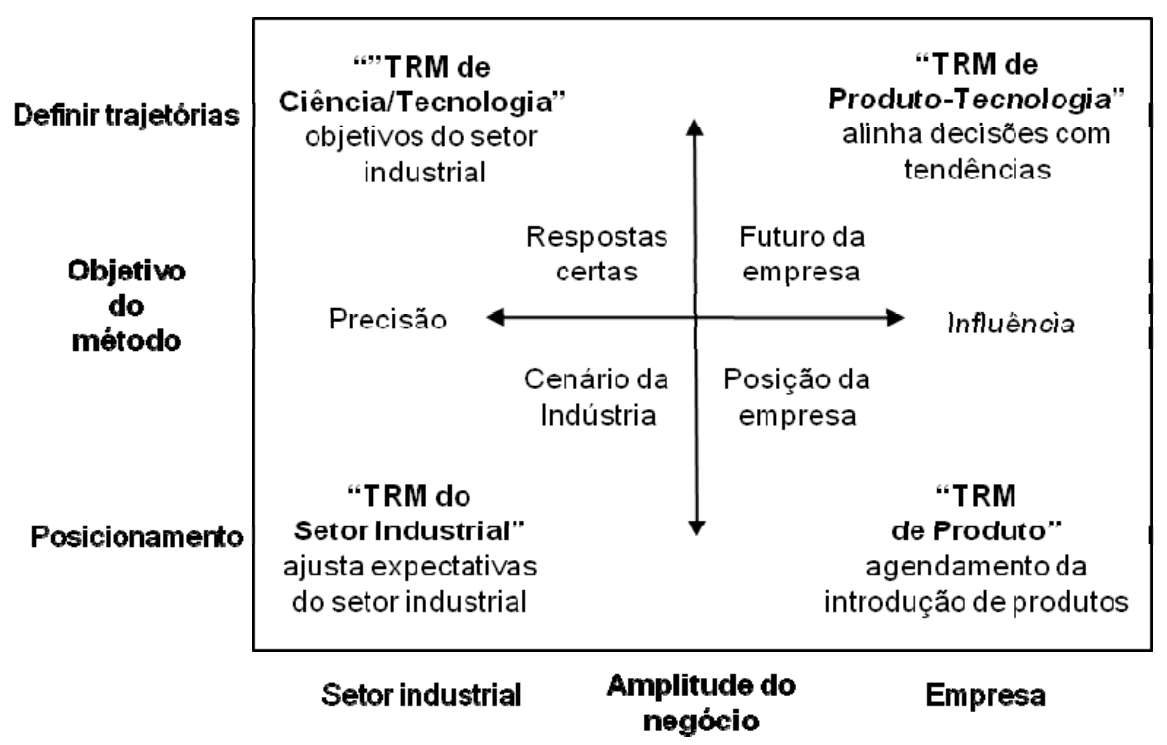

Figura 5 - Classificação do TRM segundo Kappel (2001). Adaptado da fonte.

A aplicação do technology roadmapping pode ocorrer em níveis organizacionais diferentes. Albright e Nelson (2004) notaram essa diferença e classificaram o método em dois tipos: TRM do nível estratégico e TRM do nível tático.

O TRM de nível estratégico tem menor quantidade de informações e uma lógica mais transparente. Ele se relaciona com atividades de alto nível da organização (estratégias, planos de negócio) e serve de base para tomada de decisão da alta cúpula da empresa.

O TRM de nível tático possui uma lógica mais complexa e grande quantidade de informações. Ele ajuda a gerência na coordenação das atividades e os envolvidos entender os objetivos.

O formato do roadmap deve estar alinhado com os objetivos da aplicação do método. Isso facilita que os resultados gerados sejam apresentados de forma consistente. Entre os inúmeros formatos encontrados, o mais utilizado é o proposto 
por EIRMA $(1997)^{2}$, que é também considerado o mais genérico. Exemplos de outros formatos podem ser vistos em Phaal (2004).

O roadmap de EIRMA (1997) é formado pela linha de tempo do eixo horizontal e por três camadas no eixo vertical, que representam as dimensões de mercado, produto e tecnologia. Com esse formato o roadmap permite que sejam mostrados os relacionamentos existentes entre as camadas e suas restrições de tempo. A Figura 6 mostra um modelo desse formato de roadmap.

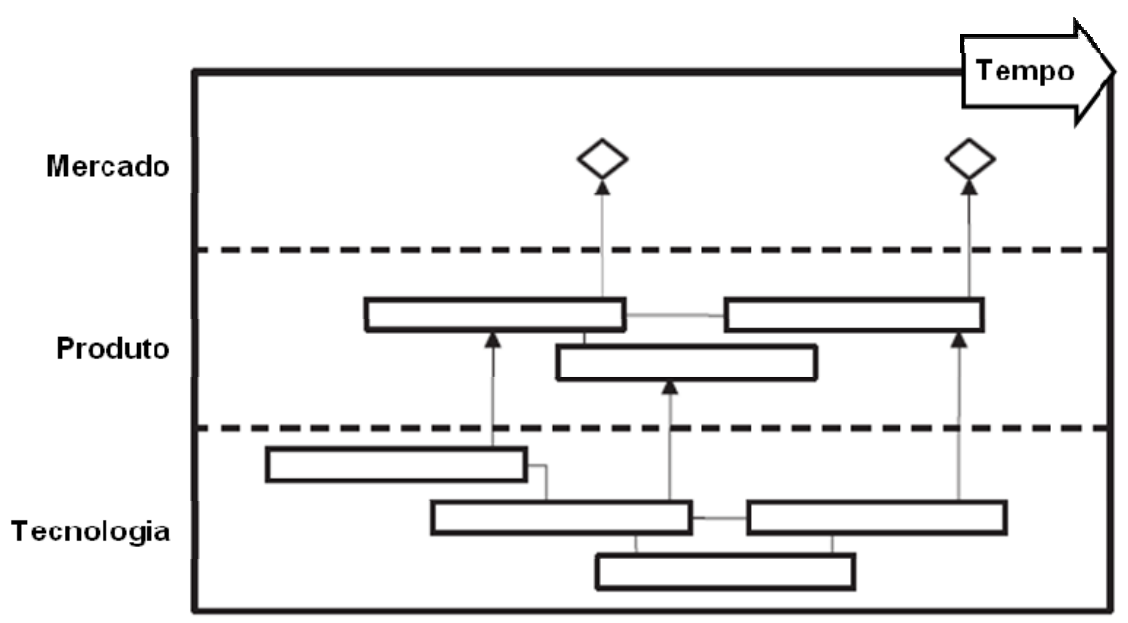

Figura 6 - Formato de roadmap proposto por EIRMA (1997). Adaptado de Phaal (2004).

Com base nas classificações do technology roadmapping e no formato de roadmap apresentado, o uso do TRM nessa pesquisa é contextualizado como:

- Segundo a classificação de Phaal (2004), o TRM é usado para o planejamento de produto, pois é usado exatamente com esse propósito na macrofase de pré-desenvolvimento do PDP.

2 EIRMA. Technology roadmapping: delivering business vision. Working group report. European Industrial Research Management Association, Paris, 52, 1997. 
- Pela classificação de Kappel (2001), a pesquisa pretende usar o TRM em uma única empresa com o objetivo de posicioná-la em relação às possíveis oportunidades de produtos. Portanto o TRM é classificado como um TRM de Produto.

- No caso da classificação de Albright e Nelson (2002), a utilização do TRM deve contribuir com o nível estratégico da organização, que corresponde ao nível onde são realizadas as atividades do pré-desenvolvimento. Assim é classificado como um TRM estratégico.

- O formato do roadmap adotado pela pesquisa é o formato proposto por EIRMA (1997) apud Phaal (2004), já que esse se mostra adequado para atender às necessidades do pré-desenvolvimento.

\subsubsection{Processos de aplicação do technology roadmapping}

Existem processos de aplicação do TRM publicados na literatura. A pesquisa optou por estudar três dos processos mais citados: Willyard e McClees (1987), Albright e Kappel (2003) e Phaal et al. (2001).

Os processos de Willyard e McClees (1987) e de Albright e Kappel (2003) são similares e descrevem superficialmente as atividades que o compõem. Todavia, eles são ricos em ferramentas que organizam as informações e facilitam a aplicação do método. Já o processo de Phaal et al. (2001), chamado de T-Plan, foi desenvolvido para guiar uma primeira tentativa de aplicação do TRM e portanto descreve em detalhes suas atividades.

O processo de Willyard e McClees (1987) é formado por oito seções: (1) descrição do negócio, (2) previsão de tecnologia, (3) matriz de mapa de tecnologia, (4) qualidade, (5) alocação de recursos, (6) portfólio de patentes, (7) descrição do produto, (8) relatórios de posição e quadros resumo, (9) e relatório preliminar. Essas 
seções podem ser realizadas de forma independente, contudo os autores enfatizam que a eficácia do método depende da realizadas de todas. No começo são verificadas as informações relacionadas ao negócio e as tecnologias. Com bases nesses dados as oportunidades de produtos são analisadas e definidas. Ao final é desenvolvido um plano para que os produtos atendam às oportunidades indicadas.

O processo de Albright e Kappel (2003) é organizado em quatro seções: (1) mercado, (2) produto, (3) tecnologia e (4) uma seção de resumo. As seções desse processo são interligadas entre suas atividades. Inicialmente é montado o programa de tecnologia e de produto, mostrando os itens em ordem de prioridade. As prioridades de cada seção são reunidas em um grupo de direcionadores comuns. Em seguida é desenvolvida uma visão externa envolvendo concorrentes, produtos e tecnologias que ajudará na definição dos planos internos. Por fim, o planejamento é apresentado com o auxilio de um roadmap.

O processo de Phaal et al. (2001) é estruturado em quatro workshops: (1) workshop de mercado, (2) workshop de produto, (3) workshop de tecnologia e (4) workshop de mapeamento. Além dos workshops, são incluídas outras duas atividades no processo. Uma de planejamento, que acontece no início, e outra de implantação e continuidade do TRM, presente no final. Destacando-se que essa última é indicada pelos autores, mas não é detalhada no processo. A Figura 7 apresenta o processo do T-Plan e a seguir cada dessas partes são descritas:

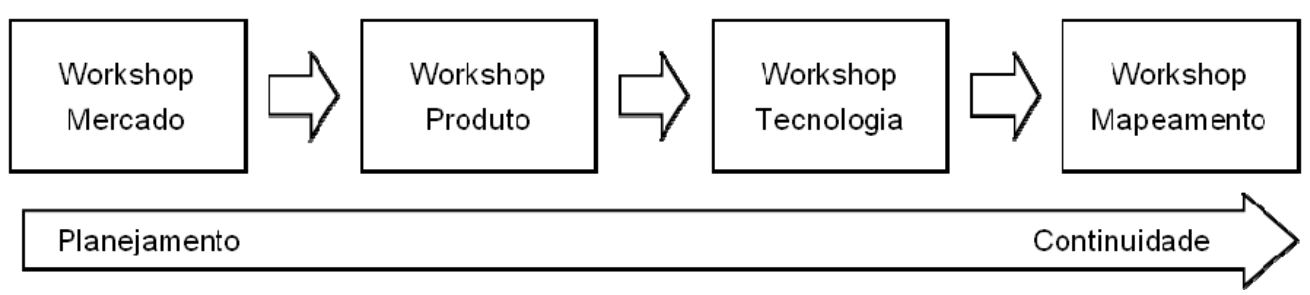

Figura 7 - Processo de aplicação do TRM proposto pelo T-Plan. Adaptado de Phaal (2004). 
- A atividade de planejamento tem como função definir o escopo de análise do método, o facilitador, o patrocinador e os participantes do processo, além de programar sua realização.

- No workshop de mercado são identificados os direcionadores do negócio e do mercado. Os direcionadores do negócio representam o alinhamento com a estratégia da empresa, enquanto que os de mercado mostram as necessidades e tendências do mercado.

- No workshop de produto são identificados os atributos de produto envolvidos com os direcionadores do mercado e do negócio. Esses atributos correspondem às características gerais dos produtos, como: peso, potência e ruído. No final eles são avaliados para se conhecer a capacidade de cada um para satisfazer os direcionadores.

- No workshop de tecnologia acontece uma análise das tecnologias usadas na entrega dos atributos de produto. Essa análise descreve como essas tecnologias devem evoluir e qual o potencial de cada uma para disponibilizar os atributos de produto para o mercado.

- No workshop de mapeamento, as informações dos outros workshops são examinadas com o objetivo de identificar oportunidades de produtos que estejam alinhadas com as estratégias do negócio, com as necessidades do mercado e com as tecnologias disponíveis. O resultado desse workshop final é um planejamento estratégico de produtos apresentado por meio de um roadmap.

A partir das características de cada processo estudado, a pesquisa escolheu como referência o processo do T-Plan. Essa decisão foi baseada no nível de detalhamento de suas atividades. 


\subsection{Gestão de portfólio de projetos de produtos}

A gestão de portfólio de projetos é um conjunto de práticas que aproxima a gestão individual dos projetos com a gestão das operações do negócio. Ou seja, por meio dela os projetos são alinhados com as estratégias e recursos da empresa (LEVINE, 2005).

A participação da gestão de portfólio no processo de desenvolvimento de produtos é dividida em duas partes. Na primeira ela auxilia na seleção dos projetos de produtos que serão realizados pela empresa. $\mathrm{Na}$ segunda parte a gestão de portfólio monitora os projetos em andamento para garantir que eles continuem atendendo aos fatores que propiciaram sua seleção (McDonough, 2003). É importante enfatizar que essas partes devem estar integradas nas operações do negócio, mesmo que sejam analisadas separadamente e que utilizem conceitos diferentes (LEVINE, 2005).

A definição da gestão de portfólio depende em certos momentos da parte para a qual ela é usada. No caso de Cooper et al. (1998), os autores a definem incluindo ambas as partes. Para eles a gestão de portfólio é um processo de decisão dinâmico, no qual uma lista de projetos de novos produtos é constantemente revisada e atualizada. Durante esse processo, novos projetos são avaliados, selecionados e priorizados, projetos existentes podem ser acelerados, cancelados ou despriorizados, e recursos podem ser alocados ou removidos de projetos ativos.

Archer e Ghasemzadeh (1999) apresentam uma definição focada na seleção dos projetos de produtos, ou seja, na primeira parte. Eles definem a gestão de portfólio de projetos como uma atividade periódica envolvida na seleção de um portfólio de projetos, dentro de propostas de projetos disponíveis e projetos em 
andamento, que atende aos objetivos estabelecidos pela organização de uma maneira desejável, sem exceder os recursos disponíveis ou violar outras restrições.

Como este trabalho tem como objetivo utilizar a gestão de portfólio nas atividades da macro-fase de pré-desenvolvimento, ele irá considerar apenas os conceitos e ferramentas relacionados à seleção de projetos de produtos. Dessa maneira o uso da gestão de portfólio para controlar os projetos em andamento não faz parte desse estudo.

Independentemente da situação onde é aplicada, a gestão de portfólio apresenta como características a presença de informações incertas, múltiplos objetivos e interdependência entre projetos (COOPER et al., 1998; BITMAN, 2005; CHIEN, 2002)

Embora a gestão de portfólio trate aparentemente apenas da seleção e controle dos projetos da empresa, o que ela busca na verdade é gerenciar o portfólio de projetos como um todo. Para isso ela analisa as combinações de projetos que melhor satisfazem os objetivos do negócio (CHIEN, 2002).

\subsubsection{Objetivos da gestão de portfólio}

A gestão de portfólio deve buscar quatro objetivos durante a seleção dos projetos de produtos que irão formar o portfólio de projetos da empresa (COOPER et al., 2002). Esses objetivos são:

- Maximização do valor do portfólio: os projetos são selecionados de modo que maximizem o valor do portfólio em função de algum objetivo do negócio, por exemplo, a lucratividade. Alguns métodos e ferramentas inseridos aqui são o VPL (valor presente líquido), o VCE (valor comercial esperado) e o Modelo de Notas.

- Equilíbrio dos projetos do portfólio: balanceamento do portfólio usando parâmetros como duração do projeto, nível de risco, tecnologias, dentre outros. Os 
métodos e ferramentas utilizados nesse caso podem ser gráficos, como por exemplo, o diagrama de bolhas.

- Alinhamento do portfólio com a estratégia do negócio: confirma que o portfólio escolhido reflete as estratégias do negócio. Um método utilizado aqui é a pré-alocação de fundos em cestas de investimento divididas por: tipos de projetos, mercados ou tecnologias.

- Alocação de recursos entre os projetos: assegura a existência de recursos para que os projetos do portfólio sejam desenvolvidos eficientemente. Um método usado para isso é a análise das necessidades de cada projeto em comparação com os recursos disponíveis.

A partir de dados obtidos em estudos de casos, Cooper et al. (2002) mostram que a busca simultânea desses objetivos assegura um portfólio capaz de gerar resultados otimizados para o negócio. Contudo os autores também notaram um constante conflito entre os objetivos, pois, por exemplo, o portfólio que traz o melhor retorno pode não ser o mais equilibrado.

Uma forma de buscar os quatro objetivos é avaliar o portfólio em função de cada um deles. Chien (2002) mostra que essa avaliação poderia ser feita por meio da decomposição dos objetivos em metas mensuráveis. Assim, para cada meta, poderia ser associado um valor que indicaria o desempenho do portfólio, e por fim esse valor poderia ser desdobrado para avaliar o objetivo.

Por exemplo, o objetivo que busca o equilíbrio do portfólio poderia ser dividido em metas relacionadas à quantidade de projetos de alto e baixo risco, curto e longo prazo, baixa e alta inovação, entre outros. Dessa forma, seria possível avaliar a porcentagem de cada tipo de projeto no portfólio e então afirmar se o portfólio é ou não equilibrado. 


\subsubsection{Processos de aplicação da gestão de portfólio}

A pesquisa analisou três processos de aplicação da gestão de portfólio: Cooper et al. (1998), Archer e Ghasemzadeh (1999) e Bitman (2005). Os critérios considerados para a seleção desses processos foram: citações em outras pesquisas, apresentação das atividades do processo e adequação aos objetivos do trabalho.

O processo de aplicação da gestão de portfólio de Cooper et al. (1998) integra as partes da gestão de portfólio referentes à seleção e ao controle dos projetos de produtos. A Figura 8 mostra o modelo das atividades desse processo.

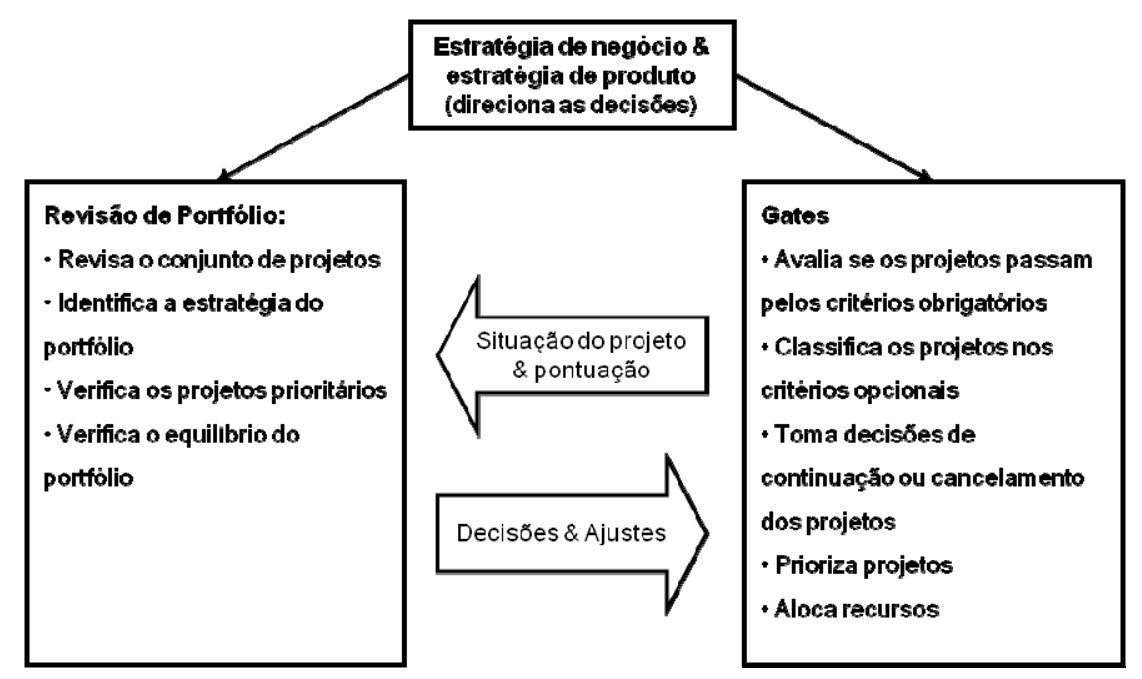

Figura 8 - Processo de gestão de portfólio de Cooper et al. (1998). Adaptado da fonte.

O processo de aplicação da gestão de portfólio de Archer e Ghasemzadeh (1999) é formado por três grandes fases: pré-processo, processo e pós-processo. O pré-processo envolve as atividades de desenvolvimento da estratégia e de seleção da metodologia. A fase do processo foi dividida pelos autores nos seguintes estágios: pré-triagem, análise individual do projeto, triagem, seleção do portfólio e ajuste do portfólio. O pós-processo está relacionado com o acompanhamento dos projetos do portfólio durante o desenvolvimento. 
Archer e Ghasemzadeh (1999) apontam como diferenciais desse modelo a flexibilização dos estágios, métodos e ferramentas, conforme as características e necessidades de cada empresa. A Figura 9 mostra o modelo das atividades desse processo.

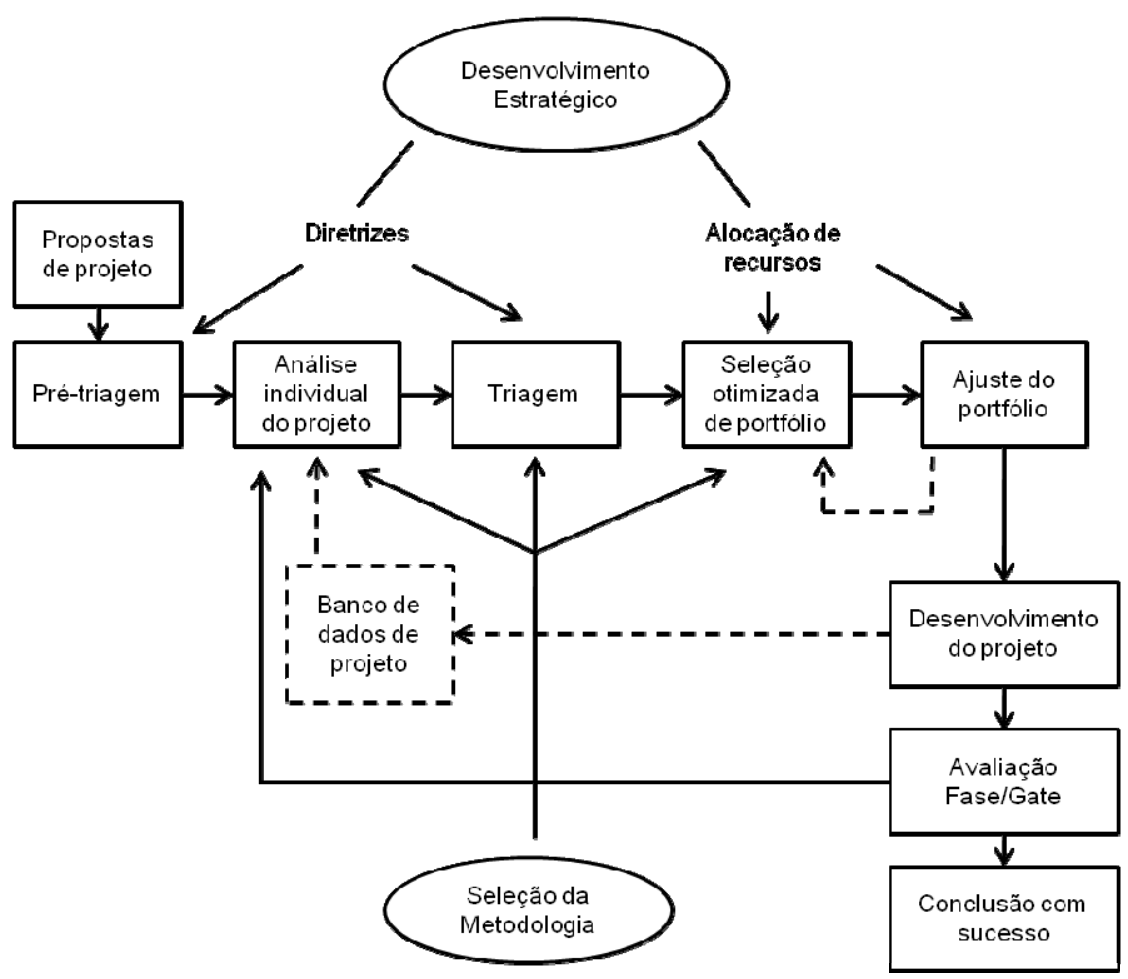

Figura 9 - Processo de gestão de portfólio de Archer e Ghasemzadeh (1999). Adaptado da fonte.

O processo de gestão de portfólio de Bitman (2005) possui dois componentes: o componente de análise do contexto do negócio e o componente de seleção dos projetos de produtos. A Figura 10 mostra o modelo das atividades desse processo.

O componente de seleção dos projetos é dividido em oito etapas: (1) definir os projetos para avaliação, (2) selecionar os atributos de balanceamento do portfólio, (3) estabelecer a importância dos tipos de atributos, (4) atribuir o valor de cada tipo de atributos para cada projeto, (5) determinar os atributos a serem usados na seleção dos projetos, (6) definir a importância de cada atributo de seleção, (7) 
atribuir o valor dos atributos para cada projeto e (8) classificar os projetos dentro do portfólio.

O componente de análise do contexto do negócio está em todas as atividades do primeiro componente. Ele é formado por quatro atividades: (1) análise da situação atual, (2) análise das tendências futuras, (3) análise da inovação e (4) análise da vantagem competitiva.

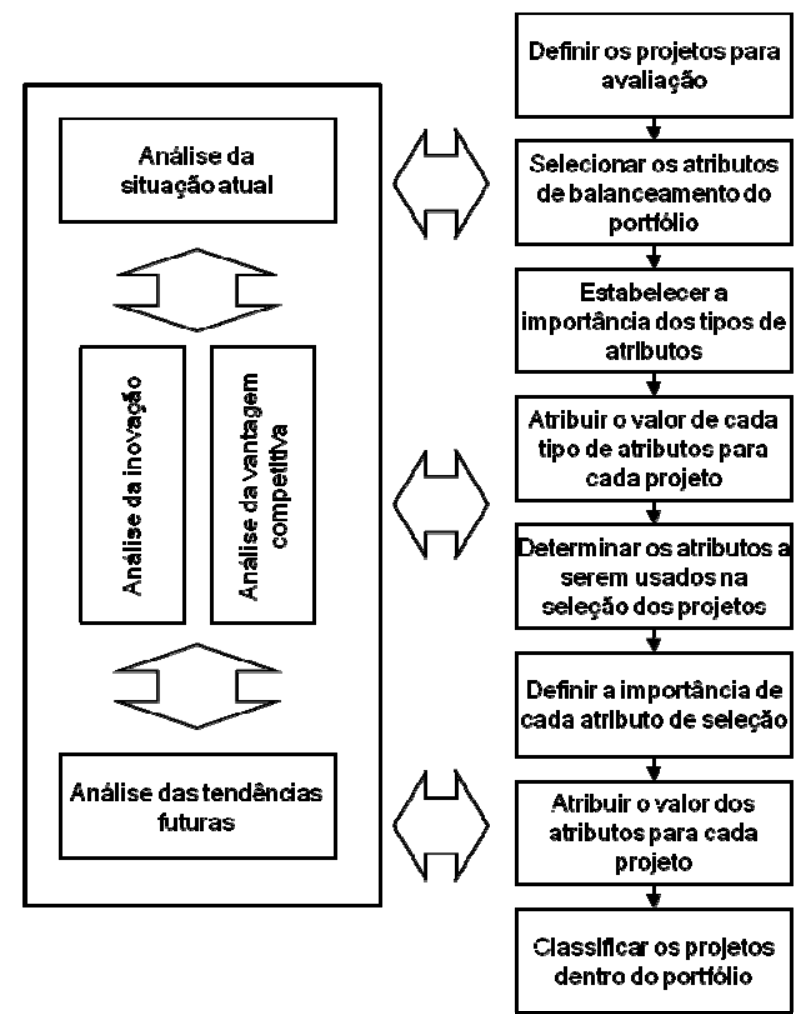

Figura 10 - Processo de gestão de portfólio de Bitman (2005). Adaptado da fonte.

A partir dos resultados da análise desses processos, a pesquisa optou pelo desenvolvimento de um novo processo para aplicação da gestão de portfólio que reunisse as melhores práticas do processo de Cooper et al. (1998) e do processo de Archer e Ghasemzadeh (1999). Essa decisão foi necessária pois nenhum dos três processos estudados atendeu completamente aos requisitos buscados pelo trabalho. 


\section{Metodologia de pesquisa}

Este capítulo descreve a metodologia científica seguida para alcançar os objetivos da pesquisa. O significado usado pelo trabalho para o termo "metodologia científica" é o apresentado por Silva e Menezes (2005), que a definem como um conjunto de etapas adotadas na investigação de um fenômeno.

No início do capitulo apresentam-se as possíveis classificações de pesquisa e os métodos científicos existentes, os quais ajudam na definição da metodologia científica de pesquisa. Por fim são descritas as etapas seguidas pelo trabalho para que essa metodologia fosse atendida.

\subsection{Classificações da pesquisa e métodos científicos}

A pesquisa é definida como um conjunto de ações baseadas em procedimentos racionais e sistemáticos, que são desenvolvidos para encontrar soluções para um problema (SILVA e MENEZES, 2005). Cada pesquisa possui suas próprias características, portanto é necessário que elas sejam classificadas para um melhor entendimento dos seus propósitos. Silva e Menezes (2005) indicam quatro critérios de classificação das pesquisas.

O primeiro critério as classifica segundo sua natureza em pesquisa básica e pesquisa aplicada. A pesquisa básica desenvolve os novos conhecimentos da ciência que ainda não possuem uma aplicação prática em vista. E a pesquisa aplicada constrói os conhecimentos que auxiliam na solução de problemas existentes.

O segundo critério classifica as pesquisas segundo a forma de abordagem do problema em pesquisa quantitativa e pesquisa qualitativa. A pesquisa quantitativa foca na quantificação dos resultados, transformado em números as informações e 
opiniões antes de analisá-las. E a pesquisa qualitativa adota a interpretação subjetiva dos fenômenos e a atribuição dos significados como estratégia na análise dos resultados.

O terceiro critério classifica as pesquisas segundo os seus objetivos em pesquisa exploratória, pesquisa descritiva e pesquisa explicativa. A pesquisa exploratória busca esclarecer ou detalhar um problema com a finalidade de torná-lo explícito ou elaborar hipóteses. A pesquisa descritiva tem como objetivo descrever as características de uma população ou fenômeno específico, ou encontrar ligações entre as variáveis de um problema. E a pesquisa explicativa identifica os fatores relacionados à ocorrência dos fenômenos, explicando as causas dos acontecimentos.

O último critério classifica as pesquisas segundo seus procedimentos técnicos em: pesquisa bibliográfica, pesquisa documental, levantamento, estudo de caso e pesquisa expo-facto. A pesquisa bibliográfica baseia-se em materiais já publicados, como livros e artigos de periódicos. A pesquisa documental é elaborada por meio de materiais sem tratamento analítico. A pesquisa experimental analisa um objetivo de estudo, escolhendo suas variáveis e controlando os efeitos sobre o objeto. 0 levantamento estuda o comportamento de uma população que se deseja conhecer. O estudo de caso analisa um ou poucos objetos de forma que seja possível conhecê-los detalhadamente. E a pesquisa expo-facto acontece quando os experimentos são aplicados depois da realização dos fatos.

Além das classificações apresentadas, deve-se definir o método científico que guia a linha de raciocínio do trabalho. Esse consiste nos caminhos seguidos para se atingir os objetivos da pesquisa (GIL, 1999; SILVA e MENEZES, 2005). Durante a sua escolha é considerado o que se deseja descobrir e a natureza do objeto 
estudado. Segundo Silva e Menezes (2005), os métodos científicos que proporcionam o raciocínio lógico das pesquisas são:

- Método dedutivo: busca conclusões por meio da lógica, partindo do geral para o específico.

- Método indutivo: tenta construir generalizações a partir de experiências em casos específicos.

- Método hipotético-dedutivo: propõe hipóteses para determinado problema e busca refutá-las como meio de encontrar a solução.

- Método dialético: parte dos fatos para interpretar a realidade e segue o raciocínio de negação pela negação para buscar soluções.

- Método fenomenológico: busca descrever uma experiência de maneira direta, da forma que ela foi comunicada, a partir de dados conhecidos.

Silva e Menezes (2005) enfatizam que a ciência dificilmente ocorre por meio de um processo de criação previsível. Assim, nem sempre a pesquisa precisa ser representada por meio de um único método científico. Pelo contrário, a obtenção de respostas adequadas para determinado problema pode ser alcançada por meio do uso de mais de um.

\subsection{Definição da metodologia da pesquisa}

A motivação da pesquisa surgiu da necessidade de se explorar a integração dos métodos utilizados no pré-desenvolvimento como forma de melhorar a realização das atividades dessa macro-fase. Junto com essa necessidade percebeuse que a integração do technology roadmapping e da gestão de portfólio era uma oportunidade para se analisar a integração dos métodos usados do prédesenvolvimento. Assim surgiu a seguinte questão de pesquisa: "A aplicação integrada do technology roadmapping e da gestão de portfólio contribui com a 
realização das atividades do pré-desenvolvimento do PDP?" A investigação dessa questão é o objetivo desse trabalho.

Contudo para se alcançar esse objetivo é necessário seguir um método de pesquisa. Entre os métodos de pesquisa estudados, o método hipotético-dedutivo mostra-se o mais adequado para esse trabalho. Como mencionado na seção anterior, o método hipotético dedutivo consiste na construção de hipóteses baseadas em um problema ou lacuna no conhecimento, que deve ser submetida a testes e críticas a fim de concluir sobre sua veracidade, ou seja, tenta-se refutar a hipótese (SILVA e MENEZES, 2005).

Portanto, para responder a lacuna do conhecimento representada pela questão de pesquisa, o trabalho assume a seguinte hipótese: "a aplicação integrada do technology roadmapping e da gestão de portfólio contribui com a realização das atividades do pré-desenvolvimento". A pesquisa buscará refutar essa hipótese durante sua realização. Entende-se por aplicação integrada nesse trabalho, a união das funcionalidades de duas partes com o objetivo de se criar uma nova parte, nas quais as anteriores estejam interligadas de maneira complementar.

Definida a linha de raciocínio do processo de pesquisa como hipotéticodedutiva, o próximo passo é definir suas características para que seja possível classificá-la segundo os critérios de classificação de pesquisa apresentados no subcapítulo anterior.

A primeira característica da pesquisa envolve o seu objetivo. Como a pesquisa investiga a capacidade da integração entre o technology roadmapping e a gestão de portfólio, ela deve explorar a aplicação integrada desses dois métodos na prática. Essa necessidade acarreta um objetivo exploratório para pesquisa, pois ela buscará 
explicar se o fenômeno da aplicação integrada dos métodos tem realmente capacidade para apoiar o pré-desenvolvimento.

A segunda característica da pesquisa é o foco na solução de problemas reais ou práticos. Essa característica define a pesquisa como aplicada quanto à sua natureza.

A terceira característica da pesquisa é a avaliação qualitativa dos resultados. Essa escolha se deve ao fato dela atuar com percepções sobre a capacidade que a integração dos métodos tem para melhorar a realização do pré-desenvolvimento. Esse aspecto não mensurável e baseado em percepções define a pesquisa dentro da abordagem qualitativa.

A quarta característica da pesquisa está relacionada com os procedimentos técnicos utilizados pelo pesquisador durante suas etapas. Uma vez que se pretende utilizar conhecimentos teóricos para embasar a aplicação integrada dos métodos, um dos procedimentos usados é a pesquisa bibliográfica. O outro procedimento seguido é o estudo de caso. Ele guia o pesquisador durante a exploração da aplicação integrada dos métodos na prática, possibilitando que sejam levantadas as informações necessárias para analisar a hipótese.

O método e as classificações dessa pesquisa estão resumidos na Tabela 1.

Tabela 1 - Método e classificações da pesquisa

\begin{tabular}{|l|l|l|}
\hline \multicolumn{2}{|c|}{ Método e classificações da pesquisa } \\
\hline \multirow{2}{*}{ Método científico } & Objetivo & Hipotético-Dedutivo \\
\cline { 2 - 3 } & Abordagem do problema & Exploratório \\
\cline { 2 - 3 } $\begin{array}{l}\text { Classificações } \\
\text { da pesquisa }\end{array}$ & Natureza & Qualitativa \\
\cline { 2 - 3 } & Procedimentos técnicos & Aplicada \\
\hline
\end{tabular}


O último passo para concluir a definição da metodologia científica é a escolha dos instrumentos de coleta de dados, que são as ferramentas usadas pelo pesquisador na pesquisa. Alguns instrumentos comumente usados dentro do método científico e das classificações estabelecidas são: diário de bordo, entrevistas, questionários, observação e análise documental. Entre esses, os que se alinham com as necessidades da pesquisa são: o diário de bordo, a análise documental, o questionário e a entrevista.

\subsection{Etapas da pesquisa}

As etapas da pesquisa devem estar alinhadas com a metodologia científica definida. Foram estabelecidas cinco etapas para a pesquisa, as quais estão mostradas na Figura 11.

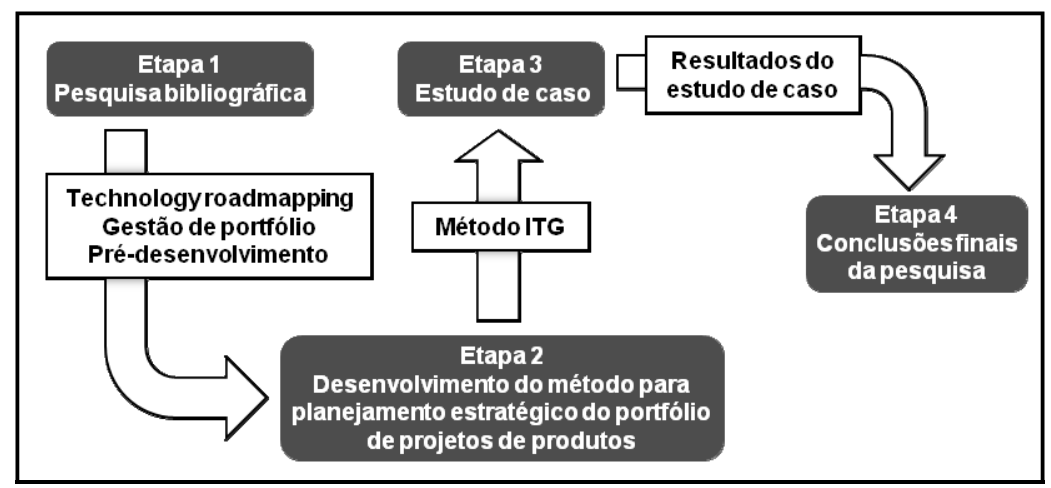

Figura 11 - Etapas da pesquisa

\subsubsection{Etapa 1 - Pesquisa bibliográfica}

A primeira etapa está associada à busca dos conhecimentos que permitem a aplicação integrada do TRM e da gestão de portfólio no pré-desenvolvimento. Ela corresponde aos estudos sobre a gestão do desenvolvimento de produtos, a macrofase de pré-desenvolvimento do PDP, o technology roadmapping e a gestão de portfólio de projetos de produtos. 
O tema gestão de desenvolvimento de produto esclarece o contexto geral onde a pesquisa está inserida. O pré-desenvolvimento permite o esclarecimento da função dessa macro-fase dentro do PDP e a identificação de quais são suas atividades. Durante o estudo do TRM e da gestão de portfólio são procurados os conceitos e os procedimentos que descrevem como aplicá-los.

Os resultados dessa etapa foram apresentados no capítulo 2 .

\subsubsection{Etapa 2-Desenvolvimento do método para planejamento estratégico do portfólio de projetos de produtos}

A segunda etapa corresponde ao desenvolvimento do método que permitirá a aplicação integração do technology roadmapping e da gestão de portfólio no prédesenvolvimento do PDP. Esse método tem a função de realizar o planejamento estratégico do portfólio de projetos de produtos e receberá o nome de Método ITG.

O Método ITG emprega os conceitos do technology roadmapping, da gestão de portfólio e do pré-desenvolvimento. Sua elaboração segue três atividades:

- Definição das atividades do método considerando as necessidades do prédesenvolvimento e os processos de aplicação do TRM e da gestão de portfólio.

- Elaboração do processo de aplicação do método seguindo o fluxo geral das fases da macro-fase de pré-desenvolvimento.

- Escolha das ferramentas a serem utilizadas em cada um das atividades do método, permitindo que esse seja aplicado conforme planejado.

O desenvolvimento do modelo do método adota o formalismo do $\mathrm{BPMN}^{3} \mathrm{e}$ utiliza a ferramenta de modelagem Intalio Designer $5.2 \AA^{4}$.

${ }^{3} \mathrm{O}$ BPMN (Business Process Modeling Notation) é uma notação de modelagem de processos publicada pelo OMG (Object Management Group). Maiores detalhes no site: www.bpmn.org. 
Os resultados dessa etapa são apresentados no capítulo 4.

\subsubsection{Etapa 3 - Estudo de caso}

A terceira etapa consiste na aplicação do Método ITG em um caso real para investigar a integração do technology roadmapping e da gestão de portfólio. $\mathrm{O}$ estudo de caso segue a sistemática de realização de estudos de caso apresentada por Voss et al. (2002) e por Yin (2005). Com base nessas referências, o pesquisador definiu as seguintes atividades a serem realizadas durante a etapa de estudo de caso:

- Elaboração do protocolo de estudo de caso: essa atividade define os requisitos a serem atendidos pela empresa onde o caso pretende ser realizado e planeja a participação do pesquisador.

- Definição da empresa e da unidade de análise: nessa atividade o pesquisador seleciona algumas empresas potenciais e realiza visitas para apresentar a pesquisa e averiguar se a empresa atende aos requisitos buscados. Após escolher a empresa, o define-se uma unidade de análise específica para realizar o caso. Assim torna-se possível controlar as variáveis que afetam os resultados.

- Planejamento do estudo de caso: essa atividade planeja a participação dos participantes e a duração das atividades.

- Execução do estudo de caso: essa atividade consiste na aplicação do Método ITG na unidade de análise selecionada e conforme o planejamento

\footnotetext{
${ }^{4}$ Essa ferramenta é adotada pelo grupo de pesquisa e sua seleção está fora do escopo deste
} trabalho. Maiores informações sobre a ferramenta podem ser encontradas no site: www.intalio.com. 
proposto. Nela são documentados os resultados e é anotado em um diário os acontecimento considerados relevantes.

- Avaliação dos resultados do estudo de caso: a estratégia de avaliação escolhida para garantir a confiabilidade da conclusão sobre a hipótese da pesquisa segue dois passos: uma avaliação antes e uma após o estudo de caso.

$\mathrm{Na}$ primeira avaliação entrevistam-se os participantes e analisam-se os documentos com o objetivo de conhecer a situação do pré-desenvolvimento da empresa antes da realização do estudo de caso. A entrevista segue um roteiro, que está disponível no apêndice 9.1 desse trabalho, e é assistida pelo pesquisador.

$\mathrm{Na}$ avaliação posterior ao estudo de caso, os participantes são entrevistados para se verificar: a contribuição do technology roadmapping e da gestão de portfolio nas atividades do pré-desenvolvimento, e a melhoria do pré-desenvolvimento em função dos seguintes indicadores de desempenho das atividades: tempo, custo, qualidade, integração funcional e sistematização. A entrevista utiliza um roteiro, que está disponível no apêndice 9.2 desse trabalho, e é assistida pelo pesquisador.

Com base nas respostas obtidas, são elaborados gráficos que descrevem: a contribuição do technology roadmapping para as atividades do pré-desenvolvimento, a contribuição da gestão de portfolio para as atividades do pré-desenvolvimento e a alteração do desempenho das atividades em relação aos indicadores: tempo, custo, qualidade, integração funcional e sistematização.

As informações desses dois passos permitem comparar a situação inicial e final da empresa na realização das atividades do pré-desenvolvimento e concluir sobre a hipótese da pesquisa. 
Os resultados das atividades dessa etapa são apresentados no capítulo 5 e no capítulo 6.

\subsubsection{Etapa 4 - Conclusões finais da pesquisa}

Nesta etapa, os resultados do estudo de caso são confrontados com a hipótese da pesquisa: "a aplicação integrada do technology roadmapping e da gestão de portfólio contribui com a realização das atividades do pré-desenvolvimento". Em função da avaliação qualitativa do pesquisador sobre essa hipótese, o trabalho responde a pergunta da pesquisa e conclui sobre o tema estudado.

Os resultados dessa etapa são apresentados no capítulo 7. 


\section{Método ITG: planejamento estratégico do portfólio de projetos de produtos}

O método de planejamento estratégico do portfólio de projetos de produtos é uma das principais contribuições deste trabalho. Sua elaboração é resultado da revisão da literatura e de experiências dos pesquisadores na aplicação do TRM e da gestão de portfólio em casos reais, como as publicadas em Oliveira e Rozenfeld (2007) e Oliveira et al. (2007). Essas experiências ajudaram entender como aplicar o TRM e a gestão de portfólio de forma integrada para apoiar as atividades do prédesenvolvimento.

Este capítulo descreve a construção do Método ITG, suas atividades e ferramentas. Assim, os interessados no método podem entender sua sistemática de aplicação e como utilizá-lo para apoiar a realização do pré-desenvolvimento do PDP da sua empresa.

\subsection{Construção do Método ITG}

A construção do método usou como referências principais: o modelo de prédesenvolvimento de Crawford e Benedetto (2006), o processo de aplicação do TRM de Phaal et al. (2001), e os processos de aplicação da gestão de portfólio de Cooper et al. (1998) e Archer e Ghasemzadeh (1999). A escolha dessas referências foi explicada no final de cada subcapítulo da revisão da literatura.

O primeiro passo da construção do método, a definição das suas atividades, iniciou com uma análise de como as atividades do technology roadmapping e da gestão de portfólio se adequavam às fases do pré-desenvolvimento de Crawford e Benedetto (2006). Essa análise verificou o objetivo e o conteúdo das três fases do pré-desenvolvimento: identificação e seleção de oportunidades para produtos, geração de conceitos de produtos, e avaliação de conceito e projeto de produto. E 
então os comparou com os objetivos e conteúdo das atividades do technology roadmapping de Phaal et al. (2001) e da gestão de portfólio de Cooper et al. (1998) e Archer e Ghasemzadeh (1999). Assim foi possível relacionar as atividades de cada método com as fases do pré-desenvolvimento.

Como resultado notou-se que as atividades do processo de aplicação do TRM de Phaal et al. (2001) relacionavam-se com a fase de identificação e seleção das oportunidades de produtos. Enquanto isso, os processos de gestão de portfólio de Cooper et al. (1998) e Archer e Ghasemzadeh (1999) atendiam à fase de avaliação de conceito e projeto do produto. Portanto, seguindo a ordem das fases do prédesenvolvimento, as atividades do technology roadmapping viriam antes das atividades da gestão de portfólio no processo do método a ser construído.

Em seguida era preciso definir quais seriam as atividades do método. Como este deveria representar a integração do technology roadmapping e da gestão de portfólio, suas atividades foram selecionadas com base nas atividades dos processos do technology roadmapping e da gestão de portfólio.

Optou-se por adotar as mesmas atividades propostas por Phaal et al. (2001) para a realização do technology roadmapping como sendo as primeiras atividades do método. Enquanto que para as próximas foi necessária uma combinação das atividades dos processos de aplicação de Cooper et al. (1998) e Archer e Ghasemzadeh (1999). Sendo que o primeiro contribui com a abordagem dos objetivos da gestão de portfólio e o segundo com as atividades de seleção dos projetos.

Seguindo a proposta de que as atividades do método seriam provenientes do technology roadmapping e da gestão de portfólio, as atividades selecionadas foram: 
- Atividades originadas do TRM: definição da unidade de análise, análise das estratégias do negócio, análise de mercado, análise de produto, análise de tecnologia, definição de estratégias de produtos

- Atividades originadas da gestão de portfólio: análise financeira de projetos, avaliação da probabilidade de sucesso do projeto, avaliação do potencial estratégico do projeto, classificação dos projetos, análise do relacionamento entre os projetos e seleção dos projetos de produto.

O próximo passo na construção do método seria definir o seu processo de aplicação. Contudo, para que existisse um fluxo no processo e este estivesse alinhado com o pré-desenvolvimento, faltava uma atividade que considerasse a fase de geração de conceitos de produto. Pois dessa forma o processo de aplicação do método poderia seguir as três fases do modelo de pré-desenvolvimento de Crawford e Benedetto (2006). Essa atividade utilizaria as oportunidades de novos produtos indicadas pelo TRM para definir novos conceitos de produtos que formariam os projetos a serem selecionados pela gestão de portfólio.

Além disso, essa atividade poderia se tornar um ponto de integração com oportunidades de produtos criadas em outras áreas da organização e que também deveriam ser consideradas na seleção dos projetos. Dessa forma, o método define a atividade de proposição de projetos de produtos para preencher a lacuna existente entre o technology roadmapping e a gestão de portfólio, e melhor atender às necessidades do pré-desenvolvimento.

Assim conseguiu-se formatar o processo de aplicação do método, que inicia com as atividades do technology roadmapping, em seguida realiza a atividade de proposição de projetos de produtos e termina com as atividades da gestão de portfólio. 
O último passo da construção do método é a escolha das ferramentas. Essas advêm primeiramente das referências usadas na definição das atividades. No caso das atividades do TRM, foram seguidas as ferramentas propostas por Phaal et al. (2001). Para a atividade de proposição de projetos de produtos foi utilizada a ferramenta proposta por Crawford e Benedetto (2006). E para as ferramentas usadas nas atividades da gestão de portfólio foram adotadas aquelas indicadas por Cooper et al. (1998) e Archer e Ghasemzadeh (1999).

Em alguns casos, quando essas referências não apresentavam ou eram superficiais em algumas das ferramentas necessárias para a realização das atividades, foram adotadas ferramentas complementares. As fontes dessas são descritas a seguir:

- avaliação financeira de projetos: Rebelatto (2004), Sebrae (2005) e Rosa (2007).

- avaliação da probabilidade de sucesso do projeto: Davis et al. (2002).

- análise do relacionamento entre os projetos: Chien (2002)

No próximo subcapítulo inicia-se a descrição do método.

\subsection{Visão geral do Método ITG}

O método é formado por 13 atividades: (1) Definição da unidade de análise, (2) Análise das estratégias do negócio, (3) Análise de mercado, (4) Análise de produto, (5) Análise de tecnologia, (6) Definição das estratégias de produtos, (7) Proposição de projetos de novos produtos, (8) Análise financeira dos projetos, (9) Avaliação da probabilidade de sucesso dos projetos, (10) Avaliação do potencial estratégico dos projetos, (11) Classificação dos projetos, (12) Análise do relacionamento entre os projetos e (13) Seleção dos projetos de produto para desenvolvimento. A Figura 12 
mostra a visão geral das atividades do método, enquanto que no apêndice 9.3 o modelo do método é descrito em detalhes por meio da notação BPMN realizada com o software Intalio Designer $5.2 \circledR$.

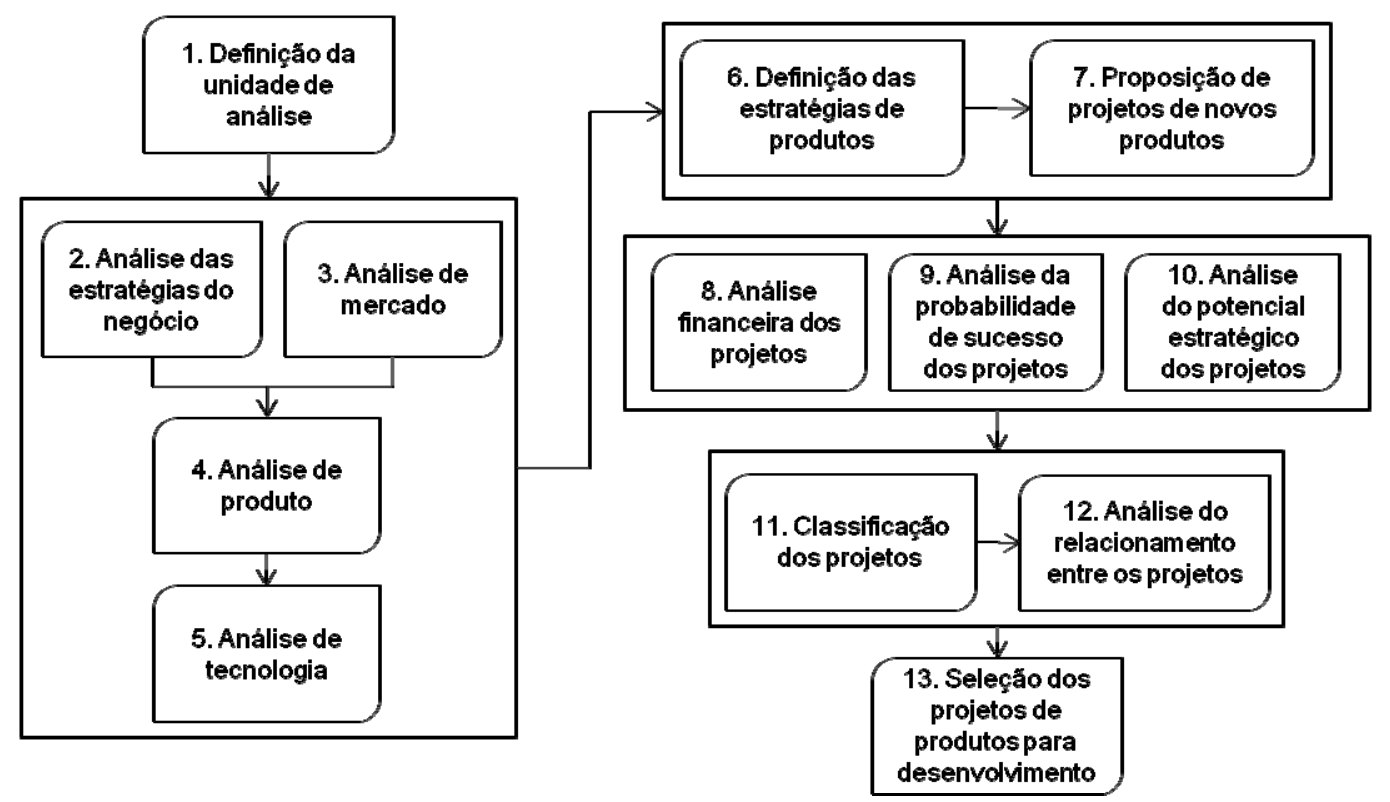

Figura 12 - Visão geral do Método ITG

A apresentação ordenada das atividades tem o intuito de sistematizar o método. Todavia o ambiente do pré-desenvolvimento é dinâmico e pode ocasionar iterações entre as atividades quando se julgar necessário (KOEN et al., 2002). A ordem proposta está relacionada com a dependência existente entre os dados usados pelas atividades.

O Método ITG foi desenvolvido com o propósito de ser flexível em relação às ferramentas utilizadas em suas atividades. Todavia, ele apresenta uma lógica de trabalho que precisa ser seguida, independentemente do conjunto de ferramentas utilizado. Portanto, nos casos onde uma ferramenta diferente atenda melhor aos requisitos do método e da empresa não existe nenhum empecilho em substituir ou modificar as ferramentas proposta pelo método. Archer e Ghasemzadeh (1999) adotaram essa mesma idéia no desenvolvimento de um modelo de gestão de 
portfólio de projetos e mostraram que assim se cria uma forma de satisfazer diferentes casos.

A aplicação do método é uma atividade multifuncional e de nível estratégico, ou seja, deve ser realizada com a participação de um time multidisciplinar formado pela alta cúpula da empresa. Essa necessidade resulta das características do technology roadmapping e da gestão de portfólio, e da confidencialidade e diversidade das informações envolvidas no pré-desenvolvimento do PDP.

O time envolvido na aplicação do método tem alto impacto na eficácia dos resultados. Mesmo assim esse trabalho não se aprofundou nos aspectos relacionados ao time de desenvolvimento. Isso é considerado uma limitação e poderia ser escopo de trabalhos futuros.

As atividades e ferramentas do Método ITG são mostradas nos próximos subcapítulos.

\subsection{Atividade 1 - Definição da unidade de análise}

Esta é a primeira atividade do método e tem como função delimitar o tema abordado pelas próximas atividades. A unidade de análise deve estar alinhada com o objetivo que a empresa possui com a aplicação do método. Essa unidade é formada por três partes: unidade de negócio, segmento de mercado e linha de produto.

A abrangência da unidade de análise impacta no detalhamento e no esforço das atividades, logo é essencial que a empresa avalie com cuidado seus objetivos antes de defini-la. O método segue a proposta de Phaal et al. (2001) e sugere a escolha de uma unidade de análise reduzida: uma única linha de produtos de uma unidade de negócios direcionada para um segmento de mercado específico. Os autores explicam que essa escolha contribui para um planejamento adequado, uma 
vez que se consegue alcançar o equilíbrio entre esforço e detalhamento apropriados para as próximas atividades do método.

A ferramenta utilizada nessa atividade é um documento que descreve o plano de aplicação do método. Ele explica o objetivo buscado com a aplicação do método, a unidade de análise e os participantes. A Figura 13 apresenta o modelo desse documento.

\section{Ferramenta 1 - Plano de aplicação do método}

\section{Objetivo da aplicação do método}

Descrever quais os resultados buscados pela empresa com a aplicação do método

\section{Unidade de análise}

Descrever a unidade de análise escolhida pela empresa em função de três fatores: unidade de negócio, linha de produto e segmento de mercado.

2.1 Unidade de negócio:

Descrever a unidade de negócio selecionada e explicar os motivos da decisão.

2.2 Linha de produto:

Descrever a linha de produtos selecionada e explicar os motivos da decisão.

2.3 Segmento de mercado:

Descrever os segmentos de mercado selecionados e explicar a decisão.

\section{Participantes da aplicação do método}

Indicar os participantes do processo de aplicação do método. Deve-se atentar para que todos os envolvidos na aplicação do método estejam de acordo com a unidade de análise selecionada.

\begin{tabular}{|l|l|}
\hline Nome do participante & Departamento \\
\hline & \\
\hline & \\
\hline & \\
\hline & \\
\hline & \\
\hline & \\
\hline & \\
\hline & \\
\hline
\end{tabular}

Figura 13 - Ferramenta 1: plano de aplicação do método 


\subsection{Atividade 2 - Análise das estratégias do negócio}

Esta atividade tem como objetivo identificar os direcionadores estratégicos do negócio que guiam as ações da empresa no processo de desenvolvimento de produtos.

Um caminho proposto pelo método para a identificação dos direcionadores do negócio é analisar a linha de produto e buscar as principais dimensões de desempenho que formam o produto. Essas dimensões de desempenho representam características quantitativas e qualitativas do produto, como: peso, velocidade, inovação, lucratividade, etc.

Phaal et al. (2001) explicam que as dimensões de desempenho do produto formam um envelope que demonstra como o desempenho dos produtos reflete o balanço entre os direcionadores de negócio/mercado (Market-Pull) e as tecnologias (Technology-Push). A Figura 14 mostra um esquema de como essas forças interagem.

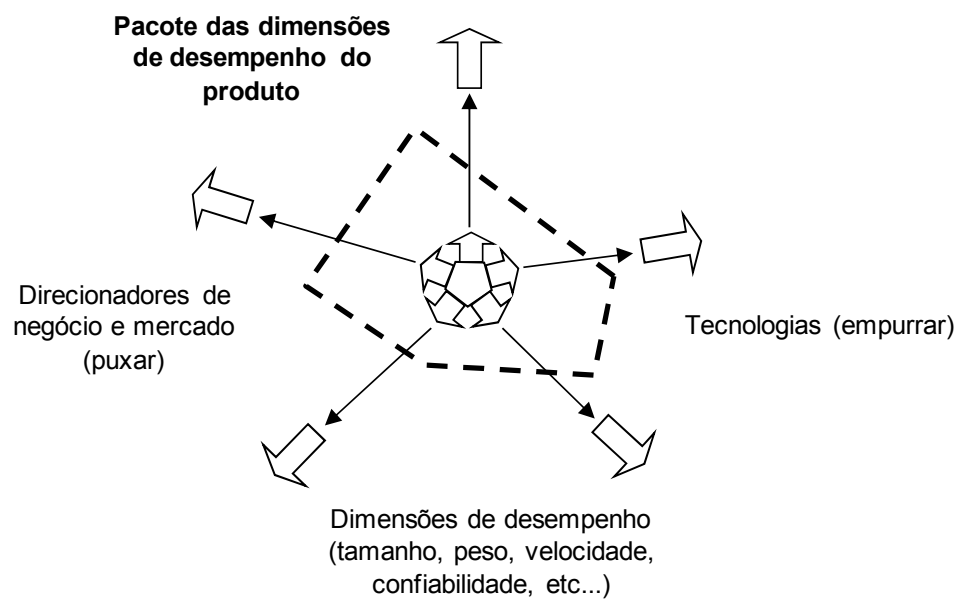

Figura 14 - Dimensões de desempenho do produto. Adaptado de Phaal et al. (2001).

Assim é importante que seja enunciado para o time envolvido na aplicação do método os significados apresentados por Phaal et al. (2001) para os termos: 
- Direcionador de mercado/negócio: está relacionado com o valor que o cliente busca no produto.

- Atributo de produto: define uma especificação para o desempenho do produto.

- Tecnologia: está relacionada com a capacidade de melhorar o desempenho do produto.

Esclarecido o significado dos termos, o time pode analisar as estratégias do negócio a partir das dimensões de desempenho do produto e selecionar os direcionadores relacionados. Alguns exemplos seriam: crescimento da participação no mercado, capacitação da organização em conhecimentos chaves, aumento do faturamento do negócio, etc.

Junto com a seleção dos direcionadores do negócio, o time precisa saber o tempo de permanência deles nas estratégias do negócio. Assim, no momento em que a estratégia do negócio for avaliada, é importante que seja anotado o tempo de validade das estratégias. Com essa informação o time consegue definir as data de início e fim dos direcionadores do negócio.

Logo após defini-los é necessário avaliar a prioridade de cada um de acordo com as variações existentes na unidade de análise. Pois, caso a unidade envolva mais de uma unidade de negócio, podem-se encontrar diferentes prioridades.

As informações utilizadas pelo time na realização dessa atividade provêm do plano estratégico. Assim é importante que esse esteja disponível e atualizado para a eficácia da atividade.

As ferramentas utilizadas nessa atividade são duas planilhas eletrônicas: uma para as dimensões do produto e outra para os direcionadores do negócio. A Tabela 2 e a Tabela 3 apresentam o modelo dessas duas planilhas. 
Tabela 2 - Ferramenta 2: planilha de dimensões de desempenho do produto

\begin{tabular}{|c|c|}
\hline $\begin{array}{c}\text { Dimensões de desempenho } \\
\text { do produto }\end{array}$ & Descrição \\
\hline & \\
\hline & \\
\hline & \\
\hline & \\
\hline & \\
\hline
\end{tabular}

Tabela 3 - Ferramenta 3: planilha de direcionadores do negócio

\begin{tabular}{|l|c|c|c|c|c|}
\hline \multirow{2}{*}{$\begin{array}{c}\text { Direcionadores } \\
\text { do negócio }\end{array}$} & \multirow{2}{*}{$\begin{array}{c}\text { Dimensão de } \\
\text { desempenho de } \\
\text { produto relacionada }\end{array}$} & \multicolumn{2}{|c|}{ Prioridade } & \multicolumn{2}{c|}{ Tempo do direcionador } \\
\cline { 3 - 7 } & & $\begin{array}{c}\text { Unidade de } \\
\text { negócio 1 }\end{array}$ & $\begin{array}{c}\text { Unidade de } \\
\text { negócio 2 }\end{array}$ & Data de início & Data de fim \\
\hline & & & & & \\
\hline & & & & & \\
\hline & & & & & \\
\hline & & & & & \\
\hline & & & & & \\
\hline
\end{tabular}

\subsection{Atividade 3 - Análise de mercado}

A análise de mercado busca encontrar quais são as necessidades dos clientes e segmentos de mercado escolhidos e também quais as tendências para os próximos anos. As necessidades e tendências identificadas serão denominadas pelo método como direcionadores de mercado, e servirão como uma guia para alinhar o planejamento dos produtos com o mercado.

A principal dificuldade dessa atividade está em conhecer as necessidades e tendências do mercado, e o tempo em que essas permanecem ativas. Phaal et al. (2001) sugere o envolvimento de participantes com experiência no mercado como forma de diminuir essa dificuldade ou até mesmo convidar clientes para discutir o assunto.

Assim como para a atividade anterior, o método propõe o uso das dimensões de desempenho do produto para a identificação dos direcionadores de mercado. 
Alguns exemplos de direcionadores de mercado são: produtos menores, produtos personalizados, produtos mais baratos, etc.

As informações utilizadas pelo time na realização dessa atividade dependem da pesquisa do mercado que está sendo analisado. Assim consegue-se uma melhor adequação dos planos com as necessidades e tendências do mercado.

Tendo os direcionadores de mercado e o tempo de atuação definidos, em seguida é avaliada a prioridade para cada um dos segmentos de mercado, já que ocorrem variações. A ferramenta utilizada nessa atividade é uma planilha eletrônica. A Tabela 4 mostra o modelo dessa planilha.

Tabela 4 - Ferramenta 4: planilha de direcionadores de mercado

\begin{tabular}{|c|c|c|c|c|c|}
\hline \multirow{2}{*}{$\begin{array}{l}\text { Direcionadores } \\
\text { de mercado }\end{array}$} & \multirow{2}{*}{$\begin{array}{c}\text { Dimensão de } \\
\text { desempenho de } \\
\text { produto relacionada }\end{array}$} & \multicolumn{2}{|c|}{ Prioridade } & \multicolumn{2}{|c|}{ Tempo do direcionador } \\
\hline & & $\begin{array}{c}\text { Segmento de } \\
\text { mercado } 1\end{array}$ & $\begin{array}{c}\text { Segmento de } \\
\text { mercado } 2\end{array}$ & Data de início & Data de fim \\
\hline & & & & & \\
\hline & & & & & \\
\hline & & & & & \\
\hline & & & & & \\
\hline & & & & & \\
\hline
\end{tabular}

\subsection{Atividade 4 - Análise de produto}

Esta atividade tem como objetivo identificar os atributos da linha de produto selecionada. Em seguida é avaliado o impacto de cada um nos direcionadores de negócio e de mercado. Por fim, planeja-se a introdução dos atributos nos novos produtos, para que os direcionadores sejam atendidos de forma adequada e no tempo apropriado.

A identificação dos atributos de produto é feita da mesma forma que a identificação dos direcionadores, isto é, usando como referência as dimensões de desempenho do produto. Alguns exemplos de atributos de produto são: motorização do produto, material do produto, largura do produto, etc. 
As prioridades dos atributos de produto devem ser avaliadas de acordo com cada unidade de negócio e segmento de mercado. Dessa forma é possível diferenciar a importância dos atributos e planejar produtos distintos para unidades de negócio e segmentos de mercados com especificidades diferentes.

A avaliação do impacto dos atributos de produtos nos direcionadores de mercado e negócio pode ser realizada usando a técnica de desdobramento do Quality Function Deployment (QFD). O uso dessa técnica é adotado no T-Plan (PHAAL et al., 2001) como forma de mensurar o desdobramento das prioridades entre as camadas de mercado/negócio, produto e tecnologia no technology roadmapping.

As informações utilizadas pelo time na realização dessa atividade dependem da análise dos seus próprios produtos e também de um benchmarking dos produtos dos concorrentes. Dessa forma é possível esclarecer os atributos de produto de forma consistente e planejá-los para atender aos direcionadores do negócio e do mercado.

As ferramentas usadas nessa atividade são duas planilhas eletrônicas: uma para identificação dos atributos de produto e a outra para avaliação do impacto nos direcionadores de negócio e de mercado. Na Tabela 5 e na Tabela 6 são apresentados os modelos dessas ferramentas.

A planilha de avaliação do impacto dos atributos nos direcionadores (Tabela 6) é preenchida conforme indicado por Phaal et al. (2001). Na parte superior são inseridas as prioridades dos direcionadores de mercado e de negócio para os segmentos de mercado e unidades de negócio analisadas. Em seguida é avaliado o impacto de cada atributo de produto em cada direcionador de mercado e de negócio. Por fim a planilha calcula o impacto total de cada atributo nos direcionadores, o qual 
corresponde à soma dos produtos das notas do atributo com as prioridades dos direcionadores. Como as prioridades dos direcionadores mudam, têm-se impactos totais diferentes para as possíveis combinações de segmento de mercado e unidade de negócio.

Tabela 5 - Ferramenta 5: planilha de atributos de produto

\begin{tabular}{|l|l|}
\hline Atributos de produto & Descrição \\
\hline & \\
\hline & \\
\hline & \\
\hline & \\
\hline & \\
\hline
\end{tabular}

Tabela 6 - Ferramenta 6: planilha de avaliação impacto dos atributos de produto nos direcionadores

\begin{tabular}{|c|c|c|c|c|c|c|c|c|c|c|c|c|c|c|}
\hline Segmentos de mercado (SM) & \multicolumn{10}{|c|}{ Prioridades } & & & & \\
\hline $\begin{array}{l}\text { Segmentos de mercado (SM) } \\
\text { Segmento de mercado } 1 \text { (SM1) }\end{array}$ & & & & & & & & & & & & & & \\
\hline Segmento de mercado 2 (SM2) & & & & & & & & & & & & & & \\
\hline Unidades de negócio (UN) & \multicolumn{10}{|c|}{ Prioridades } & & & & \\
\hline \multicolumn{11}{|l|}{ Unidades de negócio 1 (UN1) } & & & & \\
\hline \multirow{2}{*}{\multicolumn{15}{|c|}{ Unidades de negócio 2 (UN2) }} \\
\hline & & & & & & & & & & & & & & \\
\hline Atributos de produto (AP) & $\sum_{0}^{\nwarrow}$ & $\sum_{0}^{N}$ & $\sum_{0}^{m}$ & $\sum_{\Delta}^{\dagger}$ & $\sum_{0}^{10}$ & $\bar{z}$ & $\underset{\mathrm{Z}}{\mathrm{N}}$ & $\sum_{0}^{m}$ & 芝 & $\sum_{0}^{\infty}$ & 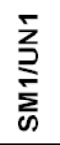 & $\underset{\sum}{\stackrel{N}{\Sigma}}$ & 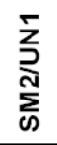 & 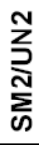 \\
\hline AP1 & & & & & & & & & & & & & & \\
\hline AP2 & & & & & & & & & & & & & & \\
\hline AP3 & & & & & & & & & & & & & & \\
\hline AP4 & & & & & & & & & & & & & & \\
\hline AP5 & & & & & & & & & & & & & & \\
\hline
\end{tabular}

\subsection{Atividade 5 - Análise de tecnologia}

Esta atividade tem por função identificar as tecnologias utilizadas pela linha de produto e avaliar quais delas são responsáveis por entregar os atributos de produto planejados. 
Com esse resultado é possível entender a capacidade das tecnologias disponíveis para planejar os próximos produtos. Assim consegue-se informar o processo de desenvolvimento de tecnologia (PDT) da empresa sobre quais serão as tecnologias necessárias para as próximas gerações de produtos. Essa integração do método com o PDT não foi analisada neste trabalho e poderia ser considerada em outros estudos.

Essa atividade baseia-se nas dimensões de desempenho do produto para identificar uma lista de tecnologias necessárias. As tecnologias levantadas são avaliadas para se saber o impacto que elas possuem nos atributos de produto. Nessa avaliação também pode ser utilizado o procedimento de desdobramento de prioridades mostrado na atividade anterior e proveniente do QFD.

As informações utilizadas pelo time na realização dessa atividade dependem do monitoramento da evolução tecnologias. Assim é possível saber quais tecnologias estão surgindo em substituição das antigas, e com isso se preparar para introduzi-las nos novos produtos.

Essa atividade utiliza duas planilhas eletrônicas: uma para identificação das tecnologias e a outra para avaliação do impacto das tecnologias nos atributos de produtos. Na Tabela 7 e na Tabela 8 são apresentados os modelos dessas planilhas.

O preenchimento da planilha de avaliação do impacto das tecnologias nos atributos de produto (Tabela 8) começa com a inserção na parte superior do impacto total calculado para os atributos de produtos na planilha apresentada na Tabela 6 . Em seguida é avaliado o impacto de cada tecnologia em cada atributo de produto. Por fim a planilha calcula o impacto total, o qual corresponde à soma dos produtos das notas das tecnologias com o impacto dos atributos. Como os impactos mudam 
segundo as combinações de segmento de mercado e unidade de negócio, têm-se diferentes impactos totais das tecnologias.

Tabela 7 - Ferramenta 7: planilha de tecnologias

\begin{tabular}{|c|c|}
\hline Tecnologias & \multicolumn{1}{|c|}{ Descrição } \\
\hline & \\
\hline & \\
\hline & \\
\hline & \\
\hline & \\
\hline
\end{tabular}

Tabela 8 - Ferramenta 8: planilha de avaliação do impacto das tecnologias nos atributos de produto

\begin{tabular}{|c|c|c|c|c|c|c|c|c|c|}
\hline \multirow{2}{*}{$\begin{array}{l}\text { Combinações SM/UN } \\
\text { SM1/UN1 }\end{array}$} & \multicolumn{5}{|c|}{ Impacto dos atributos } & & & & \\
\hline & & & & & & & & & \\
\hline \multicolumn{10}{|l|}{ SM1/UN2 } \\
\hline \multicolumn{10}{|l|}{ SM2/UN1 } \\
\hline \multirow{2}{*}{\multicolumn{10}{|c|}{ Atributos de produto (AP) }} \\
\hline & & & & & & & & & \\
\hline Tecnologias & $\overline{\frac{1}{\alpha}}$ & $\frac{N}{\alpha}$ & $\frac{m}{\alpha}$ & $\frac{a}{a^{2}}$ & $\stackrel{\substack{\alpha \\
\alpha}}{\frac{1}{\alpha}}$ & $\underset{\infty}{\stackrel{\Sigma}{z}}$ & $\sum_{\infty}^{\stackrel{N}{n}}$ & 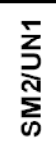 & $\sum_{\substack{N \\
N}}^{N}$ \\
\hline Tec1 & & & & & & & & & \\
\hline Tec2 & & & & & & & & & \\
\hline Tec3 & & & & & & & & & \\
\hline Tec4 & & & & & & & & & \\
\hline Tec5 & & & & & & & & & \\
\hline
\end{tabular}

\subsection{Atividade 6 - Definição das estratégias de produtos}

Esta atividade tem como objetivo formular as estratégias para os novos produtos e planejar a introdução de produtos que as atendam. Ela representa a conclusão da primeira parte do Método ITG, na qual os resultados das cinco atividades anteriores são analisados em conjunto.

Os relacionamentos existentes entre os direcionadores negócio, direcionadores de mercado, atributos de produto e tecnologias são conhecidos por meio das análises realizadas nas atividades anteriores. Esses relacionamentos delimitam os 
objetivos a serem buscados e destacam oportunidades para o desenvolvimento de novos produtos.

O desenvolvimento de um plano para as estratégias de produto considera o tempo de atuação dos direcionadores de mercado e negócio, e o tempo de disponibilização das tecnologias. Sabendo-se esses tempos é possível definir um plano estratégico para o desenvolvimento de novos produtos.

O alinhamento temporal é uma parte difícil do planejamento dos produtos, principalmente quando se envolvem as previsões futuras do negócio, mercado e tecnologias. Mesmo assim ela é essencial para um planejamento efetivo.

Como uma das bases do método é o technology roadmapping, ele adota um roadmap como principal ferramenta dessa atividade. O formato do roadmap utilizado é o formato padrão proposto por EIRMA (1997) apud Phaal (2004). A Figura 15 mostra o roadmap.

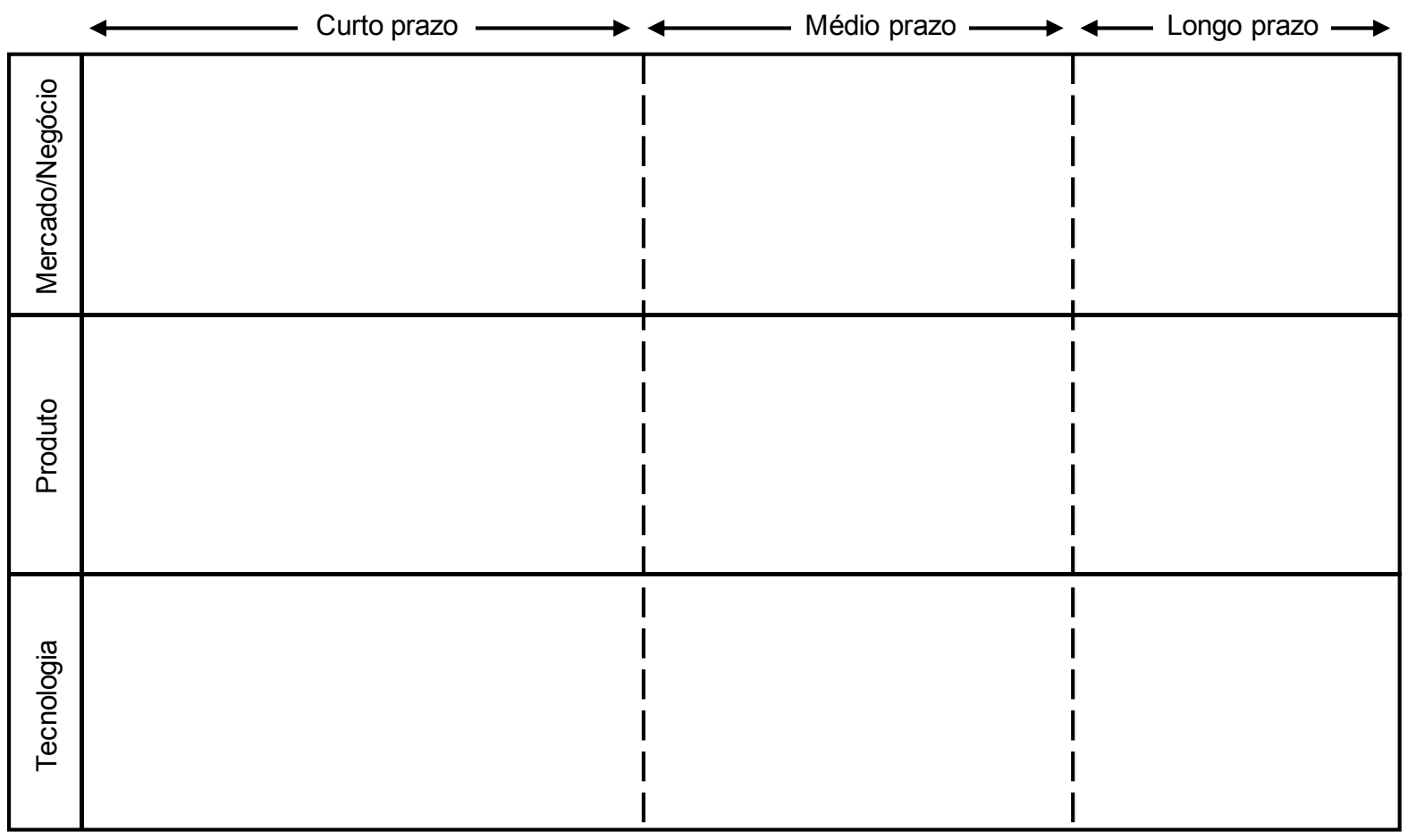

Figura 15 - Ferramenta 9: roadmap de planejamento de produto 
O horizonte de planejamento adotado pelo método depende dos objetivos e das características de cada negócio. Como referência, o método sugere que o roadmap seja divido nos horizontes: curto prazo, médio prazo e longo prazo.

O horizonte de curto prazo deve envolver o ano atual ou até mesmo o ano anterior a aplicação do método, possibilitando a integração das ações em andamento com os planos futuros da empresa. Kostoff e Schaller (2001) diferem os roadmaps em retrospectivos e prospectivos, e mostram algumas diferenças entre eles. Nesse caso o método traz um roadmap que mistura os dois tipos, mas com uma tendência para o roadmap prospectivo.

A definição do horizonte de planejamento é uma tarefa do time que participa da aplicação do método. Esse deve avaliar as necessidades e objetivos do planejamento estratégico para a unidade de análise e então definir a unidade de tempo que corresponde ao curto, médio e longo prazo.

\subsection{Atividade 7 - Proposição de projetos de novos produtos}

Esta atividade tem por objetivo criar idéias e conceitos de novos produtos para as oportunidades de produtos provenientes da atividade anterior. Ela representa a integração entre as atividades apoiadas pelo technology roadmapping e pela gestão de portfólio.

Além das oportunidades vindas do próprio método, existem outras que surgem em outras áreas da empresa, como: atendimento dos clientes, pesquisa e desenvolvimento de tecnologias e engenharia de produto. Essas podem ser reunidas com as oportunidades de produtos identificadas durante a atividade de definição das estratégias de produtos. Com isso a proposição de projetos de novos produtos consegue abranger a organização como um todo. 
A principal diferença entre as oportunidades identificadas pelo método ITG e as oportunidades indicadas pelas outras fontes da organização é que a primeira recebe uma análise detalhada dos direcionadores do mercado, atributos de produto e tecnologias.

Caso sejam consideradas as oportunidades indicadas por outras áreas da empresa, tem que ser avaliada a possibilidade de extensão da unidade de análise inicial. Isso significa incluir oportunidades de produtos de outras unidades de negocio, linhas de produto e segmentos de mercado. Essa escolha tem forte impacto no restante da aplicação do método, visto que com essa extensão, o time pode não conhecer as informações necessárias para realizar as próximas atividades. Portanto o ideal é manter a unidade de análise inicial selecionada para a aplicação do método.

A diferença entre uma oportunidade de produto e a proposta de um projeto de produto é pequena. Porém, é importante separá-las para mostrar que cada uma surge em momentos distintos. Para uma mesma oportunidade de produto poderiam ser fornecidos produtos diferentes, ou até mesmo poderia ser criado um produto que atendesse a mais de uma ao mesmo tempo. Com essa visão torna-se mais simples desenvolver propostas de propostas de produtos para as oportunidades.

O método segue um modelo de documento para definir o projeto do produto que foi adaptado da proposta de protocolo de produto apresentada por Crawford e Benedetto (2006) e utiliza os conceitos de ciclo de vida de projetos de produtos de Rozenfeld et al. (2006). Nesse modelo são especificadas as informações da oportunidade de produto que o projeto atende, em conjunto com detalhes individuais do projeto. As próximas atividades do método usarão essas informações para avaliar a proposta. A Figura 16 mostra o modelo do documento em questão. 


\begin{tabular}{|c|c|}
\hline \multicolumn{2}{|c|}{ Proposta de Projeto de Novo Produto } \\
\hline \multicolumn{2}{|l|}{ Dados do projeto } \\
\hline \multicolumn{2}{|l|}{ Código/Nome do projeto: } \\
\hline \multicolumn{2}{|l|}{ Produto do projeto: } \\
\hline \multicolumn{2}{|l|}{ Tipo do projeto: } \\
\hline \multicolumn{2}{|l|}{ Dados do mercado } \\
\hline \multicolumn{2}{|l|}{ Descrição do mercado/segmento alvo: } \\
\hline \multirow{2}{*}{\multicolumn{2}{|c|}{$\begin{array}{l}\text { Tamanho do mercado: } \\
\text { Preco estimado do produto no mercado: }\end{array}$}} \\
\hline \multirow{2}{*}{\multicolumn{2}{|c|}{\begin{tabular}{|l} 
Preço estimado do produto no mercado: \\
Requisitos críticos do mercado: \\
\end{tabular}}} \\
\hline & \\
\hline \multicolumn{2}{|l|}{ Dados do produto } \\
\hline \multicolumn{2}{|l|}{ Componentes do produto: } \\
\hline \multirow{2}{*}{\multicolumn{2}{|c|}{$\begin{array}{l}\text { Especificações/interfaces do produto: } \\
\text { Custo estimado da matéria-prima do produto: }\end{array}$}} \\
\hline & \\
\hline \multicolumn{2}{|l|}{ Dados do ciclo de vida do produto } \\
\hline \multicolumn{2}{|l|}{ a. Fase de desenvolvimento técnico e comercial } \\
\hline \multicolumn{2}{|l|}{ Tempo de desenvolvimento técnico e comercial do produto } \\
\hline \multicolumn{2}{|l|}{ Comprometimento (tempo $\times$ recursos) de competências } \\
\hline \multicolumn{2}{|l|}{$\begin{array}{l}\text { críticas do negócio no des. técnico e comercial do produto } \\
\text { Custo estimado do desenvolvimento técnico e comercial }\end{array}$} \\
\hline \multicolumn{2}{|l|}{ b. Fase de produção } \\
\hline \multicolumn{2}{|l|}{ Tempo de produção do produto } \\
\hline \multicolumn{2}{|l|}{$\begin{array}{l}\text { Comprometimento (tempo x recursos) de competências } \\
\text { críticas do negócio na producão do produto }\end{array}$} \\
\hline \multicolumn{2}{|l|}{ Custo estimado de produção } \\
\hline \multicolumn{2}{|l|}{ c. Fase de retirada do mercado } \\
\hline \multicolumn{2}{|l|}{ Tempo de retirada do mercado } \\
\hline \multirow{2}{*}{\multicolumn{2}{|c|}{$\begin{array}{l}\text { Comprometimento (tempo } \mathrm{x} \text { recursos) de competências } \\
\text { críticas do negócio na retirada do mercado } \\
\end{array}$}} \\
\hline & \\
\hline
\end{tabular}

Figura 16 - Ferramenta 10: proposta de projeto de novo produto

\subsection{Atividade 8 - Avaliação financeira de projetos}

A análise financeira de projetos é por si só um assunto amplo para estudo, portanto este método adota apenas seus conceitos básicos. As referências usadas para embasar o método neste tema foram: Rebelatto (2004), Sebrae (2005) e Rosa (2007).

Os conceitos usados pelo método são:

- Investimento: valor desembolsado pelo negócio para desenvolver o produto. Caracteriza-se pela fase na qual o negócio ainda não possui retorno financeiro com o produto resultado do projeto.

- Despesa: correspondem aos gastos com um bem ou serviço utilizados para obter a receita do produto. As despesas fixas representam os gastos cujo valor não 
depende do volume e do valor das vendas. As despesas variáveis são os gastos cujo valor está diretamente relacionado ao volume e ao valor vendido.

- Custo: são os gastos realizados com bens ou serviços usados na produção do produto. Os custos são considerados diretos quando é possível quantificar o quanto foi usado. Nos casos onde não é possível medir e atribui-se qualitativamente, considera-se que os custos são indiretos.

- Receita: representa os ganhos financeiros do negócio com a venda do produto.

- Fluxo de caixa: representa a soma de todos os gastos e receitas do negócio em um determinado período. Quanto o fluxo de caixa é negativo, significa que o negócio gastou mais do que ganhou de receita no período. Quando ele é positivo o negócio ganhou mais receita do que gastou no período.

- Fluxo de caixa acumulado: neste caso o fluxo de caixa do mês anterior é considerado no cálculo do fluxo de caixa do mês seguinte. Dessa forma os resultados do fluxo de caixa de cada período se acumulam para que no final se saiba qual o fluxo de caixa acumulado do projeto.

- Valor presente líquido (VPL): representa o valor do fluxo de caixa acumulado do projeto calculado na data atual por meio de uma taxa de juros denominada de taxa mínima de atratividade (TMA), a qual corresponde ao menor valor de juros aceitável para o negócio investir em um projeto.

- Taxa interna de retorno (TIR): essa taxa equivale à taxa mínima de atratividade que anula o VPL do projeto. Com ela é possível saber qual seria a taxa de rendimento do projeto no seu término, calculada na data atual.

- Tempo de pagamento do investimento (Payback): essa medida representa o tempo que o projeto precisa para pagar o valor investido pelo negócio. Esse tempo 
acontece quando o fluxo de caixa acumulado do projeto é anulado. O payback não considera o valor do dinheiro no tempo.

- Retorno sobre investimento (ROI): corresponde ao rendimento do valor investido no projeto. Calcula-se dividindo o valor do fluxo de caixa acumulado no final do projeto com o valor investido.

Seguindo esses conceitos, o método calcula quatro indicadores financeiros para os projetos: VPL, TIR, ROI e Payback, que serão utilizados na classificação dos projetos de produtos.

As informações usadas na análise financeira do projeto são previsões, isso causa incertezas nos valores utilizados e também nos resultados obtidos. Portanto é importante que se tenha cuidado ao tomar decisões baseadas apenas nos dados financeiros. Algumas informações a serem previstas para a análise financeira são: o investimento para desenvolvimento do produto, tempo de desenvolvimento do produto, custos e despesas de produção do produto, tempo de produção do produto, receita da venda do produto e tempo de venda do produto.

Além de informações incertas sobre o projeto, são também necessárias informações econômicas na análise financeira. No cálculo do VPL é necessário saber a taxa mínima de atratividade do projeto para o negócio. Essa informação deve vir da estratégia da empresa e depende a atual situação econômica do mercado e das taxas de referência.

O método utiliza uma planilha eletrônica para realizar a análise financeira dos projetos, a qual calcula os indicadores financeiros. A Figura 17 mostra o modelo dessa planilha. 


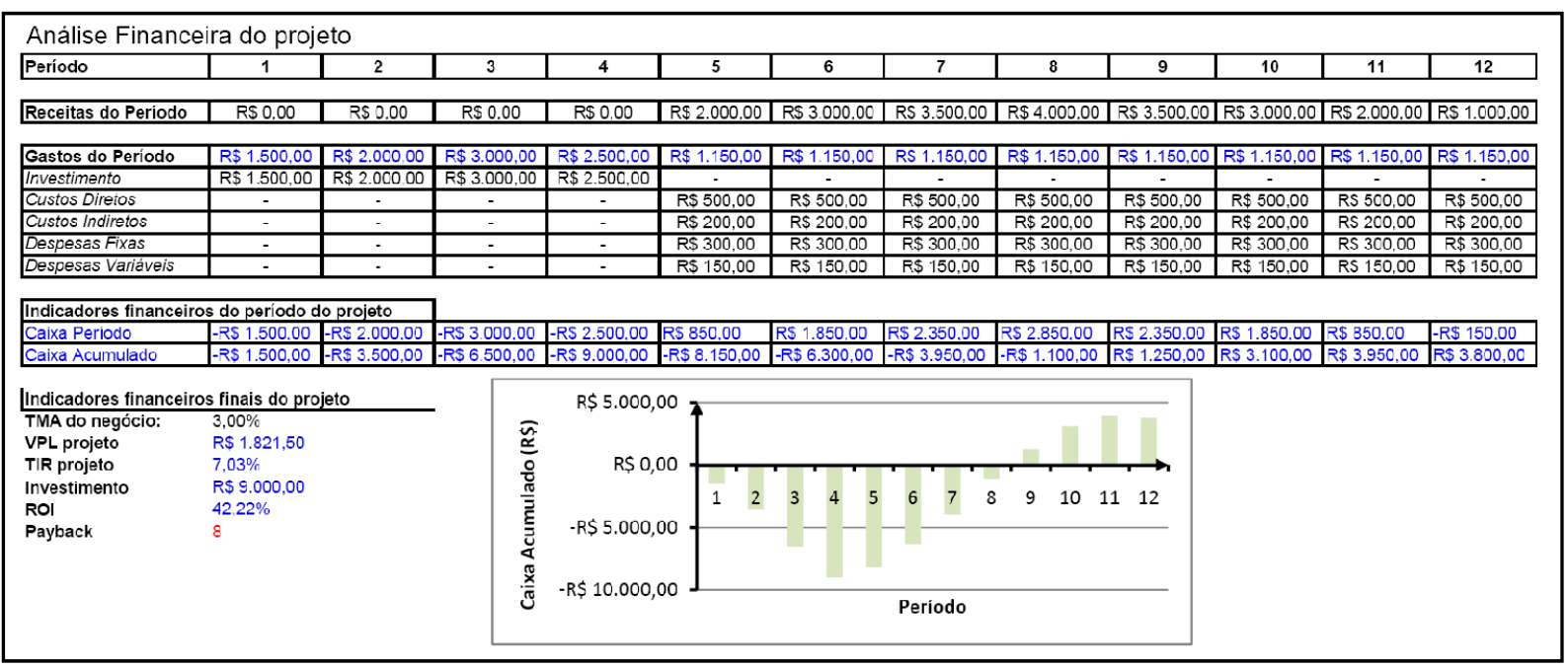

Figura 17 - Ferramenta 11: Planilha de análise financeira de projeto

É importante relembrar que cada empresa possuir seu padrão para a análise financeira dos projetos. No entanto, independentemente do cálculo adotado, devemse seguir os significados dos indicadores apresentados, uma vez que estes permitem organizar a análise financeira de maneira adequada.

\subsection{Atividade 9 - Avaliação da probabilidade de sucesso de projetos}

Esta atividade verifica os riscos envolvidos no desenvolvimento do produto para estimar a probabilidade de um projeto chegar ao seu fim e alcançar os seus objetivos.

O método divide os riscos existentes no desenvolvimento de um produto em riscos técnicos e riscos comerciais. O risco técnico corresponde aos riscos presentes no desenvolvimento do projeto do produto. Já o risco comercial representa os riscos da comercialização do produto. Por exemplo, pode existir um produto para o qual a organização não consegue encontrar um processo de fabricação adequado, o que traz um risco técnico, e pode existir um produto que esteja pronto para a venda, mas o seu canal de distribuição não está disponível, isso seria um risco comercial. 
Normalmente os riscos do desenvolvimento de produtos são semelhantes, portanto é possível criar uma lista padrão de riscos para auxiliar as empresa na avaliação dos seus projetos. Davis et al. (2001) desenvolveram uma lista padrão de riscos para avaliação da probabilidade de sucesso técnico e comercial de um projeto de produto.

Essa lista foi adotada pelo método como a ferramenta a ser utilizada nesta atividade para o cálculo da probabilidade de sucesso. Ela é formada por três partes: a lista padrão de riscos técnicos (Tabela 9), a lista padrão de riscos comerciais (Tabela 10) e a planilha de avaliação da probabilidade de sucesso do projeto (Tabela 11).

A utilização da ferramenta acontece por partes. Primeiro o time define como os riscos técnicos e comerciais do projeto serão avaliados. O método sugere que seja escolhido um membro do time que represente a área técnica e outro da área comercial para uma avaliação preliminar dos riscos comerciais e técnicos do projeto, para em seguida o time averiguar e finalizar a avaliação durante uma reunião.

O cálculo da probabilidade de sucesso do projeto é feito por meio de uma média aritmética entre as notas do projeto em cada risco. A nota final é convertida em um escala de 0 a 100, para que se tenha a visão de porcentagem. 
Tabela 9 - Ferramenta 12.1: lista padrão de riscos técnicos

\begin{tabular}{|c|c|}
\hline \multicolumn{2}{|r|}{ Lista dos riscos técnicos do projeto } \\
\hline 1. Posição proprietária & $\begin{array}{l}\text { Reflete a probabilidade de desenvolver uma patente forte e capaz de ser protegida, ou de desenvolver uma posição } \\
\text { proprietária na tecnologia. }\end{array}$ \\
\hline 5 & $\begin{array}{l}\text { Alta probabilidade que o trabalho técnico levará a patentes fortemente defendiveis (ou segredos comerciais claramente } \\
\text { identificados) que devem criar um posição exclusiva e sinergia com patentes existentes e/ou segredos comerciais. }\end{array}$ \\
\hline 4 & $\begin{array}{l}\text { Probabilidade de boa proteção; poderia levar para uam posição dominante com ameaça limitada de interferência. Pode ser } \\
\text { dificil se defender das ameaças em alguns lugares. }\end{array}$ \\
\hline 3 & $\begin{array}{l}\text { Probabilidade de boa cobertura. É possivel que a o segredo enfraqueça a proteção na cobertura. Deve levar para uma } \\
\text { diferenciação competitiva, mas pode ser dificil mantê-la por um longo periodo. }\end{array}$ \\
\hline 2 & $\begin{array}{l}\text { Poucas chances de cobertura da patente, algumas ameaças podem possivelmente bloquear a competitividade e a vantagem } \\
\text { curto prazo. }\end{array}$ \\
\hline 1 & Não existe posição prop rietária disponível. A tecnologia é fácil de copiar. \\
\hline $\begin{array}{l}\text { 2. Competências/ } \\
\text { habilidades }\end{array}$ & $\begin{array}{l}\text { Determina a probabilidade dos recursos técnicos disponíveis terem as competências necessárias para desenvolver } \\
\text { o projeto com sucesso. }\end{array}$ \\
\hline 5 & São especialistas e já realizaram (implementaram) isso antes. \\
\hline 4 & Esta alinhado com as competências chaves, porém nunca foi realizado um projeto similar. \\
\hline 3 & Não é novo para o negócio, porém nãa é uma das competência. \\
\hline 2 & É novo para o negócio, mas não é novo para o mundo \\
\hline 1 & Isto nunca foi desenvolvido antes. \\
\hline $\begin{array}{l}\text { 3. Complexidade } \\
\text { técnica }\end{array}$ & Estima o impacto da complexidade técnica do projeto na sua probabilidade de ter sucesso. \\
\hline $\begin{array}{l}5 \\
4\end{array}$ & $\begin{array}{l}\text { Elementos multiplos, simples e interativos que fazem parte da rotina. } \\
\text { Elementos multiplos e interativos que são usados regularmente. }\end{array}$ \\
\hline 3 & Elementos multiplos, complexos e interativos. Sendo a maioria usados regularmente e alguns nunca antes utilizados. \\
\hline 2 & Elementos multiplos, complexos e interativos. Sendo alguns usados regularmente e a maioria nunca antes utilizada. \\
\hline 1 & Grande número de elementos complexos e interativos que nunca foram usados. \\
\hline $\begin{array}{l}\text { 4. Acesso e uso eficaz } \\
\text { de tecnologia externa }\end{array}$ & $\begin{array}{l}\text { Determina o efeito da disponibilidade de tecnologias externas e o efeito da habilidade da organização para usar tal } \\
\text { tecnologia na probabilidade do projeto alcançar seus objetivos. }\end{array}$ \\
\hline $\begin{array}{l}5 \\
4\end{array}$ & $\begin{array}{l}\text { Sabe-se onde a tecnologia está, sabe-se como acessá-la e que ela já foi aplicada anteriormente. } \\
\text { Sabe-se onde a tecnologia está e que ela está disponivel. }\end{array}$ \\
\hline 3 & $\begin{array}{l}\text { A tecnologia possivelmente existe e tem-se uma área de monitoramento tecnológico que pode localizá-la, mas não tem-se } \\
\text { integrado rotineiramente tecnologias externas nas projetos realizados. }\end{array}$ \\
\hline 2 & A tecnologia possivelmente existe, mas não tem-se mecanismo para procurá-la e integrá-la aos projetos. \\
\hline 1 & A tecnologia não existe ou não está disponível. \\
\hline $\begin{array}{l}\text { 5. Capacidade de } \\
\text { produçäo }\end{array}$ & $\begin{array}{l}\text { Determina a probabilidade da organização ter as capacidades (tanto internas ou externas) para produzir o produto } \\
\text { ou incorporar o processo de produçâo nas suas operaçöes. }\end{array}$ \\
\hline 5 & $\begin{array}{l}\text { A tecnologia de produção é conhecida pelo negácio e a capacidade está disponível interna ou externamente. (Já foi realizado } \\
\text { antes) }\end{array}$ \\
\hline 4 & $\begin{array}{l}\text { São necessárias pequenas modificações na tecnologia conhecida. (Já foi realizado antes } \theta \text { as alterações necessárias são } \\
\text { conhecidas) }\end{array}$ \\
\hline 3 & $\begin{array}{l}\text { O processo baseia-se nos elementos básicos da tecnologia de produção: alguns elementos do processo são conhecidos poré } \\
\text { outros tem que ser desenvolvidos (Já fol feito parte do processo antes e sabe-se o que mais precisa ser feito) ou existe } \\
\text { capacidade de produção externa. }\end{array}$ \\
\hline 2 & $\begin{array}{l}\text { O processo de produção não se baseia na tecnologia de produção possuída, mas a tecnologia é conhecida por outros. (Nunc } \\
\text { fol feito antes, mas pensa-se que sabe como fazer) }\end{array}$ \\
\hline 1 & O processo de produção é desconhecido tanto interna quanto externamente (Não se sabe como fazê-lo ainda). \\
\hline
\end{tabular}


Tabela 10 - Ferramenta 12.2: lista padrão de riscos comerciais

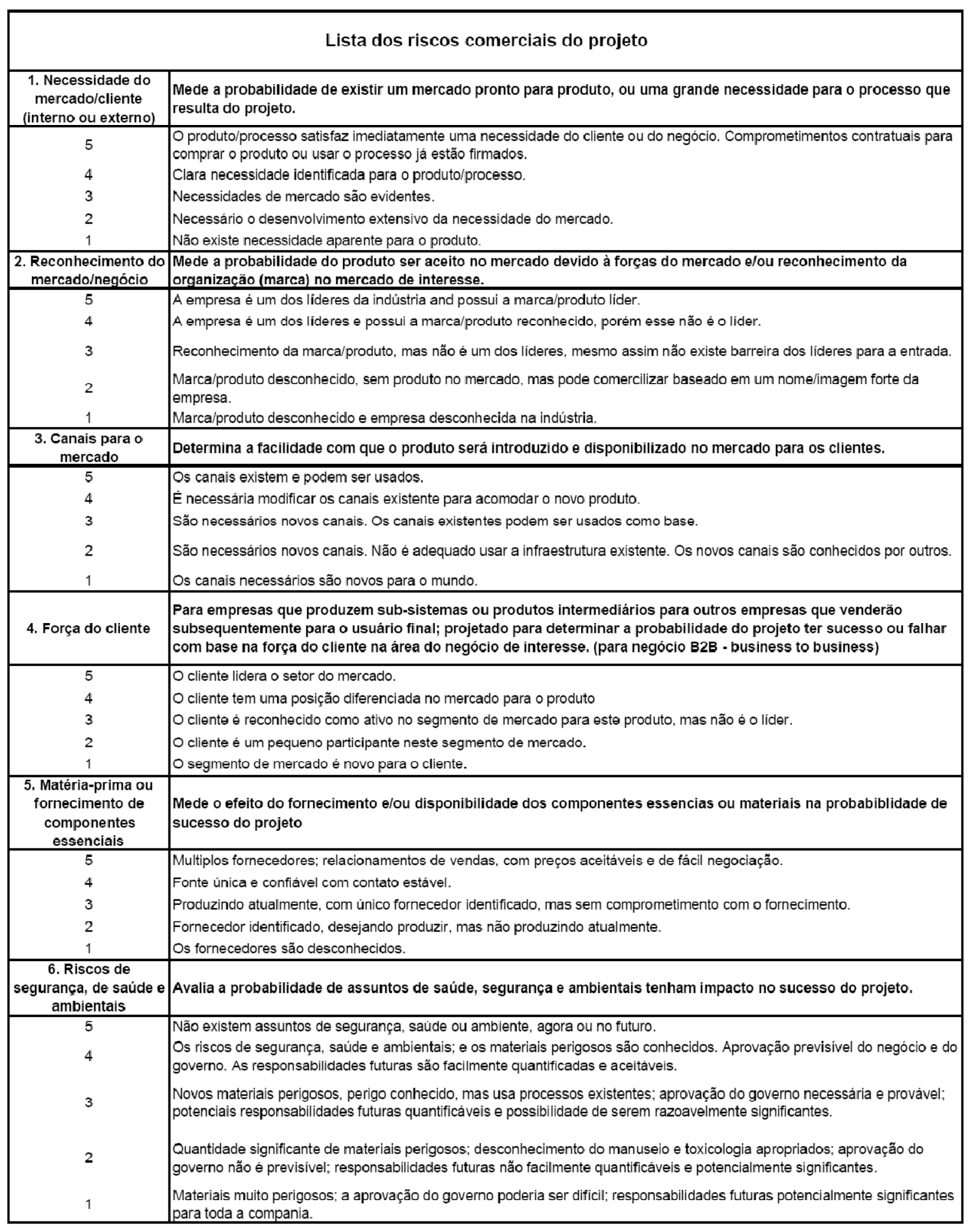


Tabela 11 - Ferramenta 12.3: planilha de avaliação da probabilidade de sucesso do projeto

\begin{tabular}{|l|c|}
\hline \multicolumn{2}{|c|}{ Avaliação da Probabilidade de Sucesso do Projeto } \\
\hline Critérios técnicos & Nota \\
\hline 1. Posição proprietária & 0 \\
\hline 2. Competëncias/ habilidades & 0 \\
\hline 3. Complexidade técnica & 0 \\
\hline 4. Acesso e uso eficaz de tecnologia externa & 0 \\
\hline 5. Capacidade de produção & 0 \\
\hline Probabilidade técnica de sucesso & $0,0 \%$ \\
\hline \multicolumn{2}{|c|}{} \\
\hline Critério comerciais & Nota \\
\hline 1. Necessidade do mercado/cliente (interno ou externo) & 0 \\
\hline 2. Reconhecimento do mercado/negócio & 0 \\
\hline 3. Canais para o mercado & 0 \\
\hline 4. Força do cliente & 0 \\
\hline 5. Matéria-prima ou fornecimento de componentes essenciais & 0 \\
\hline 6. Riscos de segurança, de saúde e ambientais & 0 \\
\hline Probabilidade comercial de sucesso & $0,0 \%$ \\
\hline \multicolumn{2}{|l|}{} \\
\hline Probabilidade de Sucesso do Projeto & $0,0 \%$ \\
\hline
\end{tabular}

É importante que o projeto em avaliação esteja claro para todos, aumentando a precisão dos resultados da avaliação. As informações sobre o projeto estão na proposta do projeto do novo produto e devem ser utilizadas como referência.

\subsection{Atividade 10 - Avaliação do potencial estratégico dos projetos}

Esta atividade tem por objetivo avaliar a capacidade do projeto de entregar resultados alinhados com as estratégias do negócio. Ela informa a convergência existente entre os projetos e as estratégias.

Da mesma forma que para a avaliação da probabilidade de sucesso do projeto, esta atividade adota uma lista padrão de critérios para avaliação do potencial estratégico. A lista seguida pelo método é apresentada por Cooper et al. (1998). Baseado nessa lista, o método disponibiliza uma ferramenta para apoiar a avaliação do potencial estratégico do projeto, a qual é formada por duas partes: a primeira com os critérios estratégicos (Tabela 12) e a segunda que realiza o cálculo do potencial estratégico (Tabela 13).

O método propõe que o representante da área executiva da empresa realize a avaliação preliminar do projeto e que, em seguida, o time se reúna para verificá-la. O 
cálculo do potencial estratégico do projeto é feito por meio de uma média aritmética entre as notas do projeto em cada critério.

Tabela 12 - Ferramenta 13.1: lista padrão de critérios estratégicos

\begin{tabular}{|c|c|}
\hline \multicolumn{2}{|r|}{ Lista padrão de critérios estratégicos } \\
\hline $\begin{array}{l}\text { Congruência com a } \\
\text { estratégia }\end{array}$ & Descrição das notas \\
\hline $\begin{array}{l}4 \\
3 \\
2 \\
1\end{array}$ & $\begin{array}{l}\text { Apenas congruência periférica com a estratégia do negócio } \\
\text { Modesta congruência, mas não com um elemento essencial da estratégia } \\
\text { Boa conguência com um elemento essencial da estratégia } \\
\text { Forte congruência com vários elementos chaves da estratégia }\end{array}$ \\
\hline Impacto na estratégia & Descrição das notas \\
\hline $\begin{array}{l}4 \\
3 \\
2 \\
1\end{array}$ & $\begin{array}{l}\text { Impacto mínimo, nenhuma repercussão no negócio se o programa/projeto fechar } \\
\text { Competitividade moderada e impacto financeiro } \\
\text { Impacto siginificante, dificuldade de recuperação se o programa/projeto fechar ou não tiver sucesso } \\
\text { Futuro da unidade de negócio depende do programa/projeto }\end{array}$ \\
\hline Posição proprietária & Descrição das notas \\
\hline $\begin{array}{l}4 \\
3 \\
2 \\
1\end{array}$ & $\begin{array}{l}\text { Facilmente copiado } \\
\text { Protegido, mas não impede tentativas de cópia } \\
\text { Solidamente protegida com segredos comerciais, patentes, cria fidelidade de clientes } \\
\text { Posição protegida por meio de uma combinação de patentes, segredos comerciais, acesso à matéria prima, etc. }\end{array}$ \\
\hline $\begin{array}{l}\text { Plataforma para } \\
\text { crescimento }\end{array}$ & Descrição das notas \\
\hline \begin{tabular}{|l|}
4 \\
3 \\
2 \\
1
\end{tabular} & $\begin{array}{l}\text { Único do tipo } \\
\text { Outras oportunidades para extensão do negócio } \\
\text { Potencial para diversificação } \\
\text { Abre novos campos técnicos e comerciais }\end{array}$ \\
\hline $\begin{array}{c}\begin{array}{c}\text { Durabilidade (Técnica e } \\
\text { Mercado) }\end{array} \\
\end{array}$ & Descrição das notas \\
\hline \begin{tabular}{|l|}
4 \\
3 \\
2 \\
1
\end{tabular} & $\begin{array}{l}\text { Nenhuma vantagem distintiva, rapidamente ultrapassado } \\
\text { Pode levar poucos anos } \\
\text { Ciclo de vida moderado (4-6 anos) mas com pouca oportunidade para melhoria incremental } \\
\text { Ciclo de vida longo com oportunidade para melhoria incremental }\end{array}$ \\
\hline $\begin{array}{c}\text { Sinergia com outras } \\
\text { operaçöes do negócio }\end{array}$ & Descriçăo das notas \\
\hline $\begin{array}{l}4 \\
3 \\
2 \\
1\end{array}$ & $\begin{array}{l}\text { Limitado para uma única unidade de negócio } \\
\text { Pode ser aplicada em outra unidade de negócio com algum esforço } \\
\text { Poderia ser adotada ou ter aplicações em vários unidades de negócio } \\
\text { Poderia ser amplamente aplicada por toda a corporação }\end{array}$ \\
\hline
\end{tabular}

Tabela 13 - Ferramenta 13.2: cálculo do potencial estratégico do projeto

\begin{tabular}{|l|c|}
\hline \multicolumn{2}{|c|}{ Avaliação do potencial estratégico do projeto } \\
\hline Critério estratégico & Nota \\
\hline Congruência com a estratégia & 0 \\
\hline Impacto na estratégia & 0 \\
\hline Posição proprietária & 0 \\
\hline Plataforma para crescimento & 0 \\
\hline Durabilidade (Técnica e Mercado) & 0 \\
\hline Sinergia com outras operações do negócio & 0 \\
\hline \multicolumn{2}{|c|}{} \\
\hline Potencial estratégico do projeto & 0 \\
\hline
\end{tabular}

As informações necessárias para a avaliação do potencial estratégico do projeto estão disponíveis na proposta do projeto. 


\subsection{Atividade 11 - Classificação dos projetos}

Esta atividade analisa as propostas de projetos de novos produtos com base dos dados da avaliação financeira, da avaliação da probabilidade de sucesso e da avaliação do potencial estratégico para definir quais são mais atrativas para o negócio.

Ela marca o início da parte do método que trata do portfólio de projetos de produtos, ou seja, a partir dela os participantes não avaliam mais os projetos individualmente, mas sim avaliam o conjunto de projetos. Desde a atividade de proposição de novos projetos de produtos até a avaliação do potencial estratégico, o foco das atividades estava nos projetos ao invés do portfólio.

As informações usadas nessa atividade para a classificação dos projetos são:

- Dados do projeto: unidade de negócio, linha de produto, segmento de mercado, tipo de produto e duração do projeto. Essas informações devem estar disponíveis na proposta do projeto.

- Informações financeiras: investimento, valor presente líquido, taxa interna de retorno, retorno sobre investimento e payback. Essas informações devem estar disponíveis na análise financeira do projeto.

- Probabilidade de sucesso do projeto: probabilidade de sucesso comercial e probabilidade de sucesso técnico. Essas informações devem estar disponíveis na avaliação da probabilidade de sucesso do projeto.

- Potencial estratégico do projeto: essa informação deve estar disponível na avaliação do potencial estratégico do projeto.

O método adota uma planilha eletrônica para reunir e organizar as informações sobre os projetos. Assim é possível ter um banco de dados dos projetos em análise, 
o que facilita a comparação entre eles e a tomada de decisão dos participantes. A Tabela 14 mostra o modelo dessa planilha.

Tabela 14 - Ferramenta 14: planilha de banco de dados dos projetos

\begin{tabular}{|c|c|c|c|c|c|c|c|c|c|c|c|c|c|}
\hline \multirow{2}{*}{$\begin{array}{l}\text { Lista de } \\
\text { projetos }\end{array}$} & \multicolumn{5}{|c|}{ Dados Projeto } & \multicolumn{5}{|c|}{ Analise financeira } & \multicolumn{2}{|c|}{$\begin{array}{l}\text { Probabilidade de } \\
\text { sucesso projeto }\end{array}$} & \multirow{2}{*}{$\begin{array}{c}\text { Potencial } \\
\text { Estrategico }\end{array}$} \\
\hline & $\begin{array}{c}\text { Unidade de } \\
\text { negócio }\end{array}$ & $\begin{array}{l}\text { Linha de } \\
\text { produto }\end{array}$ & $\begin{array}{c}\text { Segmento de } \\
\text { mercado }\end{array}$ & $\begin{array}{l}\text { Tipo do } \\
\text { produsto }\end{array}$ & Duraçấo & Inveslimerito & VPL & TIR & ROI & Payback & $\begin{array}{l}\text { Sucesso } \\
\text { técnico }\end{array}$ & $\begin{array}{l}\text { Sucesso } \\
\text { comercial }\end{array}$ & \\
\hline & & & & & & & & & & & & & \\
\hline & & & & & & & & & & & & & \\
\hline & & & & & & & & & & & & & \\
\hline & & & & & & & & & & & & & \\
\hline & & & & & & & & & & & & & \\
\hline
\end{tabular}

Uma vez tendo todas as informações necessárias para a classificação dos projetos, os participantes da aplicação do método devem decidir qual é a fórmula mais adequada para classificar os projetos. O método sugere uma combinação entre três fatores: valor financeiro, probabilidade de sucesso e valor estratégico.

O padrão proposto pelo método utiliza o valor do VPL como valor financeiro, a probabilidade de sucesso e o valor do potencial estratégico como valor estratégico. Para cada um desses dados o método normaliza o valor dos projetos em uma escala de 0 a 5, sempre considerando o maior valor como base. A normalização é uma técnica adotada na por Phaal et al. (2001) para facilitar a comparação entre os projetos. As notas normalizadas são multiplicadas para se obter a nota de classificação do projeto.

Um diferencial que pode ser acrescentado na classificação dos projetos é a inclusão de pesos nos fatores. Isto porque os três fatores (valor financeiro, probabilidade de sucesso e valor estratégico) podem possuir importâncias diferentes dentro da empresa. Neste caso, após a normalização dos fatores, cada um é multiplicado pelo seu peso antes de serem multiplicados entre si para atingir uma nota final.

A decisão de multiplicar as notas vem de experiências apresentadas por Danilevicz (2006). A autora explica que com o uso da média aritmética, os projetos 
com notas baixas em algum fator ainda têm chances de serem selecionados, caso a nota de outro fator compense a nota do fator fraco. Contudo, a multiplicação inibe essa possibilidade, pois o projeto perde muitos pontos na multiplicação de uma nota baixa.

A classificação dos projetos pode ser realizada na mesma planilha na qual os dados são armazenados, porém o método opta por utilizar uma planilha independente, deixando a planilha anterior apenas como repositório dos dados. Essa decisão segue uma melhor prática apresentado por Archer e Ghasemzadeh (1999) que busca a apresentação selecionada das informações necessárias para a tomada de decisão, evitando que o time perca-se com informações irrelevantes naquele momento.

Essa nova planilha utiliza as informações escolhidas para a realização do cálculo que classifica os projetos. A Tabela 15 mostra o modelo dessa planilha. A nota final dos projetos é calculada pela multiplicação das notas normalizadas da probabilidade de sucesso, valor financeiro e valor estratégico do projeto. Por fim os projetos são ordenados da maior para a menor nota.

Tabela 15 - Ferramenta 15: planilha de classificação dos projetos

\begin{tabular}{|c|c|c|c|c|c|c|c|}
\hline \multirow{2}{*}{$\begin{array}{l}\text { Lista de } \\
\text { projetos }\end{array}$} & \multicolumn{2}{|c|}{ Probabilidade de sucesso do projeto } & \multicolumn{2}{|c|}{ Valor financeiro do projeto } & \multicolumn{2}{|c|}{ Potencial estratégico do projeto } & \multirow{2}{*}{$\begin{array}{l}\text { Nota final } \\
\text { do projeto }\end{array}$} \\
\hline & $\begin{array}{c}\text { Nota prob. sucesso } \\
\text { original }\end{array}$ & $\begin{array}{c}\text { Nota prob. sucesso } \\
\text { normalizada }\end{array}$ & $\begin{array}{l}\text { Valor financeiro } \\
\text { original }\end{array}$ & $\begin{array}{l}\text { Valor financeiro } \\
\text { normalizado }\end{array}$ & $\begin{array}{l}\text { Nota valor } \\
\text { estratégico }\end{array}$ & $\begin{array}{l}\text { Valor estratégico } \\
\text { normalizado }\end{array}$ & \\
\hline & & & & & & & \\
\hline & & & & & & & \\
\hline & & & & & & & \\
\hline & & & & & & & \\
\hline
\end{tabular}

\subsection{Atividade 12 - Análise do relacionamento entre os projetos}

Esta atividade busca encontrar relacionamentos entre os projetos que possam influenciar na seleção. Chien (2002) mostra que podem existir quatro tipos de relacionamentos entre os projetos do portfólio: 
- Dependência: quando o resultado de um projeto depende do resultado de outro.

- Compartilhamento de atividades/recursos: quando a soma dos custos dos projetos não representa a soma dos custos individuais de cada um.

- Impacto: quando o resultado de um projeto impacta no resultado de outro.

- Tempo: quando são consideradas relações de tempo entre os projetos.

O método adota esses quatro tipos de relacionamentos apresentados por Chien (2002) na avaliação do relacionamento entre os projetos. Ele utiliza uma planilha na forma de matriz, onde o time marca os relacionamentos, e então consegue visualizar na linha/coluna de pontos do projeto quais dependem e quais impactam os outros projetos do portfólio. A partir dessa informação é possível reconhecer os relacionamentos que podem determinar a seleção de algum projeto. A Figura 18 mostra o modelo dessa planilha. 


\begin{tabular}{|c|c|c|c|c|c|c|c|c|c|c|c|c|c|}
\hline \multicolumn{7}{|c|}{$\begin{array}{l}\text { 1. Análise da dependência entre os } \\
\text { projetos: quando o resultado de um projeto da } \\
\text { lintla da malti< deperide do resullado de umI } \\
\text { projeto da coluna da matriz. }\end{array}$} & \multicolumn{7}{|c|}{$\begin{array}{l}\text { 2. Análise do compartilhamento de } \\
\text { atividades/recursos: quando a soma dos } \\
\text { cuslus dos projelos nãu representa a sorna } \\
\text { dos custos individuais de cada um. }\end{array}$} \\
\hline & $\begin{array}{l}- \\
\frac{0}{0} \\
\frac{1}{2} \\
0 \\
\end{array}$ & $\begin{array}{l}N \\
0 \\
\frac{2}{0} \\
\frac{2}{2} \\
\end{array}$ & $\begin{array}{l}m \\
0 \\
\frac{0}{0} \\
\frac{0}{2} \\
0\end{array}$ & 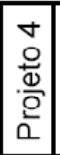 & $\begin{array}{l}0 \\
0 \\
0 \\
\frac{0}{2} \\
0 \\
0\end{array}$ & 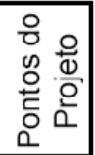 & & 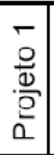 & $\begin{array}{l}N \\
0 \\
\frac{0}{0} \\
\frac{0}{2} \\
0\end{array}$ & \begin{tabular}{|l|}
$m$ \\
0 \\
$\frac{2}{d}$ \\
$\frac{2}{2}$ \\
$\frac{2}{2}$
\end{tabular} & 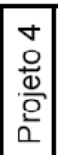 & 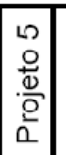 & 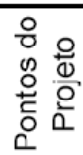 \\
\hline Projeto 1 & 7 & & & & & 0 & Projeto 1 & $Z$ & & & & & 0 \\
\hline Projeto 2 & & $Z$ & & & & 0 & Projeto 2 & & 2 & & & & 0 \\
\hline Projeto 3 & & & $Z$ & & & 0 & Projeto 3 & & & $Z$ & & & 0 \\
\hline Projeto 4 & & & & $\angle$ & & 0 & Projeto 4 & & & & 7 & & 0 \\
\hline Projeto 5 & & & & & 7 & 0 & Projeto 5 & & & & & $Z$ & 0 \\
\hline \begin{tabular}{|l|} 
Pontos do \\
Projeto
\end{tabular} & 0 & 0 & 0 & 0 & 0 & & \begin{tabular}{|l|} 
Pontos do \\
Projeto \\
\end{tabular} & 0 & 0 & 0 & 0 & 0 & \\
\hline \multicolumn{7}{|c|}{$\begin{array}{l}\text { 3. Análise do impacto entre os projetos: } \\
\text { quando o resultado de um projeto da linha da } \\
\text { matriz impacta no resultado de outro projeto } \\
\text { da coluna da matriz }\end{array}$} & \multicolumn{7}{|c|}{$\begin{array}{l}\text { 4. Análise do tempo entre os projetos: } \\
\text { quando são consideradas relaçőes de tempo } \\
\text { entre os projetos. O projeto da linha da matriz } \\
\text { devem acontecer antes do projeto da coluna } \\
\text { da matriz. }\end{array}$} \\
\hline & $\begin{array}{l}- \\
\frac{0}{2} \\
\frac{1}{2} \\
\frac{2}{2}\end{array}$ & 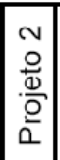 & $\begin{array}{l}m \\
\stackrel{0}{0} \\
\frac{0}{0} \\
\frac{0}{2} \\
\frac{0}{2}\end{array}$ & 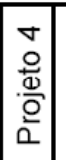 & $\begin{array}{l}0 \\
0 \\
\frac{0}{0} \\
\frac{0}{2}\end{array}$ & 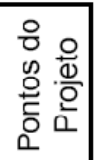 & & $\begin{array}{l}\bar{a} \\
\frac{2}{0} \\
\frac{0}{2} \\
\frac{0}{2}\end{array}$ & $\begin{array}{l}v \\
\frac{0}{0} \\
\frac{0}{0} \\
\frac{0}{2}\end{array}$ & $\begin{array}{l}m \\
\frac{0}{2} \\
\frac{0}{2} \\
\frac{2}{2} \\
\end{array}$ & $\begin{array}{l}\nabla \\
\stackrel{0}{0} \\
\frac{0}{0} \\
\underline{0}\end{array}$ & $\begin{array}{l}0 \\
0 \\
\frac{0}{2} \\
\frac{0}{0} \\
0\end{array}$ & 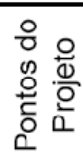 \\
\hline Projeto 1 & 7 & & & & & 0 & Projeto 1 & 7 & & & & & 0 \\
\hline Projeto 2 & & 7 & & & & 0 & Projeto 2 & & 7 & & & & 0 \\
\hline Projeto 3 & & & $Z$ & & & 0 & Projeto 3 & & & $Z$ & & & 0 \\
\hline Projeto 4 & & & & $\angle$ & & 0 & Projeto 4 & & & & $Z$ & & 0 \\
\hline Projeto 5 & & & & & 7 & 0 & Projeto 5 & & & & & $Z$ & 0 \\
\hline $\begin{array}{l}\text { Pontos do } \\
\text { Projeto }\end{array}$ & 0 & 0 & 0 & 0 & 0 & & \begin{tabular}{|l} 
Pontos do \\
Projeto
\end{tabular} & 0 & 0 & 0 & 0 & 0 & \\
\hline
\end{tabular}

Figura 18 - Ferramenta 16: planilha de análise dos relacionamentos entre os projetos

\subsection{Atividade 13 - Seleção de projetos de produto para desenvolvimento}

Esta é a última atividade do método e tem como objetivo definir quais projetos devem ser incluídos no portfólio de projetos em andamento no negócio. A dificuldade desta atividade está em selecionar o melhor conjunto de projetos para o negócio e não apenas em escolher os melhores projetos.

Como descrito por Cooper et al. (2002), o portfólio de projetos selecionados deve atender a quatro objetivos: maximização do valor, alinhamento com a estratégia, balanceamento de recursos e equilíbrio. Dois desses objetivos foram inicialmente tratados na atividade de classificação dos projetos: a maximização do 
valor e o alinhamento com a estratégia. Isto porque a classificação foi feita considerando como critérios a probabilidade de sucesso, o valor financeiro e o valor estratégico. Os dois primeiros fatores contribuem com a maximização do portfólio e o terceiro com o alinhamento com a estratégia.

Como resultado da atividade anterior tem-se uma lista de projetos classificados. No entanto sabe-se que em todo negócio existem restrições de recursos que limitam a quantidade de projetos capaz de ser desenvolvida. Dessa forma, o método propõe que a primeira parte da atividade de seleção de projetos separe, de acordo com a ordem de classificação, os projetos que estão dentro do limite de recursos da empresa.

O método apresenta duas alternativas para o corte da quantidade de projetos em função dos recursos. Uma relacionada com o objetivo de alinhamento com a estratégia e que se baseia no conceito de cestas de investimento apresentado por Cooper et al. (1998). A outra envolve o objetivo de alocação de recursos entre os projetos e é apoiada pelas limitações de recursos críticos da organização, a qual também foi apresentada por Cooper et al. (1998).

A aplicação de cestas de investimento para restrição da quantidade de projetos necessita que a empresa conheça quais os tipos de cestas e qual a porcentagem do investimento pretende gastar em cada uma. Tendo essas informações, os projetos são divididos entre as cestas pelo seu tipo e seguindo sua ordem de classificação. Quando se atingi o limite de investimento de uma cesta, os outros projetos do mesmo tipo são colocados em espera. A Figura 19 mostra o modelo da planilha utilizada na aplicação das cestas de investimento. 


\begin{tabular}{|c|c|}
\hline $\begin{array}{c}\text { Valor disponivel para } \\
\text { investimento }\end{array}$ & \\
\hline $\begin{array}{c}\text { Tipos de cestas de } \\
\text { investimento }\end{array}$ & $\begin{array}{c}\% \\
\text { Investimento }\end{array}$ \\
\hline & \\
\hline & \\
\hline & \\
\hline
\end{tabular}
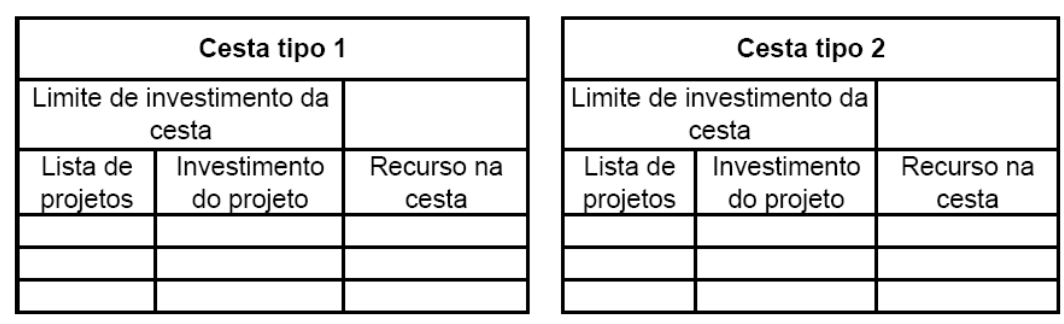

\begin{tabular}{|c|c|c|}
\hline \multicolumn{3}{|c|}{ Cesta tipo 3 } \\
\hline $\begin{array}{c}\text { Limite de investimento } \\
\text { da cesta }\end{array}$ & \\
\hline $\begin{array}{c}\text { Lista de } \\
\text { projetos }\end{array}$ & $\begin{array}{c}\text { Investimento } \\
\text { do projeto }\end{array}$ & $\begin{array}{c}\text { Recurso na } \\
\text { cesta }\end{array}$ \\
\hline & & \\
\hline & & \\
\hline & & \\
\hline
\end{tabular}

Figura 19 - Ferramenta 17: planilha de análise de cestas de investimento

A alocação de recursos entre os projetos depende da disponibilidade de cada um desses recursos na organização. Portando para os recursos considerados críticos deve-se estimar sua disponibilidade antes de liberar o uso por um novo projeto. Com isso, da mesma forma que para as cestas de investimentos, os projetos são alocados para cada um dos recursos críticos segundo sua ordem de classificação. Quando os recursos disponíveis não suportarem mais os projetos alocados para ele, os projetos restantes são colocados em espera. A Tabela 16 mostra o modelo da planilha utilizada na alocação de recursos.

Tabela 16 - Ferramenta 18: planilha de análise de alocação de recursos críticos

\begin{tabular}{|c|c|c|c|c|c|c|}
\hline rercurso crítico: & \multicolumn{2}{|l|}{} & \multicolumn{2}{|l|}{} & \multicolumn{2}{|l|}{} \\
\hline disponibilidade: & & & & & \\
\hline Projetos & uso & restante & uso & restante & uso & restante \\
\hline & & & & & & \\
\hline & & & & & & \\
\hline & & & & & & \\
\hline & & & & & & \\
\hline
\end{tabular}

Dependendo do resultado obtido com a aplicação dessas ferramentas, o time de desenvolvimento pode obter duas respostas diferentes. Nesse caso cabe aos participantes decidir de acordo com os objetivos da empresa quais projetos serão considerados e quais serão colocados em espera. 
Além das restrições de recursos, o relacionamento entre os projetos também deve ser considerado na seleção de projetos, pois dependendo da relação existente torna-se impossível selecionar um projeto e colocar outro em espera. Por exemplo, caso a análise dos relacionamentos entre os projetos tenha mostrado que existem projetos com impacto em vários outros projetos, significa que tais projetos precisam ser selecionados para que os outros do portfólio tenham maiores chances de sucesso. Da mesma forma, aqueles que dependem fortemente de outros projetos podem indicar uma maior chance de fracasso, caso não seja possível incluir suas dependências no portfólio, e assim deveriam ser colocados em espera.

Por fim, os participantes da aplicação do método selecionam os projetos que irão provavelmente compor o portfólio de projetos da empresa. Inicialmente eles seguem a referência da classificação dos projetos elaborada na atividade anterior. Em seguida decidem quais projetos da lista serão escolhidos com base na disponibilidade de recursos. E, então, verificam se existe algum relacionamento entre os projetos que implicaria na seleção ou remoção de algum projeto do portfólio.

Antes de finalizar a seleção dos projetos é necessário que seja verificado o último objetivo do portfólio, equilíbrio do portfólio, e o alinhamento dos projetos selecionados com os planos estratégicos para o desenvolvimento de novos produtos, descrito no roadmap de planejamento do produto.

Para a verificação do equilíbrio do portfólio, os projetos previamente selecionados são plotados em gráficos de bolhas conforme as dimensões de equilíbrio requisitadas pelo negócio. O gráfico de bolhas adotado pelo método engloba as dimensões: retorno financeiro, probabilidade de sucesso e duração do projeto. Cooper et al. (1998) apresenta outros exemplos. Por meio da visualização 
dos projetos nos gráficos os participantes conseguem notar se existe algum desequilíbrio no portfólio de projetos:

- Os projetos localizados no quadrante superior direito ( $1^{\circ}$ Quadrante) têm alta probabilidade de sucesso e alto VPL, e são os mais interessantes para o negócio.

- Os projetos do quadrante superior esquerdo (2 ${ }^{\circ}$ Quadrante) têm alta probabilidade de sucesso e baixo VPL, portanto são interessantes para garantir o fluxo de caixa da empresa.

- Os projetos do quadrante inferior esquerdo ( $3^{\circ}$ Quadrante) têm baixa probabilidade de sucesso e baixo VPL, assim são considerados os projetos de menor valor para a empresa.

- Os projetos do quadrante inferior direito (4 Quadrante) têm baixa probabilidade de sucesso e alto VPL, portanto esses são projetos mais arriscados, mas com melhor retorno financeiro para a empresa.

A dimensão da duração dos projetos, representada pelo tamanho da bolha, indica a distribuição dos projetos no tempo. Ela é importante, pois evita que a empresa apenas desenvolve projetos com retorno concentrado em um único período no tempo, ou seja, faz com que existam resultados distribuídos no curto, médio e longo prazo.

Uma opção para ajustar o equilíbrio é criar os mesmos gráficos para os projetos em espera e verificá-los lado a lado. Assim, caso um projeto em espera possa trazer um portfólio mais equilibrado e os participantes concordem em incluí-lo para aumentar o desempenho do portfólio, esse pode ser adicionado entre os projetos selecionados. A planilha utilizada na verificação do equilíbrio do portfólio é apresentada na Figura 20. 

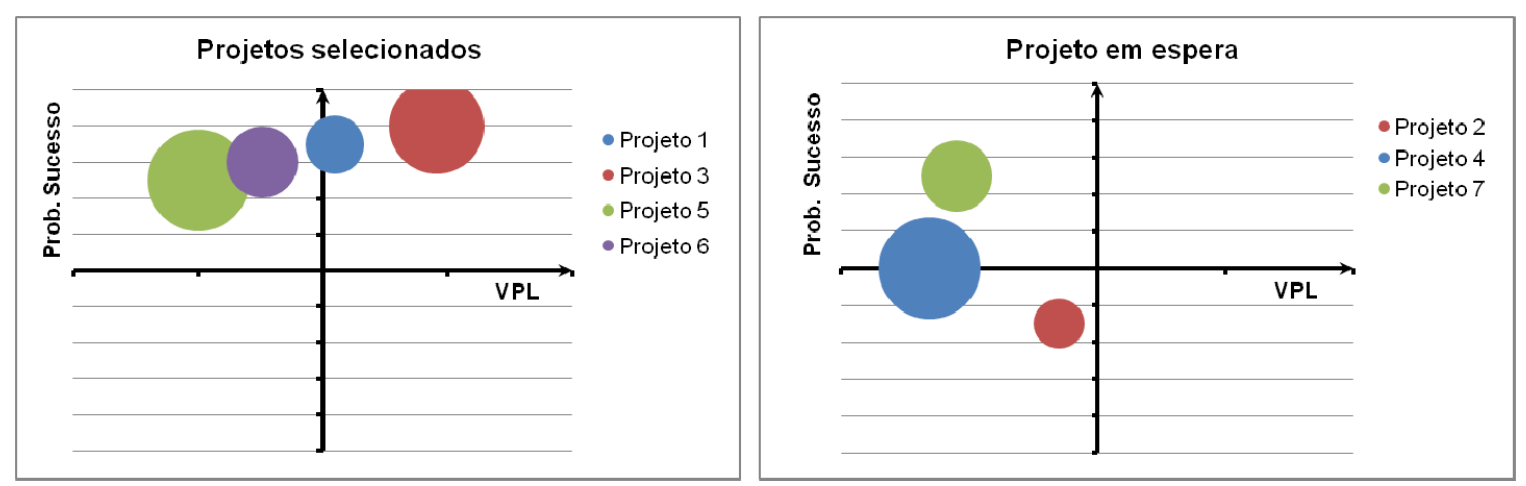

Figura 20 - Ferramenta 19: planilha de verificação do equilíbrio do portfólio de projetos

Para a verificação do alinhamento dos projetos selecionados com o plano estratégico dos produtos mostrado no roadmap, o método propõe a criação de um mini-roadmap com o portfólio de projetos selecionados.

O mini-roadmap reutiliza os dados do roadmap de produto desenvolvido na atividade de definição das estratégias de produtos. Assim ele mostra os direcionadores de negócio e mercado, e as tecnologias relacionadas com os projetos selecionados. O modelo usado para o mini-roadmap é o mesmo usado para o roadmap de planejamento de produto apresentado na Figura 15.

Por fim, o roadmap de produto e o mini-roadmap do portfólio de projetos selecionados são comparados com a finalidade de observar o alinhamento existente entre o plano estratégico de produtos e os projetos que serão realizados. No caso de ser notado algum desalinhamento, o time deve decidir se realiza alguma modificação no portfólio dos projetos selecionados. O uso do roadmapping como forma de buscar o alinhamento estratégico é indicador por Cooper et al. (2001). 


\section{Preparação do estudo de caso}

Esse capítulo descreve os resultados das três primeiras atividades da etapa 3 da metodologia da pesquisa.

\subsection{Protocolo de estudo de caso}

Antes de iniciar as atividades do estudo de caso é preciso definir os requisitos para a escolha da empresa onde o caso pretende ser realizado e planejar como será a participação do pesquisador. Essas informações constituem o protocolo do estudo de caso e são apresentadas a seguir.

\subsubsection{Definição dos requisitos de escolha da empresa}

Os requisitos definidos para atender aos objetivos buscados pela pesquisa são:

- A empresa deve possuir um processo de desenvolvimento de produtos em suas operações. Esse requisito é primordial para a realização da pesquisa, visto que tem como objetivo avaliar a contribuição do Método ITG na realização das atividades iniciais desse processo.

- A empresa deve possuir uma estrutura organizacional que permita a formação de um time multifuncional para participar das atividades do caso. Esse requisito é importante para aplicação eficiente do Método ITG, já que este é embasado no technology roadmapping e na gestão de portfólio, e esses dependem de times multifuncionais.

- A cúpula da empresa deve ter interesse na aplicação do Método ITG e se comprometer a desenvolver o estudo de caso até o seu fim, contruibuindo assim para a plenitude do trabalho.

- A empresa deve possuir uma linha de produtos que disponha de informações sobre o mercado. 
- A empresa deve aceitar compartilhar os resultados obtidos com o pesquisador mediante acordo de confidencialidade.

\subsubsection{Participação do pesquisador no caso}

A participação do pesquisador no estudo de caso deve permitir que a empresa desempenhe as atividades do Método ITG e utilize as ferramentas de forma adequada, garantindo assim a fidelidade da pesquisa. Portanto, o pesquisador decidiu atuar como um facilitador durante a aplicação do método. Ele acompanhou todas as atividades do método e tirou dúvidas sobre a aplicação das ferramentas, ao mesmo tempo em que anotou os fatos e arquivou os resultados.

\subsection{Definição da empresa e da unidade de análise}

A definição da empresa e da unidade de análise segue as especificações do protocolo do estudo de caso. O pesquisador analisou na região de São Carlos quais eram as oportunidades para a realização do estudo. Entre as que surgiram destacou-se a empresa Nanox Tecnologia S.A.

Assim foi realizada uma visita na empresa para apresentar os objetivos do estudo de caso e analisar se as características da empresa estavam de acordo com os requisitos da pesquisa. Por fim concluiu-se que a empresa atendia aos requisitos da pesquisa, além de ter interesse em participar do estudo.

A Nanox Tecnologia $S / A^{5}$ está situada na cidade de São Carlos, interior do estado de São Paulo. Essa cidade é reconhecida pela presença de várias empresas de alta tecnologia resultantes de Spin-Offs da Universidade de São Paulo (USP) e

5 Maiores informações sobre a empresa podem ser consultadas no seu site: http://www.nanox.com.br/. 
da Universidade Federal de São Carlos (UFSCar). A empresa foi fundada em 2005 por pesquisadores da UFSCar, seguindo essa tendência da cidade. Desde então atua na indústria química desenvolvendo produtos baseados em nanotecnologia. Atualmente a empresa conta com 20 funcionários e tem clientes em vários setores da economia, como: têxtil, petroquímico e produtos de consumo.

Segundo a classificação para o porte de empresas do Sebrae ${ }^{6}$, a Nanox é considerada um pequena empresa. Dentro dessa classificação ela recebeu em 2007 o prêmio FINEP ${ }^{7}$ (Financiadora de Estudos e Projetos) de Inovação Tecnológica como reconhecimento do seu sucesso. Uma das suas características marcantes que tem contribuído para o alto grau de inovação tecnológica da empresa é a formação dos seus funcionários. Em 2008, 35\% dos funcionários possuíam título de mestre e $25 \%$ título de doutor.

O interesse da empresa na realização do estudo de caso surgiu com realização de um diagnóstico do processo de desenvolvimento de produtos que indicou a necessidade de uma melhoria na realização da macro-fase de pré-desenvolvimento. Além disso, a atual fase de crescimento da empresa e sua estratégia de inovação colaboraram com o interesse em realizar o trabalho.

Entre os produtos desenvolvidos, a empresa decidiu em conjunto com o pesquisador envolver no estudo a linha de produtos antimicrobianos, a qual se situa em um mercado em crescimento no Brasil. Portanto, a linha de produtos antimicrobianos foi escolhida como a unidade de análise do estudo de caso.

${ }^{6}$ Maiores informações sobre a classificação do porte de empresa do Sebrae podem ser encontrados em seu site - www.sebrae.com.br

${ }^{7}$ Agência do governo brasileiro que investe no desenvolvimento de projetos. Para maiores informações visite o site - www.finep.gov.br 


\subsection{Planejamento do estudo de caso}

Esta atividade tem como função apresentar o Método ITG para a empresa, definir os participantes e planejar as atividades que serão realizadas.

Como resultado dessa atividade foi definido um time formado por 4 pessoas, sendo cada uma representante do alto escalão das seguintes áreas: comercial, engenharia, financeira e executiva. Essas pessoas participaram de todas as atividades do caso. Considerando que, dependendo da atividade, poderia surgir mais algum participante para auxiliar no trabalho.

O pesquisador explicou as atividades e ferramentas do Método ITG para os participantes. Ele também disponibilizou todo o material necessária para que o time conseguisse aplicá-lo.

A duração estimada para o projeto foi de cinco meses. Essa duração foi estipulada considerando a disponibilidade dos participantes e a esforço previsto para cada atividade. 


\section{Resultados e avaliação do estudo de caso em uma pequena empresa de base tecnológica}

Este capítulo apresenta os resultados do estudo de caso seguindo a ordem das 13 atividades do Método ITG. As informações mostradas são fruto das anotações feitas pelo pesquisador no diário de bordo e dos documentos gerados na aplicação do método. Os dados foram modificados para manter a confidencialidade, portanto todos os nomes e valores apresentados não equivalem aos dados reais.

No final deste capítulo encontram-se as avaliações dos resultados do estudo de caso. Essas foram realizadas de acordo com a estratégia de avaliação definida na metodologia de pesquisa.

\subsection{Atividade 1 - Definição da unidade de análise}

Primeiramente, desde a seleção da empresa para a realização do estudo de caso existiu um consenso para a unidade de análise englobar a linha de produtos antimicrobianos denominada de NanoxClean®. A empresa buscava esclarecer as oportunidades existentes no mercado e planejar o desenvolvimento da linha de produtos de maneira mais consistente e estruturada. Com relação à definição da unidade de negócio, não foi necessária uma escolha, pois a empresa é constituída por apenas uma.

Além da linha de produtos e da unidade de negócio, também era necessário selecionar os segmentos de mercado que fariam parte da unidade de análise. Nesse momento surgiram algumas dúvidas, já que a linha de produtos tinha oportunidades em vários segmentos. 
Assim foi realizada uma avaliação que selecionou o segmento de mercado aqui denominado como $\mathrm{NMER}^{8}$. Os critérios que apoiaram essa decisão foram: tempo de lançamento do produto no mercado, alinhamento com as capacidades da organização, variabilidade dos requisitos do mercado, facilidade de acesso à informação, atratividade do mercado e potencial de retorno financeiro para a empresa.

\subsection{Atividade 2 - Análise das estratégias do negócio}

Esta atividade iniciou pela identificação das dimensões de desempenho do produto. Foram identificadas seis dimensões, porém essas não são descritas por motivo de confidencialidade. A Tabela 17 apresenta o tipo de cada uma delas.

Tabela 17 - Dimensões de desempenho de produto do caso Nanox

\begin{tabular}{|l|l|}
\hline \multicolumn{1}{|c|}{ Dimensões do produto } & \multicolumn{1}{|c|}{ Descrição } \\
\hline dimensão comercial & envolve a percepção inicial do produto no mercado \\
\hline dimensão técnica A & envolve a adequação do produto a interface do produto do cliente \\
\hline dimensão técnica B & envolve a adequação do produto ao canal de distribuição \\
\hline dimensão técnica C & envolve a adequação do produto ao processo de fabricação \\
\hline dimensão técnica D & envolve a definição dos materiais usados no produto \\
\hline dimensão sócio-ambiental & envolve a adequação do produto as legislações e normas \\
\hline
\end{tabular}

Em seguida analisaram-se as estratégias do negócio e foram identificados os direcionadores do negócio que poderiam impactar no desenvolvimento dos produtos da unidade de análise. Esses direcionadores não são descritos devido ao acordo de confidencialidade. Como nesse caso foi selecionado apenas um segmento de mercado e uma unidade de negócio, não será necessário diferenciar a prioridade

${ }^{8} \mathrm{O}$ termo NMER é uma sigla adotada para representar o segmento de mercado escolhido, que significa Novo Mercado. 
dos direcionadores em função dessas variáveis. A Tabela 18 apresenta o tipo de cada um.

Tabela 18 - Direcionadores de negócio do caso Nanox

\begin{tabular}{|c|c|c|c|c|}
\hline \multirow{2}{*}{$\begin{array}{l}\text { Direcionadores do } \\
\text { negócio }\end{array}$} & \multirow{2}{*}{$\begin{array}{l}\text { Dimensão de produto } \\
\text { relacionada }\end{array}$} & \multirow{2}{*}{$\begin{array}{c}\text { Prioridade na } \\
\text { unidade de } \\
\text { nөgócio }\end{array}$} & \multicolumn{2}{|c|}{ Tempo do direcionador } \\
\hline & & & Data de início & Data de fim \\
\hline $\begin{array}{l}\text { Direcionador de } \\
\text { processos do negócio }\end{array}$ & $\begin{array}{l}\text { dimensão comercial, } \\
\text { dimensões técnicas A e D }\end{array}$ & alta & imediata & constante \\
\hline $\begin{array}{l}\text { Direcionador de } \\
\text { marketing do negócio }\end{array}$ & $\begin{array}{l}\text { dimensão comercial, } \\
\text { dimensão sócio-ambiental e } \\
\text { dimensão técnicas A }\end{array}$ & alta & imediata & 2 anos \\
\hline $\begin{array}{l}\text { Direcionador } \\
\text { econômico do negócio }\end{array}$ & dimensões técnicas $B, C$ e D & média & imediata & 2 anos \\
\hline $\begin{array}{l}\text { Direcionador de } \\
\text { posicionamento no } \\
\text { mercado do negócio }\end{array}$ & dimensões técnicas A e B & baixa & imediata & constante \\
\hline
\end{tabular}

Durante a realização dessa atividade surgiram duas dificuldades para o time:

- A primeira estava relacionada com o significado do termo "dimensão de desempenho de produto" e gerou dúvidas na atividade. Em vários momentos o time confundia itens que estariam relacionados com direcionadores de negócio, direcionadores de mercado, atributos de produto e tecnologia. Dessa forma o pesquisador decidiu esclarecer o significado de cada um dos termos por meio de exemplos. Essa intervenção garantiu que os dados usados estivem de acordo com o método. No entanto, esse pode ser um sinal da necessidade de incluir algum aspecto que enfatize a diferenciação entre os termos usados.

- A segunda dificuldade aconteceu quando o time tentou definir a prioridade dos direcionadores e suas datas de início e fim. Isso pode ter acontecido devido à presença de incertezas em relação ao plano estratégico do negócio, o qual é uma entrada para a atividade. Essa dificuldade poderia ter sido reduzida caso fosse feita uma análise preliminar do plano estratégico, permitindo ao time conhecer as 
informações necessárias para definir tanto a prioridade quanto o tempo de cada direcionador.

\subsection{Atividade 3 - Análise de mercado}

Esta atividade foi iniciada considerando como referência as dimensões de desempenho de produto identificadas na atividade anterior e apresentadas na Tabela 17. Nela foi necessária uma maior participação do representante da área comercial, pois ele possuía maior contato com os clientes e assim tinha uma melhor percepção das necessidades e tendências do mercado.

Mesmo com a experiência do membro da área comercial, faltavam conhecimentos sobre o mercado. Uma possível causa dessa ausência de informações poderia ser a recente aplicação dessa linha de produtos no segmento de mercado NMER. Por causa dessa dificuldade foi necessário prolongar a atividade para que fosse possível consultar alguns clientes.

Na semana seguinte, após a aquisição de novas informações, o time conseguiu definir de forma mais consistente os direcionadores de mercado. No entanto, devido a curta existência desse mercado conseguiu-se apenas encontrar as necessidades atuais dos clientes, enquanto que as tendências foram desconsideradas. Os direcionadores de mercado identificados pelo time não são apresentados devido à confidencialidade, mesmo assim a Tabela 19 descreve o tipo de cada um. 
Tabela 19 - Direcionadores de mercado do caso Nanox

\begin{tabular}{|c|c|c|c|c|}
\hline \multirow{2}{*}{$\begin{array}{l}\text { Direcionadores de } \\
\text { mercado }\end{array}$} & \multirow{2}{*}{$\begin{array}{l}\text { Dimensão de } \\
\text { produto } \\
\text { relacionada }\end{array}$} & \multirow{2}{*}{$\begin{array}{c}\text { Prioridade no } \\
\text { segmento de } \\
\text { mercado }\end{array}$} & \multicolumn{2}{|c|}{ Tempo do direcionador } \\
\hline & & & Data de início & Data de fim \\
\hline $\begin{array}{l}\text { Direcionador econômico do } \\
\text { mercado }\end{array}$ & $\begin{array}{l}\text { Dimensão } \\
\text { comercial }\end{array}$ & Alta & imediata & constante \\
\hline $\begin{array}{l}\text { Direcionador de interface } \\
\text { com o produto do cliente A }\end{array}$ & \begin{tabular}{|c} 
Dimensão técnica \\
$\mathrm{A}$
\end{tabular} & Alta & imediata & constante \\
\hline $\begin{array}{l}\text { Direcionador de interface } \\
\text { com o produto do cliente B }\end{array}$ & \begin{tabular}{|c|} 
Dimensão técnica \\
A
\end{tabular} & Média & imediata & constante \\
\hline $\begin{array}{l}\text { Direcionador de interface } \\
\text { com o produto do cliente C }\end{array}$ & \begin{tabular}{|} 
Dimensão técnica \\
$\mathrm{A}$
\end{tabular} & Alta & imediata & constante \\
\hline $\begin{array}{l}\text { Direcionador de interface } \\
\text { com o produto do cliente } D\end{array}$ & \begin{tabular}{|c|} 
Dimensão técnica \\
A
\end{tabular} & Baixa & imediata & constante \\
\hline $\begin{array}{l}\text { Direcionador de atendimento } \\
\text { a normas ambientais }\end{array}$ & $\begin{array}{c}\text { Dimensão sócio- } \\
\text { ambiental }\end{array}$ & Média & imediata & constante \\
\hline $\begin{array}{l}\text { Direcionador de atendimento } \\
\text { a normas sociais }\end{array}$ & $\begin{array}{c}\text { Dimensão sócio- } \\
\text { ambiental }\end{array}$ & Média & imediata & constante \\
\hline $\begin{array}{l}\text { Direcionador de atendimento } \\
\text { requisitos do cliente A }\end{array}$ & $\begin{array}{l}\text { Dimensões } \\
\text { técnicas C e D }\end{array}$ & Média & imediata & constante \\
\hline $\begin{array}{l}\text { Direcionador de atendimento } \\
\text { requisitos do cliente B }\end{array}$ & $\begin{array}{c}\text { Dimensões } \\
\text { técnicas A, C e D }\end{array}$ & Alta & imediata & constante \\
\hline
\end{tabular}

O pesquisador notou alguns pontos relevantes na realização desta atividade:

- Na avaliação dos direcionadores de mercado existia uma tendência do time em priorizar o que era mais importante para o negócio, o que não era o propósito, já que deveria ser avaliado o que era mais importante para o mercado.

- O time ficou satisfeito com a visão que adquiriu em relação às necessidades do mercado e mostrou interesse em expandir essa prática para outras linhas de produtos da empresa.

\subsection{Atividade 4 - Análise de produto}

Esta atividade seguiu as dimensões de desempenho de produto como ponto de partida para a identificação dos atributos da linha de produto. Foram identificados cinco atributos de produto, os quais são descritos por meio dos seus tipos na Tabela 20. 
Tabela 20 - Atributos de produto do caso Nanox

\begin{tabular}{|l|l|}
\hline \multicolumn{1}{|c|}{ Atributos de produto } & \multicolumn{1}{|c|}{ Descrição } \\
\hline Atributo de produto 1 & $\begin{array}{l}\text { define a capacidade do produto fornecer o benefício primordial } \\
\text { requisitado pelo cliente }\end{array}$ \\
\hline Atributo de produto 2 & define o tipo de material utilizado pelo produto \\
\hline Atributo de produto 3 & define a interface com o produto do cliente \\
\hline Atributo de produto 4 & define o tipo de benefício que é fornecido ao cliente \\
\hline Atributo de produto 5 & define o desempenho do produto quando utilizado pelo cliente \\
\hline
\end{tabular}

A identificação desses atributos de produto nunca havia sido realizada pela empresa. Essa nova visão do produto permitiu ao time entender o que estava oferecendo ao mercado e assim ter maiores chances de atender às suas necessidades.

A próxima parte da atividade consistia em avaliar o impacto que cada um dos atributos de produto possuía nos direcionadores de negócio e de mercado. Para isso os participantes utilizaram a seguinte escala: (0) neutro, (1) baixo impacto, (2) médio impacto e (3) alto impacto.

Em seguida, com o resultado dessa avaliação em mãos, foi aplicada a ferramenta de desdobramento de prioridades baseada no conceito de QFD e apresentada na Tabela 6. Neste instante foi necessário converter os valores qualitativos de prioridade dos direcionadores, os quais são encontrados na Tabela 18 e na Tabela 19, em valores numéricos. A conversão decidida por consenso entre o time foi a seguinte: alta $=3$, média $=2$ e baixa $=1$.

A avaliação do impacto dos atributos de produto nos direcionadores foi realizada por cada um dos participantes do time. Logo após foi calculada a média das notas, que foi usada no preenchimento da planilha. A Tabela 21 descreve o resultado obtido, porém com os valores modificados. 
Devido ao maior número de direcionadores de negócio em relação ao número de direcionadores de mercado, o resultado do impacto dos atributos de produto pode valorizar diferentemente a perspectiva de mercado. Portanto, o time deve entrar a fundo no significado para assegurar que os resultados estejam de acordo com o objetivo da avaliação. Além disso, o time também deve atentar para a normalização das notas, que foi realizada para manter a nota final na mesma escala da avaliação do impacto.

Tabela 21 - Avaliação do impacto dos atributos de produto nos direcionadores do caso Nanox

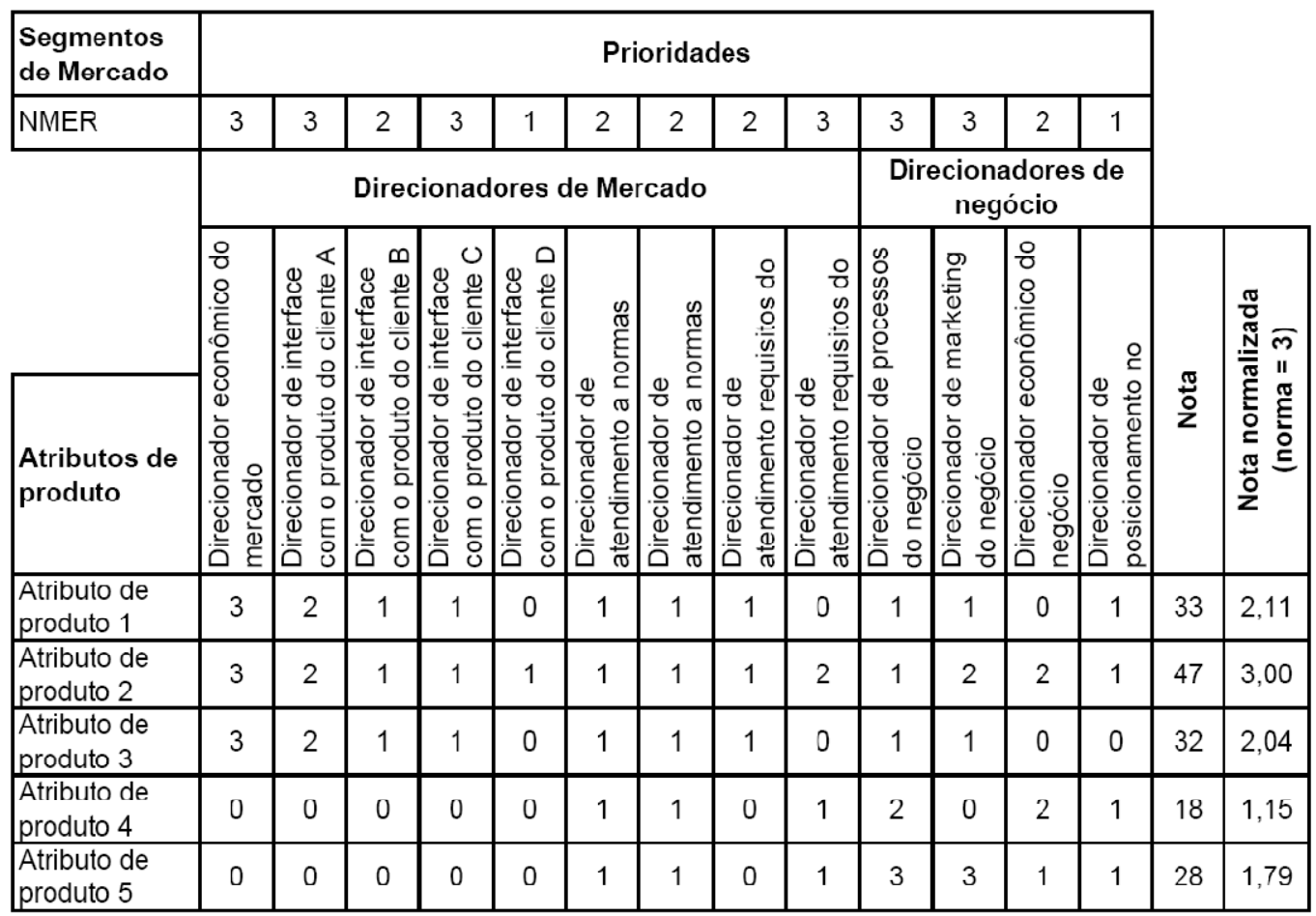

Os resultados da avaliação mostraram que os atributos de produto 1,2 e 3 possuíam maior influência nos direcionadores. A partir desse resultado o time identificou que os novos produtos lançados deveriam possuir um diferencial nesses atributos para que os clientes os escolhessem no momento da compra.

Assim, a estratégia desenvolvida pelo time foi de entrar no mercado com um produto de alto desempenho nesses atributos, para em seguida lançar um produto complementar com os outros atributos. Dessa maneira, a linha de produtos 
atenderia às necessidades básicas e teria, no futuro, um diferencial competitivo sobre os concorrentes.

No entanto é importante relembrar que não foi possível identificar as tendências do mercado para essa linha de produtos. Talvez nos próximos anos, com a evolução do mercado e o conhecimento dessas tendências, seja necessário replanejar os novos produtos e seus atributos.

\subsection{Atividade 5 - Análise de tecnologia}

Esta atividade buscou identificar as tecnologias usadas nos atributos de produto e avaliar quais delas possuíam maior relevância. Assim como nas outras atividades, os membros também utilizaram as dimensões de desempenho de produto como referência para a identificação das tecnologias. Na Tabela 22, as tecnologias levantadas são apresentadas com base nos seus tipos.

Tabela 22 - Tecnologias do caso Nanox

\begin{tabular}{|l|l|}
\hline Tecnologias & \multicolumn{1}{|c|}{ Descrição } \\
\hline tecnologia 1 & relacionada aos métodos de interface com o produto do cliente \\
\hline tecnologia 2 & capacita a escolha dos benefícios do produto para o cliente \\
\hline tecnologia 3 & relacionado ao material utilizado no produto \\
\hline tecnologia 4 & relacionados aos métodos de fabricação do produto \\
\hline
\end{tabular}

Conhecendo as tecnologias, a próxima tarefa era aplicar a planilha apresentada na Tabela 8 para avaliar o impacto delas nos atributos de produto identificados na última atividade. Essa avaliação foi realizada por cada um dos participantes do time, para em seguida ser calculada a média das notas, que foi colocada na planilha. A escala utilizada foi igual a da atividade de análise de produto: 0) neutro, (1) baixo impacto, (2) médio impacto e (3) alto impacto, mantendo assim a uniformidade. A Tabela 23 mostra os resultados dessa avaliação com os valores modificados. 
Junto com esses valores, o time inseriu os valores do impacto dos atributos de produto na parte superior da planilha, os quais provêem da atividade anterior. Por fim a planilha calculou a nota normalizada (escala de 0 a 3 ) do impacto das tecnologias nos atributos de produto.

Tabela 23 - Avaliação do impacto das tecnologias nos atributos de produto do caso Nanox

\begin{tabular}{|c|c|c|c|c|c|c|c|}
\hline $\begin{array}{l}\text { Segmentos de } \\
\text { Mercado }\end{array}$ & \multicolumn{5}{|c|}{ Impacto do atributo } & & \\
\hline \multirow[t]{3}{*}{ NMER } & 2.11 & 3 & 2.04 & 1.15 & 1.79 & & \\
\hline & \multicolumn{5}{|c|}{ Atributos de produto } & & \\
\hline & 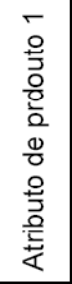 & 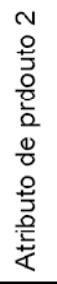 & 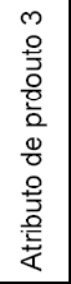 & 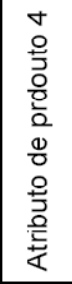 & 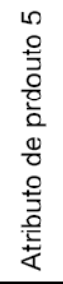 & ثँ & 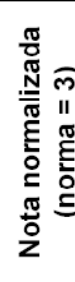 \\
\hline tecnologia 1 & 2 & 2 & 0 & 2 & 3 & 17,87 & 2,80 \\
\hline tecnologia 2 & 2 & 1 & 2 & 0 & 2 & 14,87 & 2,33 \\
\hline tecnologia 3 & 0 & 2 & 2 & 3 & 0 & 13,53 & 2,12 \\
\hline tecnologia 4 & 3 & 1 & 0 & 2 & 3 & 16,98 & 2,66 \\
\hline tecnologia 5 & 0 & 2 & 3 & 3 & 2 & 19,15 & 3,00 \\
\hline
\end{tabular}

A partir desses resultados foi possível notar que as tecnologias 1, 4 e 5 são as com maior impacto. E como a nota final leva em consideração a nota recebida pelos atributos de produto, pode-se afirmar que essas tecnologias são as que propiciam a entrega dos atributos mais importantes.

Essa informação permite que os membros da empresa avaliem a situação das tecnologias prioritárias e verifiquem se elas são capazes de atender ao que é buscado, ou se é preciso planejar o desenvolvimento ou aquisição de novas tecnologias para os futuros produtos.

Em função das opções apresentadas e também devido às limitações do estudo de caso, que está direcionado ao estudo do PDP, os membros do time planejaram os produtos considerando apenas as tecnologias disponíveis na empresa. 
Os participantes sentiram dificuldades para visualizar quais seriam as novas tecnologias, pois não existe na empresa uma área ou pessoa responsável por monitorá-las. Essa barreira despertou no time o interesse de criar um cargo responsável pela atividade de vigilância tecnológica, que acompanharia as novidades tecnológicas e facilitaria a previsão de futuras oportunidades.

\subsection{Atividade 6 - Definição das estratégias de produtos}

Esta atividade representa a conclusão da primeira parte do estudo de caso, a qual está baseada no technology roadmapping. Nela os participantes do estudo de caso reúnem as informações das atividades anteriores e criam o roadmap de planejamento de produto.

Inicialmente foi montado um quadro com o formato do roadmap de planejamento de produto que foi apresentada na Figura 15. Em seguida os membros da empresa colocaram os post-its ${ }^{\circledR}$ dos direcionadores de negócio e mercado na camada superior do roadmap. Os post-its $®$ que representavam os atributos de produto foram colocados de maneira que mostrassem o desenvolvimento do produto de entrada e do produto complementar. Por fim foram adicionados os post-its $®$ das tecnologias necessárias para os atributos de produto.

Com as três camadas preparadas, os participantes definiram a integração e o alinhamento entre elas. Esse é o momento mais importante da atividade, pois agora é que são notadas as oportunidades, as restrições e as ações necessárias para que seja possível o desenvolvimento dos produtos.

Os participantes notaram, durante essa etapa, problemas nos relacionamentos dos atributos de produto, limitações de tempo que não permitiriam 0 desenvolvimento do produto e até mesma a ausência de tecnologias. 
Outros resultados importantes para a empresa foram: a importância de investigar as novas tecnologias, a necessidade de conhecer as tendências futuras do mercado e a percepção de que outros mercados poderiam necessitar de produtos com funções similares às planejadas para o segmento de mercado NMER.

A seguir são apresentadas fotos que mostram o roadmap de planejamento de produto desenvolvido pelos participantes da empresa durante o estudo de caso. A Figura 21 mostra a versão inicial do roadmap, na qual são buscados os relacionamentos entre as camadas, a Figura 22 apresenta alguns dos participantes do estudo de caso e a Figura 23 mostra a versão final do roadmap.

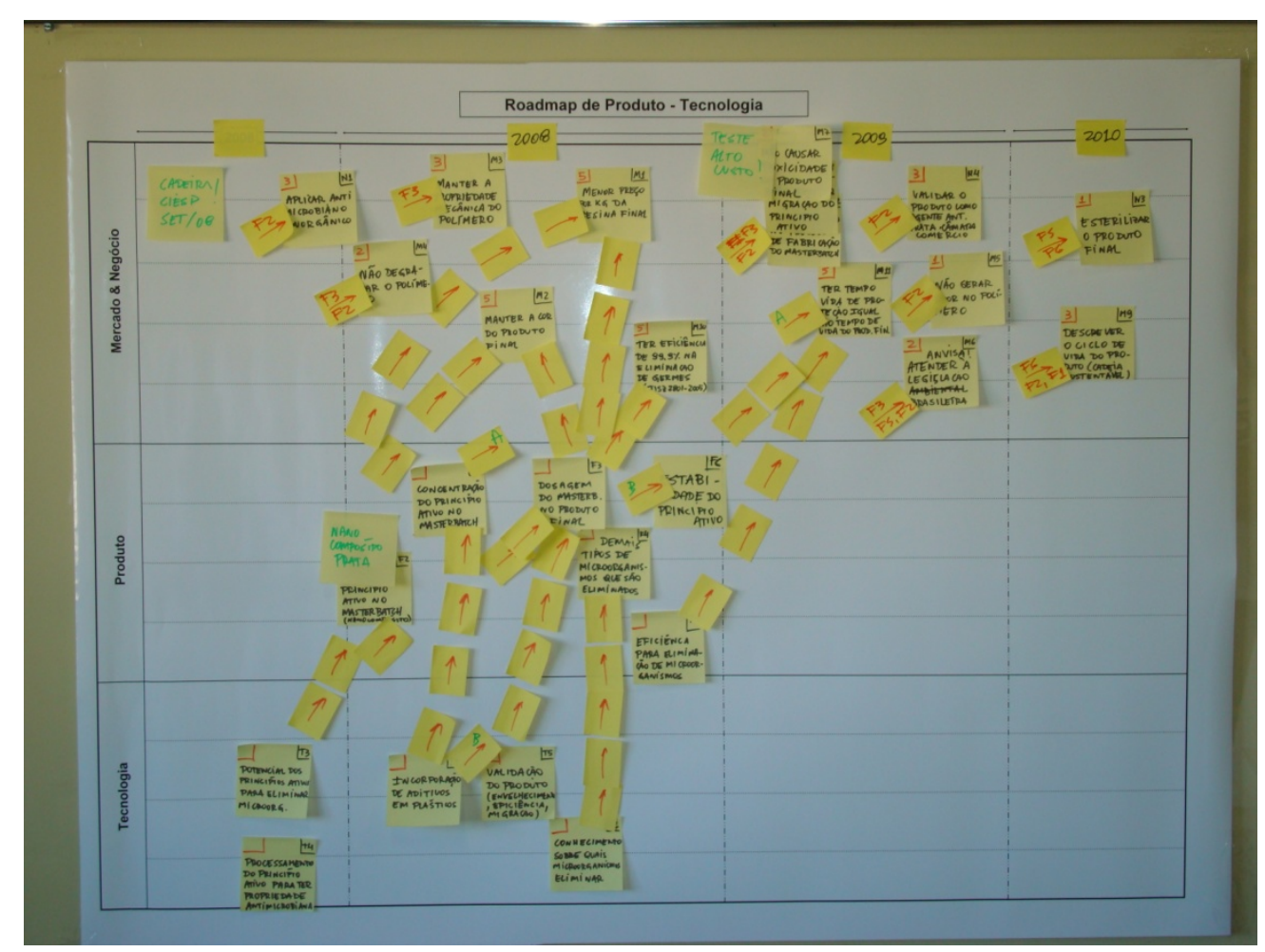

Figura 21 - Versão inicial do roadmap de planejamento do produto do caso Nanox 


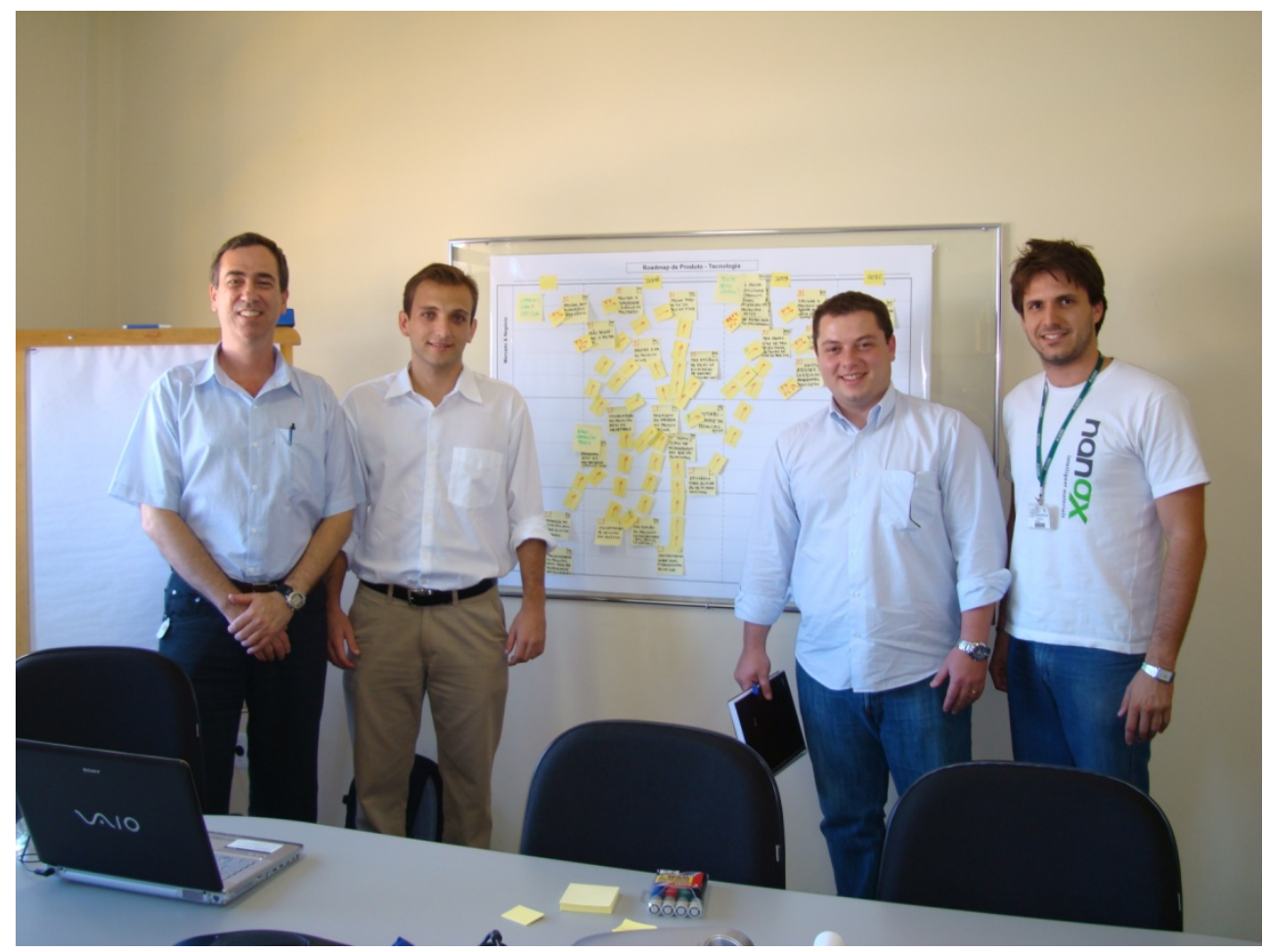

Figura 22 - Participantes do estudo de caso Nanox

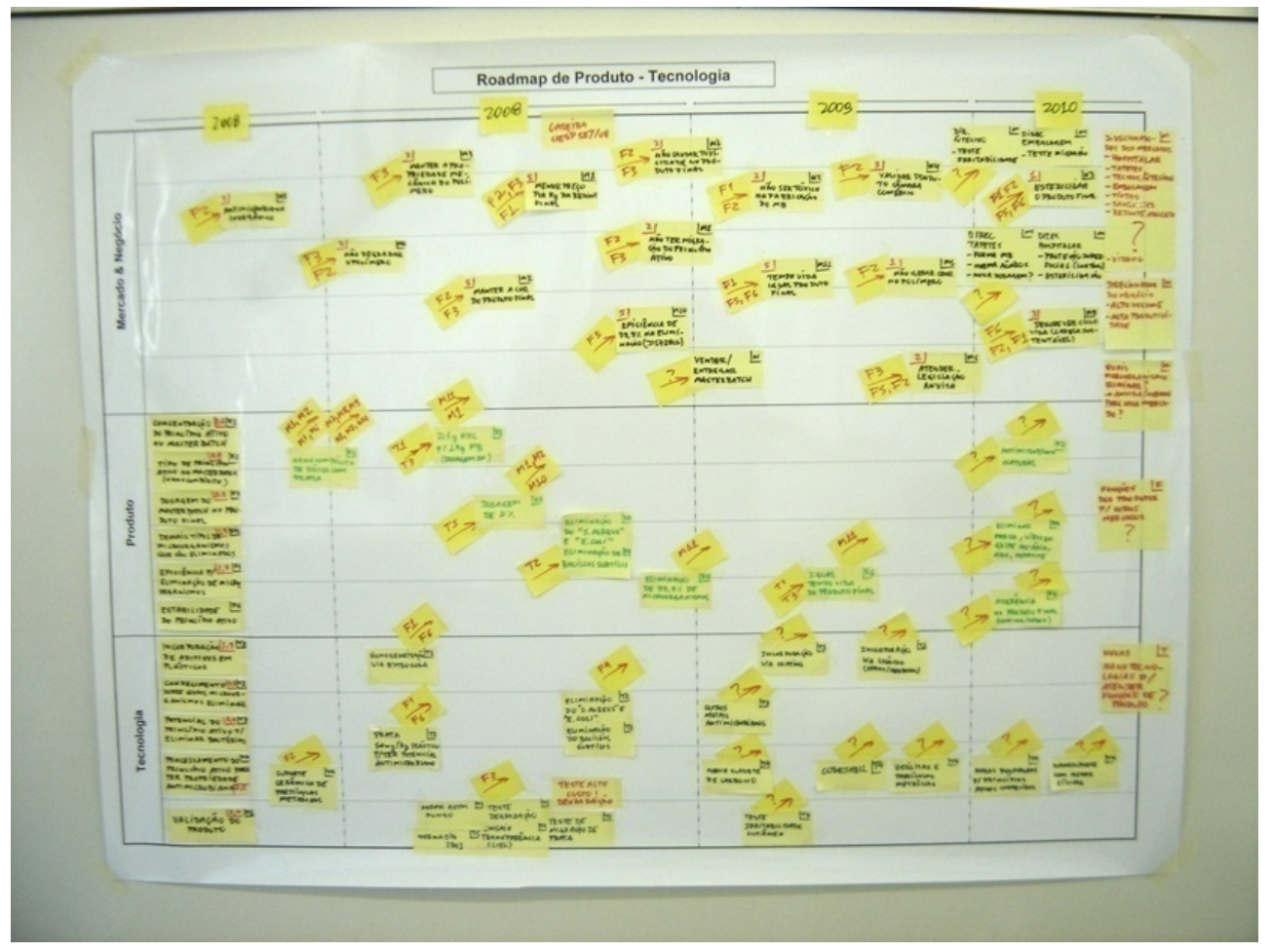

Figura 23 - Roadmap de planejamento de produto do caso Nanox 


\subsection{Atividade 7 - Proposição de projetos de novos produtos}

Esta atividade define propostas de projetos de novos produtos para as oportunidades de produtos identificadas na atividade anterior. Neste momento, existe a opção de considerar oportunidades para novos produtos indicadas por outras áreas da empresa, como explicado no subcapítulo 4.9, o que amplia a unidade de análise e dificulta a aplicação do método.

Em função dos resultados da atividade anterior, foram formuladas quatro propostas de projetos de novos produtos, que receberam os nomes: projeto $\mathrm{A}$, projeto $B$, projeto $C$ e projeto $D$. Nessas propostas foram descritas as principais informações do conceito e do projeto do produto, conforme indicado na Figura 16. O preenchimento do modelo com as informações de cada projeto foi designado para um membro do time, que poderia consultar os outros para tirar dúvidas ou pedir informações sobre as propostas.

A proposta detalhada de cada um dos projetos não é apresentada devido à confidencialidade. A Figura 24 mostra uma imagem que representa essas quatro propostas.

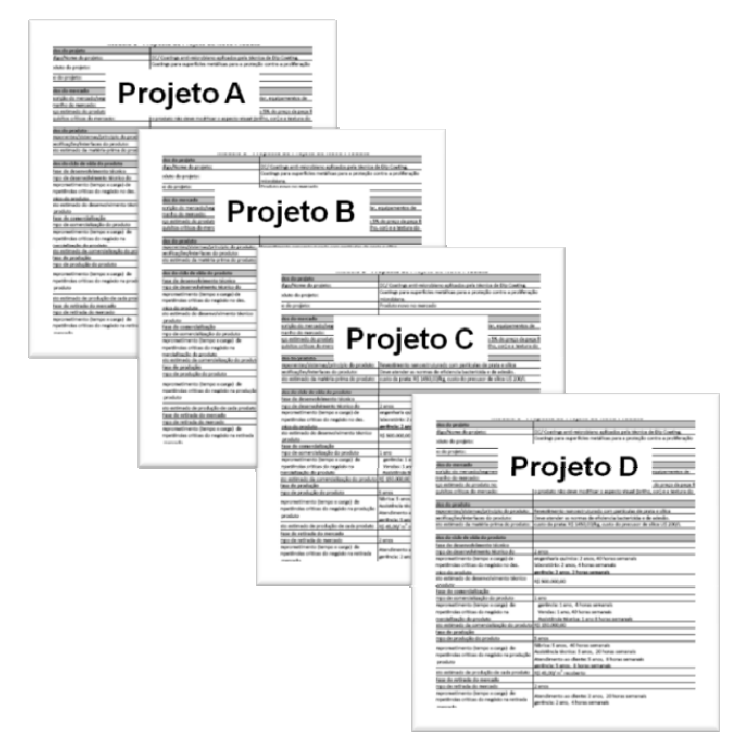




\subsection{Atividade 8 - Avaliação financeira de projetos}

Esta atividade tem como objetivo calcular os indicadores financeiros das propostas de projeto. Ela foi realizada pelo membro da empresa usualmente responsável por esse tipo de operação. Como a empresa possuía sua própria ferramenta para a avaliação financeira e essa estava alinhada com os requisitos do método, ela optou por manter sua forma padrão de cálculo.

As informações necessárias para a avaliação financeira dos projetos dependiam em grande parte de previsões dos participantes envolvidos. A experiência da empresa permitia estimar com boa precisão os custos de desenvolvimento dos projetos. No entanto, devido à informação limitada do mercado, a estimativa da quantidade de venda e da precificação do produto teve um alto grau de incerteza. Mesmo assim, os resultados das avaliações financeiras foram uma boa referência para a comparação dos projetos.

A Tabela 24 mostra os indicadores financeiros: investimento, VPL, TIR, ROI e Payback para os quatro projetos avaliados. Os valores foram modificados para manter a confidencialidade das informações da empresa.

Tabela 24 - Indicadores financeiros das propostas de projetos do caso Nanox

\begin{tabular}{|c|c|c|c|c|c|}
\hline Projetos & Investimento & VPL & TIR & ROI & Payback \\
\hline Projeto A & $\mathrm{R} \$ 156.250,00$ & $\mathrm{R} \$ 2.116 .313,78$ & $94,12 \%$ & $196,51 \%$ & 2 anos \\
\hline Projeto B & $\mathrm{R} \$ 92.575,00$ & $\mathrm{R} \$ 143.763,13$ & $85,95 \%$ & $220,00 \%$ & 3 anos \\
\hline Projeto C & $\mathrm{R} \$ 195.555,56$ & $\mathrm{R} \$ 270.104,05$ & $40,93 \%$ & $164,44 \%$ & 4 anos \\
\hline Projeto D & $\mathrm{R} \$ 274.950,00$ & $\mathrm{R} \$ 1.484 .469,38$ & $74,22 \%$ & $312,95 \%$ & 3 anos \\
\hline
\end{tabular}

\subsection{Atividade 9 - Avaliação da probabilidade de sucesso do projeto}

Esta atividade foi realizada pelos participantes do estudo de caso com o apoio da ferramenta apresentada no subcapítulo 4.11. Devido à restrição de tempo dos participantes, eles escolheram o representante da engenharia para realizar as 
avaliações e em seguida todos juntos revisaram os resultados. A Tabela 25 apresenta a probabilidade de sucesso calculada para as quatro propostas de projetos de produto.

Tabela 25 - Avaliação de probabilidade de sucesso de projetos do caso Nanox

\begin{tabular}{|c|c|c|c|c|}
\hline \multicolumn{5}{|c|}{ Avaliação da Probabilidade de Sucesso do Projeto } \\
\hline Critérios técnicos & Projeto A & Projeto B & Projeto C & Projeto D \\
\hline 1. Posição proprietária & 2 & 4 & 2 & 2 \\
\hline 2. Competências/ habilidades & 4 & 4 & 4 & 2 \\
\hline 3. Complexidade técnica & 3 & 2 & 3 & 2 \\
\hline 4. Acesso e uso eficaz de tecnologia externa & 4 & 3 & 4 & 4 \\
\hline 5. Capacidade de produção & 3 & 2 & 3 & 3 \\
\hline Probabilidade técnica de sucesso & $64,0 \%$ & $60,0 \%$ & $64,0 \%$ & $52,0 \%$ \\
\hline Critério comerciais & Projeto A & Projeto B & Projeto C & Projeto D \\
\hline 1. Necessidade do mercado/cliente (interno ou externo) & 2 & 4 & 2 & 2 \\
\hline 2. Reconhecimento do mercado/negócio & 1 & 1 & 1 & 1 \\
\hline 3. Canais para o mercado & 4 & 4 & 4 & 4 \\
\hline 4. Força do cliente & 4 & 5 & 4 & - \\
\hline 5. Matéria-prima ou fornecimento de componentes essenciais & 3 & 3 & 3 & 3 \\
\hline 6. Riscos de segurança, de saúde e ambientais & 3 & 3 & 3 & 3 \\
\hline Probabilidade comercial de sucesso & $56,7 \%$ & $66,7 \%$ & $56,7 \%$ & $52,0 \%$ \\
\hline Probabilidade de Sucesso do Projeto & $60,3 \%$ & $63,3 \%$ & $60,3 \%$ & $52,0 \%$ \\
\hline
\end{tabular}

A avaliação da probabilidade de sucesso mostrou os principais riscos envolvidos no desenvolvimento dos projetos e permitiu compará-los de forma estruturada. Os resultados obtidos indicam que os projetos $A, B$ e $C$ tinham probabilidades de sucesso similares, enquanto que o projeto D possuía uma menor probabilidade de sucesso.

\subsection{Atividade 10 - Avaliação do potencial estratégico do projeto}

Os participantes do estudo de caso seguiram nesta atividade o mesmo procedimento adotado na atividade anterior. Eles escolheram o representante da área executiva para avaliar os quatro projetos e então se reuniram para revisar e concordar sobre os resultados. As ferramentas usadas foram apresentadas na Tabela 12 e na Tabela 13.

Os resultados obtidos para cada um dos projetos estão descritos na Tabela 26. Seguindo o padrão da ferramenta utilizada, a escala de notas seria de 0 a 24, porém 
os participantes decidiram convertê-la para uma escala de 0 a 5 , a fim de comparar mais facilmente os projetos. A avaliação do potencial estratégico dos projetos mostra um melhor potencial estratégico dos projetos $A, B$ e $C$, enquanto que o projeto $D$ possui um potencial inferior.

Tabela 26 - Resultados da avaliação do potencial estratégico dos projetos do caso Nanox

\begin{tabular}{|c|c|c|c|c|}
\hline \multicolumn{5}{|c|}{ Avaliação do potencial estratégico do projeto } \\
\hline Critério estratégico & Projeto A & Projeto $\mathrm{B}$ & Projeto C & Projeto D \\
\hline Congruência com a estratégia & 3 & 3 & 3 & 2 \\
\hline Impacto na estratégia & 3 & 4 & 3 & 2 \\
\hline Posição proprietária & 3 & 3 & 3 & 2 \\
\hline Plataforma para crescimento & 3 & 3 & 3 & 3 \\
\hline Durabilidade (Técnica e Mercado) & 3 & 4 & 3 & 3 \\
\hline Sinergia com outras operações do negócio & 3 & 3 & 3 & 2 \\
\hline Potencial estratégico do projeto (escala 0-24) & 18 & 20 & 18 & 14 \\
\hline Potencial estratégico do projeto (escala $0-5$ ) & 3,8 & 4,2 & 3,8 & 2,9 \\
\hline
\end{tabular}

\subsection{Atividade 11 - Classificação dos projetos}

Essa é a primeira atividade do método que trata da avaliação do portfólio de projetos de produtos, visto que as anteriores tinham como foco o projeto individual. Sua primeira tarefa era reunir todas as informações das propostas de projetos em uma única planilha, com o intuito de facilitar o acesso às informações dos projetos. Os participantes usaram o modelo fornecido pelo método para isso. A Tabela 27 mostra essa planilha preenchida com os dados dos projetos.

Tabela 27 - Dados dos projetos do caso Nanox

\begin{tabular}{|c|c|c|c|c|c|c|c|c|c|c|c|c|c|}
\hline \multirow{2}{*}{$\begin{array}{l}\text { Lista de } \\
\text { projetos }\end{array}$} & \multicolumn{5}{|c|}{ Dados Projeto } & \multicolumn{5}{|c|}{ Análise financeira } & \multicolumn{2}{|c|}{$\begin{array}{l}\text { Probabilidade de } \\
\text { sucesso projeto }\end{array}$} & \multirow{2}{*}{$\begin{array}{l}\text { Potencial } \\
\text { Estratégico }\end{array}$} \\
\hline & $\begin{array}{l}\text { Unidade de } \\
\text { negócio }\end{array}$ & \begin{tabular}{|l|} 
Linha de \\
produto
\end{tabular} & $\begin{array}{c}\begin{array}{c}\text { Segmento de } \\
\text { mercado }\end{array} \\
\end{array}$ & $\begin{array}{l}\text { Tipo do } \\
\text { produto }\end{array}$ & Duração & Investimento & VPL & TIR & ROI & Payback & $\begin{array}{l}\text { Sucesso } \\
\text { técnico }\end{array}$ & $\begin{array}{l}\text { Sucesso } \\
\text { comercial }\end{array}$ & \\
\hline Projeto A & - & \begin{tabular}{|l} 
antimicro \\
biano
\end{tabular} & NMER & $\begin{array}{l}\text { novo } \\
\text { produto }\end{array}$ & 4 anos & $R \$ 156.250,00$ & $\mathrm{R} \$ 2.116 .313,78$ & $94 \%$ & $197 \%$ & 2 anos & $64,0 \%$ & $56,7 \%$ & 3,8 \\
\hline Projeto B & - & $\begin{array}{l}\text { antimicro } \\
\text { biano }\end{array}$ & NMER & melhoria & 8 anos & $\mathrm{R} \$ 92.575,00$ & $\mathrm{R} \$ 143.763,13$ & $86 \%$ & $220 \%$ & 3 anos & $60,0 \%$ & $66,7 \%$ & 4,2 \\
\hline Projeto C & - & \begin{tabular}{|l}
$\begin{array}{l}\text { antimicro } \\
\text { biano }\end{array}$ \\
\end{tabular} & NMER & $\begin{array}{l}\text { reposiciona } \\
\text { mento }\end{array}$ & 6 anos & $\mathrm{R} \$ 195.555,56$ & $\mathrm{R} \$ 270.104,05$ & $41 \%$ & $164 \%$ & 4 anos & $64,0 \%$ & $56,7 \%$ & 3,8 \\
\hline Projeto D & - & $\begin{array}{l}\text { antimicro } \\
\text { biano }\end{array}$ & NMER & $\begin{array}{l}\text { novo } \\
\text { produto }\end{array}$ & 5 anos & $\mathrm{R} \$ 274.950,00$ & $\mathrm{R} \$ 1.484 .469,38$ & $74 \%$ & $313 \%$ & 3 anos & $52,0 \%$ & $58,0 \%$ & 2,9 \\
\hline
\end{tabular}

Tendo em mãos as informações de cada projeto, os participantes devem decidir como pretendem classificá-los. Eles analisaram a sugestão do método, 
contudo notaram que seria interessante para a empresa realizar algumas adaptações na fórmula indicada. Com relação ao uso dos fatores, os participantes decidiram manter a combinação: valor financeiro, probabilidade de sucesso e valor estratégico.

A principal mudança foi no cálculo do valor financeiro. O representante financeiro mostrou que os projetos com baixo investimento e alta taxa de retorno eram os mais atrativos para a empresa. Assim ele propôs uma fórmula para o cálculo do valor financeiro que combinava o valor de investimento do projeto e sua TIR. Os outros dois fatores seguiram a sugestão do método: a média da probabilidade de sucesso técnico e comercial para o valor da probabilidade de sucesso do projeto e o valor do potencial estratégico para o valor estratégico do projeto.

Os três fatores foram normalizados em uma escala de 0 a 5 , com exceção do valor estratégico que já se encontrava nessa escala. Por fim eles foram multiplicados entre si para se obter a nota final do projeto, e então também normalizados na escala de 0 a 5. Os resultados da classificação estão na Tabela 28.

Tabela 28 - Nota de classificação dos projetos do caso Nanox

\begin{tabular}{|l|c|c|c|c|c|c|c|c|}
\hline \multirow{2}{*}{$\begin{array}{c}\text { Lista } \\
\text { projetos }\end{array}$} & $\begin{array}{c}\text { Probabilidade de sucesso } \\
\text { do projeto }\end{array}$ & \multicolumn{2}{|c|}{ Valor financeiro do projeto } & Potencial \\
\cline { 2 - 8 } & $\begin{array}{c}\text { Nota prob. } \\
\text { sucesso } \\
\text { original }\end{array}$ & $\begin{array}{c}\text { Nota prob. } \\
\text { sucesso } \\
\text { normalizada }\end{array}$ & Investimento & TIR & $\begin{array}{c}\text { Valor } \\
\text { financeiro } \\
\text { normalizado }\end{array}$ & $\begin{array}{c}\text { Nota } \\
\text { fo projeto }\end{array}$ & $\begin{array}{c}\text { Nota final do } \\
\text { projeto }\end{array}$ & $\begin{array}{c}\text { projeto } \\
\text { normalizada }\end{array}$ \\
\hline Projeto A & $60,3 \%$ & 4,8 & $R \$ 156.250,00$ & $94,12 \%$ & 3,9 & 3,8 & 70,0 & 5,0 \\
\hline Projeto D & $63,3 \%$ & 5,0 & $R \$ 92.575,00$ & $85,95 \%$ & 3,1 & 4,2 & 65,1 & 4,6 \\
\hline Projeto C & $60,3 \%$ & 4,8 & $R \$ 195.555,56$ & $40,93 \%$ & 2,9 & 3,8 & 51,2 & 3,7 \\
\hline Projeto D & $52,0 \%$ & 4,1 & $R \$ 274.950,00$ & $74,22 \%$ & 4,5 & 2,9 & 53,5 & 3,8 \\
\hline
\end{tabular}

Os projetos foram classificados na seguinte ordem: $\left(1^{\circ}\right)$ Projeto $A,\left(2^{\circ}\right)$ Projeto $B,\left(3^{\circ}\right)$ Projeto $D,\left(4^{\circ}\right)$ Projeto C. Essa indica a classificação inicial e é usada como referência na seleção dos projetos de produtos. 


\subsection{Atividade 12 - Análise do relacionamento entre os projetos}

Esta atividade analisa se existe alguma relação entre as propostas de projetos que influencie na seleção. Os resultados obtidos estão na Figura 25 e indicam que:

- No relacionamento de dependência, o projeto A é o que mais depende dos outros projetos, enquanto que o projeto $\mathrm{C}$ é o que mais contribui com os outros projetos.

- No relacionamento de compartilhamento de atividades/recursos, o projeto C é o que mais compartilha com os outros projetos.

- No relacionamento de impacto, os projetos B e C são os que mais têm impacto nos outros projetos, enquanto que o projeto A é o que mais recebe impacto.

- No relacionamento de tempo, o projeto C viria antes dos outros projetos, enquanto que o projeto A viria após.

A partir dos resultados da avaliação notou-se que o projeto $C$ e o projeto $A$ têm relacionamentos que influenciam na seleção dos projetos. Portanto, o time deverá considerar essa restrição. 


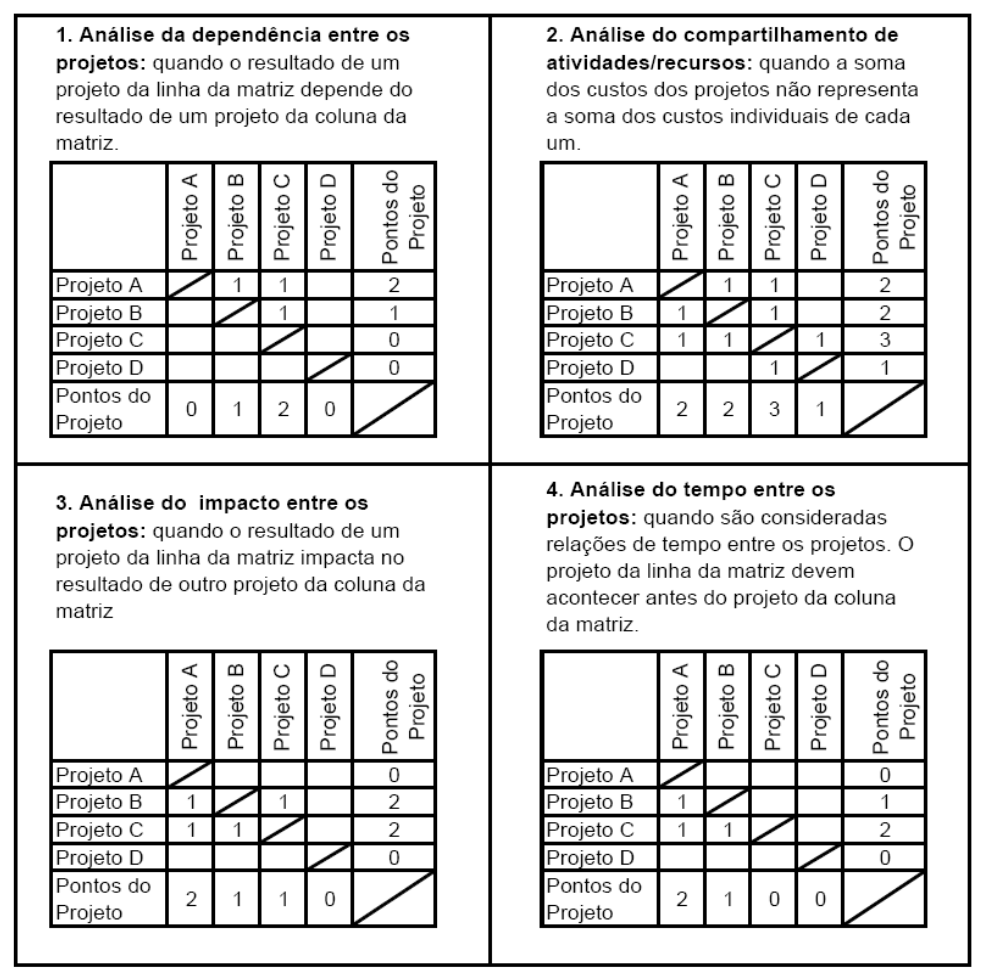

Figura 25 - Análise do relacionamento dos projetos do caso Nanox

\subsection{Atividade 13 - Seleção de projetos de produto para desenvolvimento}

Nesta atividade os participantes do estudo de caso analisaram os projetos classificados para decidir quais seriam selecionados para desenvolvimento pela empresa.

Entre as ferramentas sugeridas pelo método para uso nesta atividade, os membros da empresa notaram que não era preciso usar a ferramenta de cestas de investimento (Figura 19) e a ferramenta de alocação de recursos (Tabela 16). Segundo eles, os investimentos e recursos necessários para os projetos estavam disponíveis e permitiam a realização dos quatro projetos da lista. Da mesma forma, o resultado da análise de relacionamentos não influenciou na escolha dos projetos.

Já com relação à verificação do equilíbrio do portfólio e ao alinhamento com as estratégias, os participantes da empresa seguiram o indicado pelo método. Os resultados mostraram para os membros da empresa as características do portfólio 
que havia sido selecionado. A Figura 26 mostra o gráfico de bolhas para os quatro projetos selecionados.

O resultado final mostra que o portfólio escolhido está localizado em quadrantes de interesse do negócio. Um fator destacado pelo gráfico é o posicionamento quase constante da probabilidade de sucesso dos projetos em uma taxa levemente acima da média, o que poderia indicar algum risco para o negócio. Os projetos $A$ e $D$ estão no $1^{\circ}$ quadrante, que representa os projetos mais interessantes para o negócio, pois têm maior probabilidade de sucesso e maior retorno financeiro. Os projetos $\mathrm{B}$ e C estão no $2^{\circ}$ quadrante, que representa os projetos com maior probabilidade de sucesso e menor retorno financeiro.

A comparação entre o mini-roadmap e o roadmap de planejamento pode ser vista na Figura 27 e na Figura 28, que mostram os membros da empresa em discussão durante a atividade. Essa comparação mostrou que os projetos estavam completamente alinhados com as estratégias do negócio, o que provavelmente é uma consequência dos projetos terem sido propostos a partir de oportunidades já alinhadas com os objetivos do negócio.

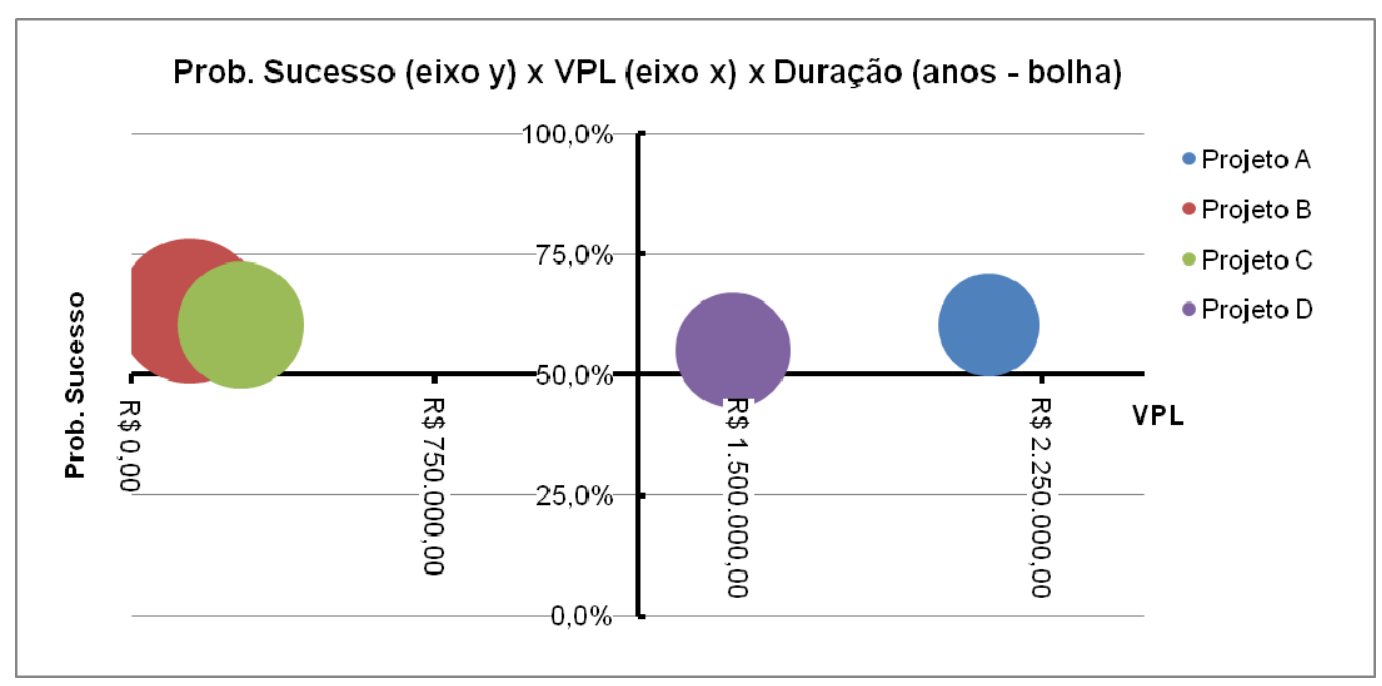

Figura 26 - Gráfico de bolhas dos projetos selecionados do caso Nanox 


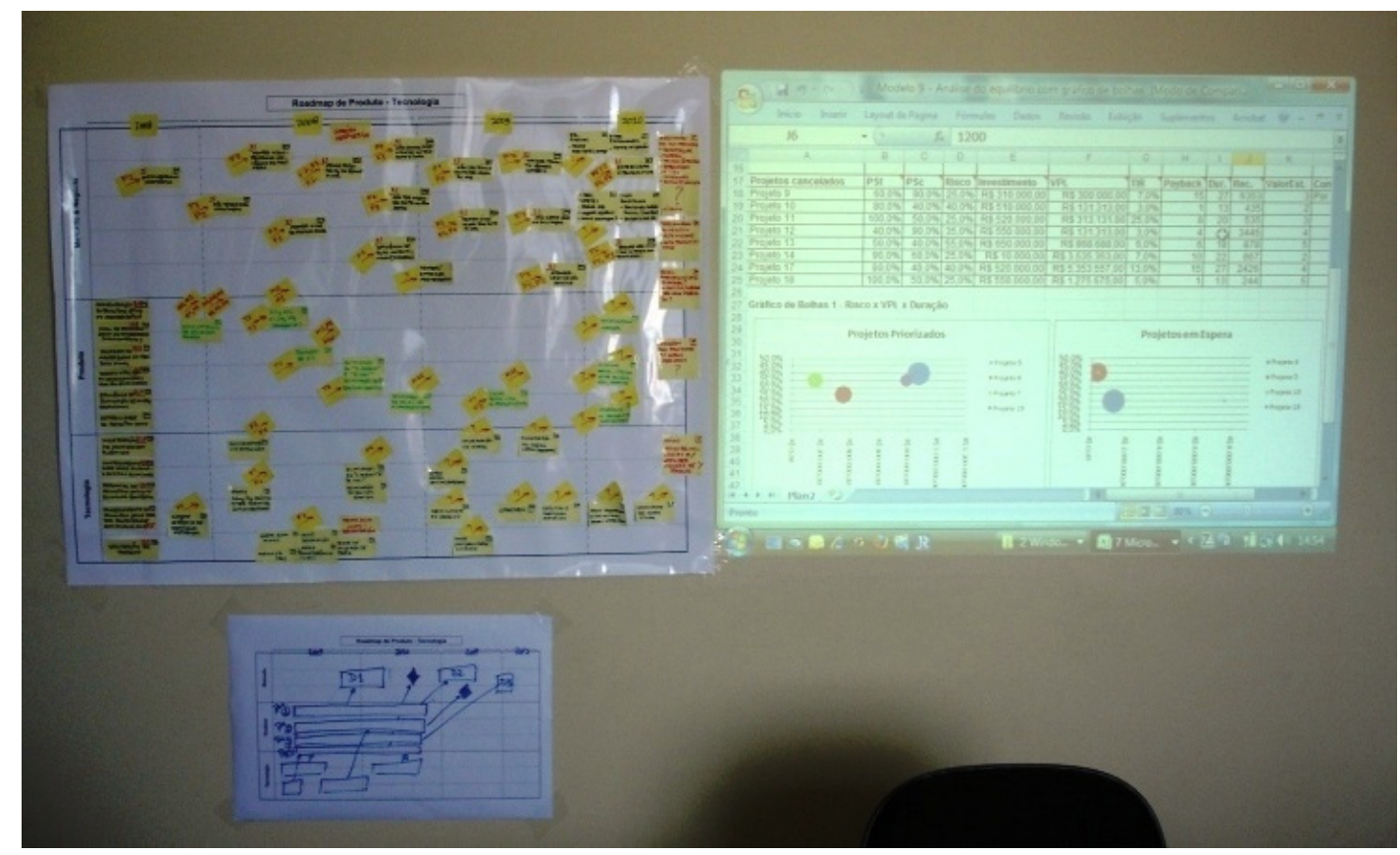

Figura 27 - Comparação entre o mini-roadmap e o roadmap de planejamento

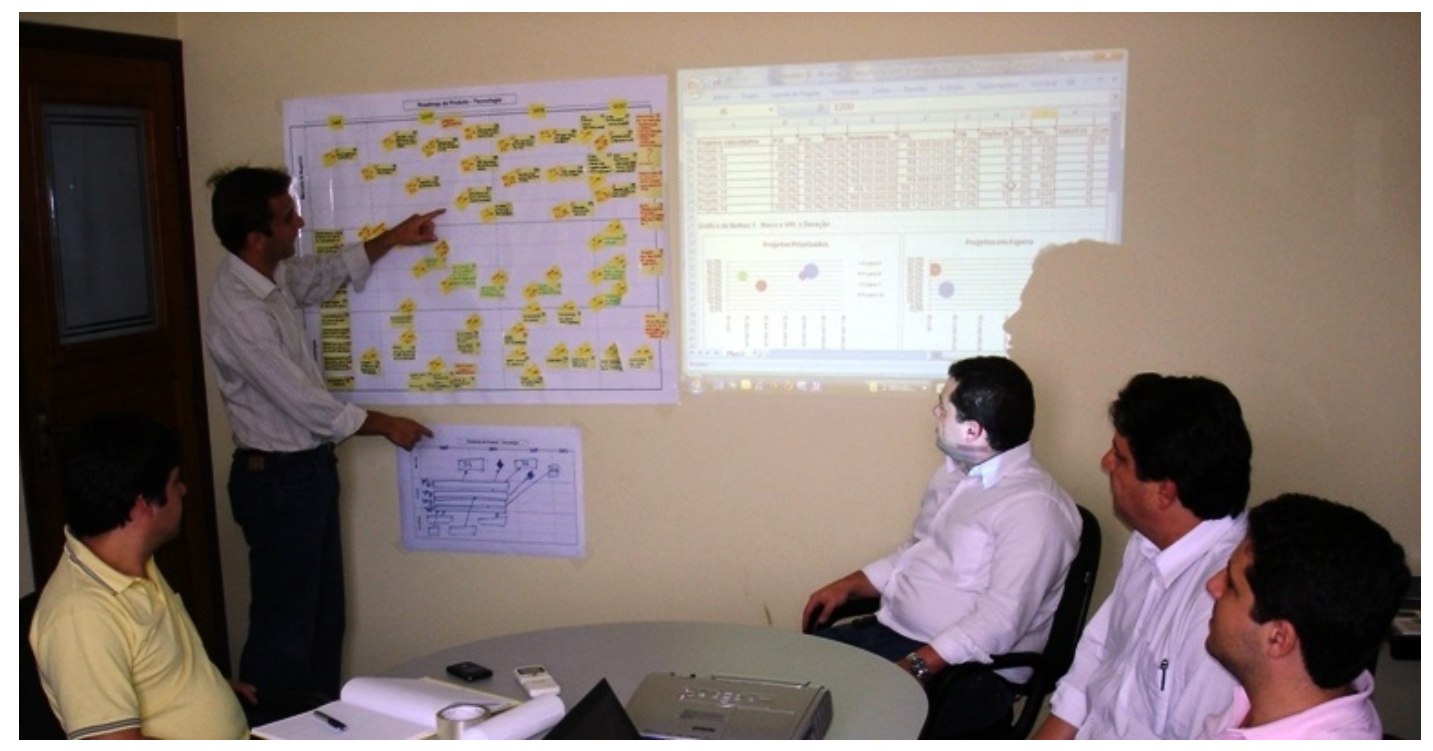

Figura 28 - Membros da empresa durante atividade de seleção de projetos

Por fim, o time decidiu desenvolver os projetos $A, B, C$ e $D$ na próxima fase do processo de desenvolvimento de produtos. 


\subsection{Avaliação dos resultados do estudo de caso}

Esta atividade tem como objetivo avaliar os resultados do estudo de caso para que seja possível ao pesquisador concluir sobre a hipótese da pesquisa. Os resultados apresentados atendem à estratégia de avaliação definida na metodologia de pesquisa.

\subsubsection{Passo 1 - Avaliação anterior ao estudo de caso}

Neste passo foram realizadas entrevistas assistidas pelo pesquisador com os participantes do estudo de caso. O roteiro usado pode ser encontrado no apêndice 9.1 do trabalho. A duração das entrevistas foi de aproximadamente 50 minutos cada.

Devido ao estilo de entrevista aplicada, os resultados obtidos foram qualitativos. $O$ pesquisador encontrou os seguintes resultados durante as entrevistas:

- Questão 1 - Existe um alinhamento das estratégias de produto com as estratégias da empresa, com o mercado, com as tecnologias e com a organização? As respostas mostram que a empresa considera os aspectos de negócio, mercado e tecnologias nas estratégias de produtos.

- Questão 2 - As estratégias de produto possuem metas de aplicação? Os participantes afirmaram em suas respostas que existem metas para seus produtos, mas elas não estavam formalizadas.

- Questão 3 - As idéias de novos produtos são aproveitadas na proposição de novos projetos de produtos? Segundo o resultado das entrevistas, as idéias são aproveitadas esporadicamente. Por meio dos comentários o pesquisador verificou que não existe um procedimento que auxilia nessa tarefa.

- Questão 4 - A organização sabe quais as informações mínimas necessárias para se propor o projeto/conceito de um novo produto? Os entrevistados mostram 
que a empresa tem uma idéia das informações necessárias, porém esse conhecimento está implícito na organização.

- Questão 5 - As informações usadas na avaliação dos projetos são consideradas confiáveis? As respostas obtidas nessa questão indicam grande confiança da empresa na avaliação dos projetos. Um dos motivos é que os próprios clientes são os fornecedores das informações usadas na avaliação dos projetos.

- Questão 6 - Quais tipos de avaliações são aplicados nos projetos? Os entrevistados mostraram uma diversificação das avaliações usadas, mas com uma tendência para a avaliação financeira. Um detalhe interessante comentado foi o direcionamento da avaliação em função do tipo de projeto.

- Questão 7 - Existe um procedimento para definição do portfólio de projetos de produto? As respostas e os comentários indicam a presença de um procedimento informal para a definição do portfólio de projetos de produtos. Os entrevistados afirmaram que esse procedimento era sempre seguido pela empresa.

- Questão 8 - Quais objetivos são buscados na definição do portfólio de projetos de produto? As respostas mostram que a empresa considera os quatro objetivos da gestão de portfólio na seleção dos seus projetos. Entre eles pode-se notar uma pequena tendência para o objetivo voltado para o alinhamento com a estratégia.

- Questões 9 - Qual a expectativa da organização sobre a taxa de sucesso comercial dos projetos de produto? As respostas dos entrevistados indicam uma expectativa de probabilidade de sucesso comercial alta para os projetos de produtos desenvolvidos pela empresa.

- Questão 10 - Qual a expectativa da organização sobre a taxa de sucesso técnico dos projetos de produto? Assim como para a probabilidade de sucesso 
comercial, as respostas mostram uma expectativa de probabilidade de sucesso técnica alta para os projetos de produtos desenvolvidos pela empresa.

- Questão 11 - Existe a comunicação das estratégias de produto para a organização? Os entrevistados afirmaram que existia uma comunicação parcial das estratégias da empresa, que tinha como objetivo alinhar os funcionários com os objetivos do negócio.

O pesquisador também realizou uma verificação dos documentos da empresa relacionados às atividades do pré-desenvolvimento do PDP. No entanto não foram encontrados indícios que mostrassem resultados diferentes dos identificados com as entrevistas.

\subsubsection{Passo 2 - Avaliação posterior ao estudo de caso}

Neste passo o pesquisador entrevistou os participantes após a conclusão do estudo de caso, seguindo o roteiro apresentado no apêndice 9.2. Diferentemente das entrevistas iniciais, essas avaliaram a melhoria que os participantes sentiram na realização das atividades do pré-desenvolvimento.

Além da avaliação da melhoria do pré-desenvolvimento, as entrevistas verificaram quais atividades foram apoiadas pelo technology roadmapping e pela gestão de portfólio. Na Figura 29, Figura 30 e Figura 31 são apresentadas as respostas assinaladas pelos entrevistados. A escala do gráfico representa o número de vezes que cada resposta foi escolhida. 


\section{Avaliação da contribuição do technology roadmapping}

Plano inicial projeto

Avaliação final

Avaliação técnica

Avaliação comercial

Pré-avaliação

Definir conceito/idéia

Analisar oportunidade

Definir time idéias

Criar estratégia

Selecionar oportunidades

Avaliar oportunidades

Classificar oportunidades

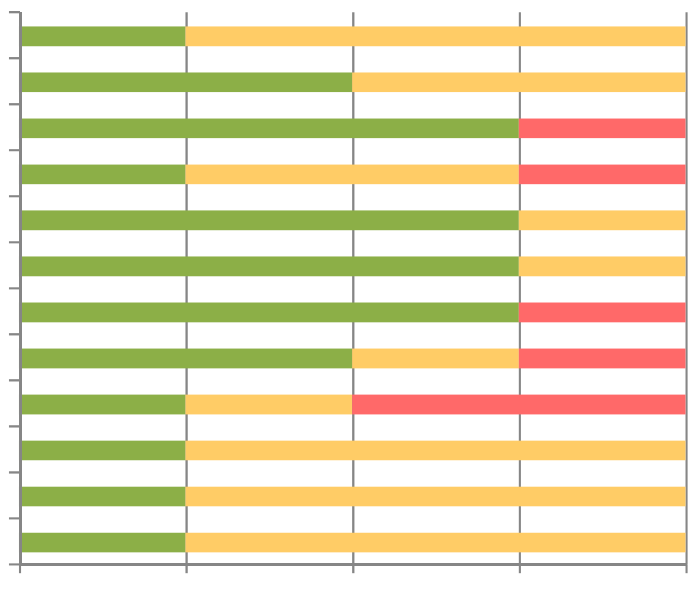

- Contribui claramente

Contribui indiretamente

- Não contribui

0

1

2

3

4

Figura 29 - Contribuição do technology roadmapping nas atividades do pré-desenvolvimento

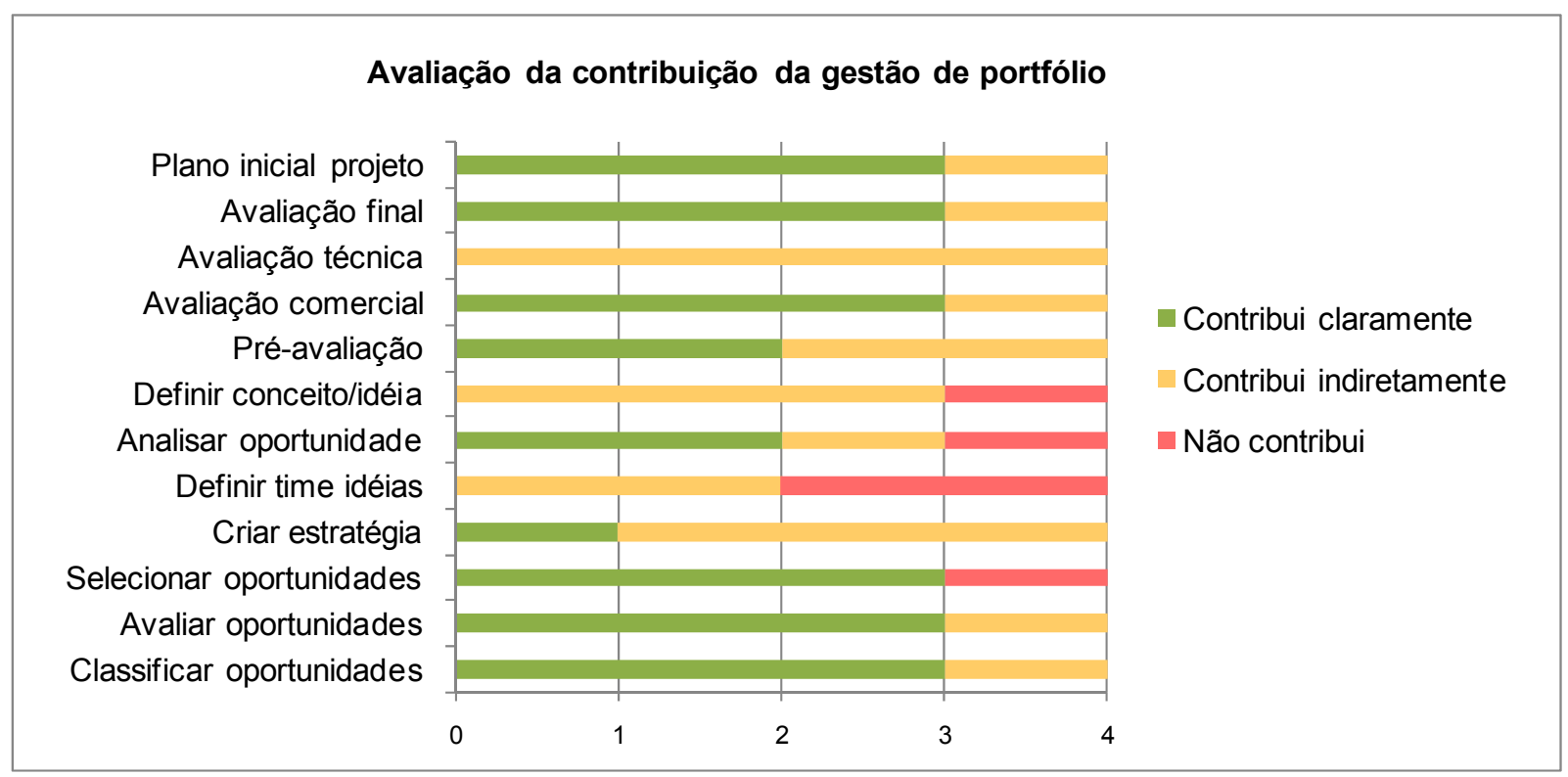

Figura 30 - Contribuição da gestão de portfólio nas atividades do pré-desenvolvimento 


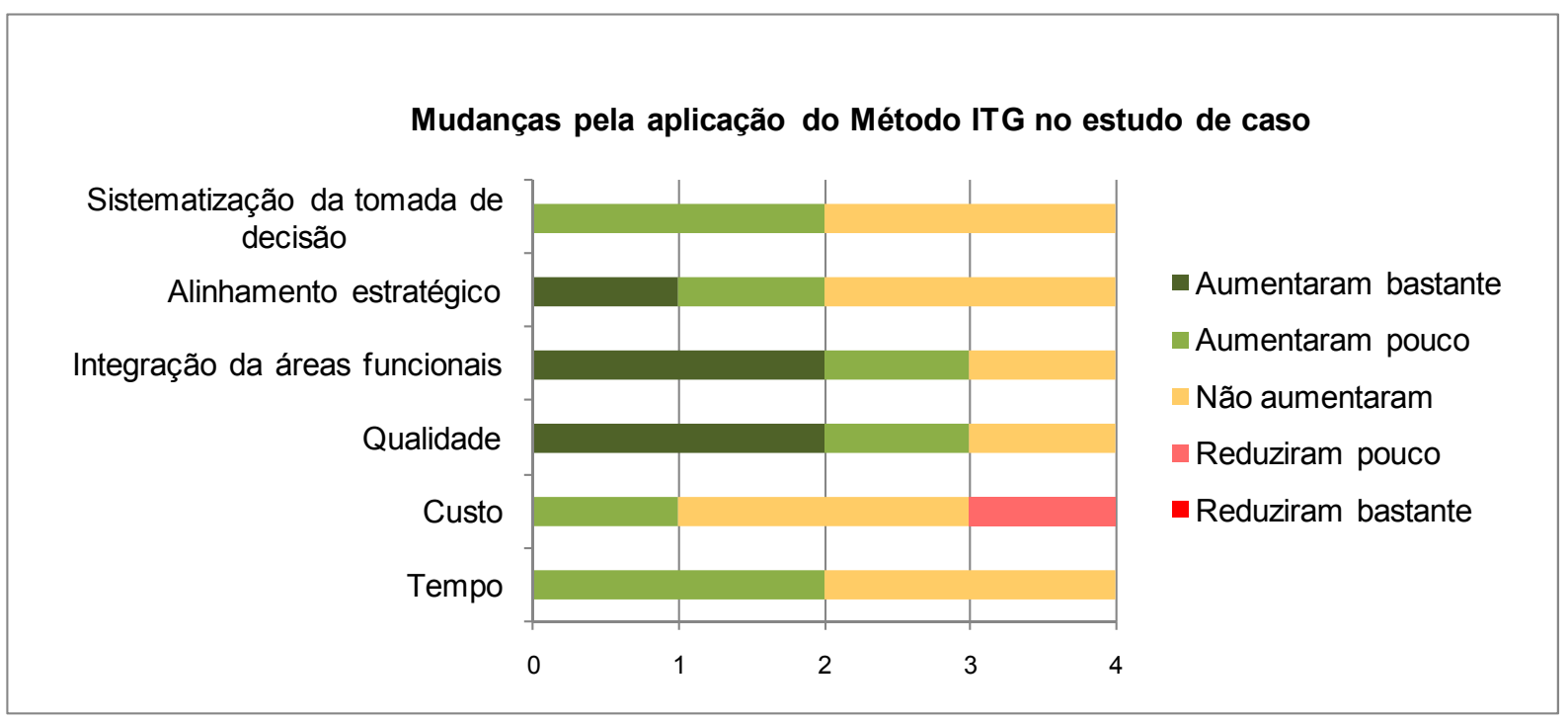

Figura 31 - Mudanças ocasionadas pelo método nas atividades do pré-desenvolvimento ${ }^{9}$

A seguir são descritos os resultados de cada questão em função das respostas assinaladas e dos comentários dos participantes:

- Questão 1 - Qual a contribuição dos métodos aplicados no estudo de caso para a realização de cada atividade do pré-desenvolvimento? As respostas apresentadas na Figura 29 para o TRM e na Figura 30 para a gestão de portfólio mostram que os métodos contribuem para a realização das atividades do prédesenvolvimento. Além disso, é possível notar uma complementaridade entre eles, o confirma uma vantagem para a integração.

- Questão 2 - Os métodos aplicados no estudo de caso aumentaram ou reduziram o tempo padrão da empresa na realização das atividades do prédesenvolvimento? Por quê? Os resultados indicam um aumento no tempo de realização das atividades do pré-desenvolvimento. Esse pode ser conseqüência da

${ }^{9} \mathrm{O}$ aumento dos indicadores de custo e tempo representa uma mudança desfavorável para o pré-desenvolvimento. Ao contrário dos outros indicadores, para os quais o aumento significa uma melhoria. 
sistematização das atividades, uma vez que com a aplicação do método o time passou a aplicar um conjunto estruturado de ferramentas que não eram utilizadas anteriormente. Essas ferramentas tomaram maior tempo dos participantes quando comparado com a situação inicial, contudo os resultados obtidos com a aplicação das ferramentas contribuíram para a melhoria das atividades e, portanto justificam o aumento do tempo.

- Questão 3 - Os métodos aplicados no estudo de caso aumentaram ou reduziram o custo padrão da empresa na realização das atividades do prédesenvolvimento? Por quê? Como não foi medido o tempo de participação de cada membro na situação inicial e na situação final, torna-se difícil afirmar precisamente a alteração de custo. Tomando como base o crescimento do tempo gasto para realização das atividades, consequentemente o custo aumentou. Todavia os participantes comentaram que a sistematização das atividades e a disponibilização de ferramentas melhoraram a eficiência das atividades. Isto significa que na situação inicial os resultados obtidos tinham menor valor agregado do que os resultados alcançados após a aplicação do método. Assim eles concluíram que o aumento dos custos ocasionado pelo aumento de tempo era compensado pelo aumento do valor agregado nas atividades, o que permitia afirmar que os custos ficaram inalterados. A média das respostas confirma essa percepção dos participantes, já que indica a não alteração dos custos de realização das atividades.

- Questão 4 - Os métodos aplicados no estudo de caso aumentaram ou reduziram a qualidade da empresa na realização das atividades do prédesenvolvimento? Por quê? Os entrevistados mostraram em suas respostas um crescimento da qualidade. Com a aplicação do método o time passou a utilizar 
conceitos e ferramentas aprimorados e consequentemente obteve um aumento na qualidade de suas atividades.

- Questão 5 - Os métodos aplicados no estudo de caso aumentaram ou reduziram a integração das áreas funcionais na realização das atividades do prédesenvolvimento? Por quê? As respostas indicam um aumento na integração das áreas funcionais. Essa mudança pode ser conseqüência da forma de aplicação do método, que depende da participação de um time multifuncional para a realização das atividades e tomadas de decisão. Além disso, durante a dinâmica das reuniões do time cria-se uma oportunidade de discussão e alinhamento dos interesses das áreas funcionais, o que também colabora com a integração.

- Questão 6 - Os métodos aplicados no estudo de caso aumentaram ou reduziram o alinhamento dos novos projetos de produto com as estratégias do negócio na realização das atividades do pré-desenvolvimento? Por quê? As respostas dos entrevistados mostram um aumento do alinhamento estratégico dos projetos. Essa percepção de melhoria é consequência dos momentos em que o método analisa as estratégias do negócio e verifica o alinhamento estratégico dos projetos. Com isso o time consegue ter uma maior segurança que os projetos selecionados atendem às estratégias do negócio.

- Questão 7 - Os métodos aplicados no estudo de caso aumentaram ou reduziram a sistematização da tomada de decisão nas atividades do prédesenvolvimento? Por quê? Os resultados obtidos nas entrevistas apresentam um aumento na sistematização da tomada de decisão das atividades do prédesenvolvimento. Esse pode ser resultado da disponibilização de um procedimento e de ferramentas para auxiliar nas atividades. 
- Questão 8 - O estudo de caso causou alguma mudança em como a empresa define as estratégias (caminhos) para os seus novos produtos? Se sim, qual a mudança? Se não, a empresa vê possibilidades para aproveitar os conhecimentos aplicados? Segundo os entrevistados ocorreram várias mudanças na empresa resultantes do estudo de caso. A principal mencionada por eles é a programação de investimentos em projetos de avaliação de novas oportunidades para o negócio.

- Questão 9 - O estudo de caso causou alguma mudança em como a empresa trata a criação e gerenciamento das idéias/conceitos de novos produtos? Se sim, qual a mudança? Se não, a empresa vê possibilidades para aproveitar os conhecimentos aplicados? As respostas dos entrevistados mostram como principal mudança a maneira como a empresa analisava os seus novos produtos. Eles acreditam que os produtos propostos atenderão melhor ao mercado, às estratégias e às tecnologias.

- Questão 10 - O estudo de caso causou alguma mudança em como a empresa gerencia a introdução de projetos de novos produtos no portfólio de projetos em andamento? Se sim, qual a mudança? Se não, a empresa vê possibilidades para aproveitar os conhecimentos aplicados? Os entrevistados mostraram que a empresa conheceu novas alternativas para realizar a gestão do portfólio de novos projetos de produtos. Contudo os participantes afirmaram que essas novas alternativas não causaram modificações na forma como a empresa realiza essa atividade no momento.

- Questão 11 - Quais foram os pontos fortes e fracos identificados com relação aos métodos (atividades e ferramentas) usados no estudo de caso? Os entrevistados mencionaram como pontos fortes do método a simplicidade das 
ferramentas usadas e o curto período de tempo necessário para sua aplicação. Entre os pontos fracos eles destacaram a disponibilização de ferramentas que auxiliassem na análise de mercado, o que pode indicar a necessidade de complementar o método com novas ferramentas.

- Questão 12 - Quais foram os principais benefícios do estudo de caso para a organização e quais foram as principais dificuldades enfrentadas para sua realização? Com relação aos benefícios, os entrevistados mostraram que o estudo de caso trouxe o início de uma mudança cultural na empresa. Ele forneceu um aprendizado sobre como planejar e selecionar de uma maneira mais adequada os projetos de produtos. Com relação às dificuldades notaram-se: a necessidade de auxílio externo para a aplicação do método, indisponibilidade de tempo dos participantes e a novidade do tema. 


\section{Conclusões da pesquisa}

A pesquisa estudou inicialmente o technology roadmapping, a gestão de portfólio e o pré-desenvolvimento do PDP, e com as informações adquiridas desenvolveu um método de aplicação integrada do technology roadmapping e da gestão de portfólio. Esse método foi aplicado em uma pequena empresa de base tecnológica por meio de estudo de caso. Os dados coletados em entrevistas com os participantes desse caso permitiram analisar os efeitos da sua aplicação na macrofase de pré-desenvolvimento do PDP da empresa estudada.

Este trabalho primeiramente concluiu que a hipótese de pesquisa: "a aplicação integrada do technology roadmapping e da gestão de portfólio contribui para a realização das atividades do pré-desenvolvimento" é válida. No restante desse capítulo são enunciadas as outras conclusões do trabalho.

Os resultados da avaliação realizada na empresa, antes do estudo de caso, mostraram que ela não possuía um processo padrão que especificasse quais e como as atividades do pré-desenvolvimento deveriam ser realizadas. No entanto, as respostas dos participantes evidenciaram a existência informal e ineficaz das três principais fases desse macro-processo descritas por Crawford e Benedetto (2006), que são: identificação e seleção de oportunidades de produtos, geração de conceitos de produtos, e avaliação de conceito e projeto de produto.

A avaliação realizada após o estudo de caso indica uma contribuição positiva da aplicação integrada do technology roadmapping e da gestão de portfólio. Foram analisados cinco indicadores das atividades do pré-desenvolvimento: tempo, custo, qualidade, integração funcional e sistematização da tomada de decisão. A média das respostas obtidas nas entrevistas com os participantes mostra uma melhoria de quatro indicadores: tempo, qualidade, integração funcional e sistematização da 
tomada de decisão; e uma constância do indicador de custo quando comparado com a situação inicial.

A percepção do pesquisador mostrou que a melhoria alcançada nesses indicadores deve ser consequência da utilização de ferramentas e conceitos com potencial já reconhecido na literatura e organizados em um procedimento claro de aplicação. Além disso, o uso de um grupo multifuncional, como premissa para a aplicação do método, contribui diretamente para a qualidade, integração funcional e comunicação dos resultados.

Outro fator positivo foi a realização das três fases do pré-desenvolvimento, o que criou um fluxo desde as oportunidades de produtos definidas por meio do technology roadmapping até seleção de projetos de produtos apoiada pela gestão de portfólio. Além do fluxo entre as fases do pré-desenvolvimento, a construção de propostas de projetos de produtos embasadas nas estratégias do negócio, nas necessidades do mercado e nas capacidades tecnológicas colaborou para uma melhor expectativa de sucesso técnico e comercial dos projetos, e para o alinhamento dos projetos com a estratégia.

Sobre o indicador de custo, a constância notada parece ser consequência do aumento do valor agregado e da eficiência das atividades feitas, o que está relacionado com a sistematização das atividades e o uso de ferramentas e conceitos apropriados.

$\mathrm{Na}$ revisão da literatura, notou-se que os trabalhos de Lee et al. (2008) e Albright e Nelson (2002) já haviam indicado um potencial do technology roadmapping para ajudar na seleção e planejamento do portfólio de produtos. No entanto, esses trabalhos não abordaram os conceitos da gestão de portfólio para complementar o uso do technology roadmapping no planejamento do portfólio de 
projetos, mas sim aplicam o TRM como uma abordagem alternativa para o planejamento do portfólio. Dessa forma, essa pesquisa traz uma contribuição evidente para o preenchimento de uma lacuna existente nos trabalhos científicos.

É importante destacar a ligação existente entre o resultado alcançado pelo trabalho e o contexto no qual foi realizado o estudo de caso. A pequena empresa de base tecnológica representa um ambiente com uma maior proximidade entre os níveis organizacionais e áreas funcionais, uma vez que um mesmo empregado pode ter responsabilidades que permeiam essas divisões. Essa característica auxiliou a aplicação integrada dos métodos, pois foi possível envolver no time pessoas com visão holística do negócio e ao mesmo tempo responsáveis pela realização das atividades do pré-desenvolvimento. Portanto, o resultado positivo encontrado com a aplicação integrada do technology roadmapping com a gestão de portfólio pode ter relação com essa característica organizacional da empresa onde foi realizado o estudo de caso.

Como o produto considerado na aplicação do método é um produto químico, o seu desenvolvimento está fortemente relacionado com tecnologias de processamento, que são as responsáveis por gerar o produto final a partir das matérias primas. Nesse sentido, os resultados obtidos com a aplicação do método neste trabalho repercutem para um caso específico relacionado com o desenvolvimento de produtos químicos. Assim, a aplicação do método em outros tipos de produtos industrializados pode trazer contribuições diferentes das encontrados nesse trabalho.

Além das limitações relacionadas com o tipo de organização e com o tipo de produto, a situação inicial da empresa na realização das atividades do prédesenvolvimento também pode restringir a abrangência dos resultados da pesquisa. 
Neste caso, segundo a avaliação do pesquisador, o pré-desenvolvimento da empresa estudada era ineficaz, não possuía um processo estabelecido e não tinha uma comunicação formal dos seus resultados. Porém, como a quantidade de empresas com essas características é alta, esses resultados têm um grande potencial de exploração. Por exemplo, existem muitas pequenas empresas de base tecnológica localizadas na região de São Carlos com características similares, nas quais o método poderia ser aproveitado. Mesmo assim, deve-se relembrar que os resultados desse trabalho são fruto de um único estudo de caso e, portanto, não existe a intenção de generalização.

A aplicação integrada do technology roadmapping e da gestão de portfólio realizada nesse trabalho considerou superficialmente os aspectos relacionados com o planejamento de novas tecnologias. Esse fato reflete o escopo da macro-fase de pré-desenvolvimento do PDP mostrado por Crawford e Benedetto (2006), que considera as informações das tecnologias, mas não tem como objetivo planejar o desenvolvimento ou aquisição das tecnologias usadas nos produtos.

Além disso, a pequena empresa de base tecnológica, onde o método foi aplicado, tinha como objetivo desenvolver produtos a partir das tecnologias disponíveis, ou seja, sua estratégia atual estava focada no Technology-Push. Portanto o estudo de caso desconsiderou os aspectos relacionados com o planejamento de novas tecnologias, que provavelmente estaria mais aparente em uma estratégia Market-Pull, na qual o mercado indica as necessidades dos novos produtos e suas tecnologias.

Devido ao potencial presente no technology roadmapping para contribuir com o planejamento das novas tecnologias, nota-se que esse trabalho não usufruiu plenamente dos benefícios da aplicação integrada do technology roadmapping e da 
gestão de portfólio, visto que ele desconsiderou o planejamento de novas tecnologias durante a aplicação do método na empresa estudada. Contudo, também se entende que para a inclusão do planejamento de novas tecnologias de maneira adequada dever-se-ia realizar a aplicação integrada do technology roadmapping e da gestão de portfólio no planejamento estratégico do processo de inovação da empresa, o qual envolve tanto o processo de desenvolvimento de produtos quanto o processo de desenvolvimento de tecnologias. Dessa forma seria possível ter entradas de novos projetos de produto e de tecnologia para o processo de inovação a partir da aplicação do método.

O pesquisador sugere para trabalhos futuros:

- A realização de outros estudos de caso em empresas com características organizacionais e produtos diferentes. Dessa forma seria possível avaliar o potencial da aplicação integrada do technology roadmapping e da gestão de portfólio em empresas onde as barreiras organizacionais existentes, principalmente entre a engenharia e vendas, são maiores.

- A investigação do impacto da aplicação integrada do technology roadmapping e da gestão de portfólio no planejamento de produtos diferentes do considerado neste trabalho, que foi um produto químico.

- A aplicação integrada do technology roadmapping e da gestão de portfólio para contribuir com o planejamento estratégico da inovação. Dessa forma seria investigado o potencial da aplicação dos métodos para auxiliar no planejamento das tecnologias e dos produtos. Além disso, os resultados poderiam ajudar no esclarecimento dos relacionamentos existentes entre 0 processo de desenvolvimento de produtos (PDP) e o processo de desenvolvimento de 
tecnologias (PDT), que é considerado pelos estudos acadêmicos um tema ainda obscuro.

- A análise de outros métodos complementares ao technology roadmapping e à gestão de portfólio que poderiam ser integrados para auxiliar na realização do prédesenvolvimento. Dentre eles pode-se destacar a gestão de idéias, pois esse poderia contribuir para a parte central da macro-fase de pré-desenvolvimento, a definição de idéias e conceitos de novos projetos de produtos, que foi superficialmente apoiada pelos métodos integrados neste trabalho. 


\section{Bibliografia}

ALBRIGHT, R. E.; KAPPEL, T. A. Technology roadmapping: roadmapping the corporation. Research Technology Management, v.46, n.2, p.31-40, 2003.

ALBRIGHT, R. E; NELSON, B. Product and technology mapping tools for planning and portfolio decision making. In: BELLIVEAU, P.; GRIFFIN, A.; SOMERMEYER, S. The PDMA Toolbook 2 for new product development. New York: John Wiley \& Sons, 2004. Capítulo 15.

ARCHER, N.; GHASEMZADEH, F. Integrated framework for project portfolio selection. International Journal of Project Management, v.17, n.4, p.207-216, 1999.

BITMAN, W. R. R\&D portfolio management framework for sustained competitive advantage. In: IEEE INTERNATIONAL ENGINEERING MANAGEMENT CONFERENCE, 2005, pp.775 - 779.

CHENG, L. Caracterização da Gestão de Desenvolvimento do Produto: Delineando o seu Contorno e Dimensões Básicas. In: CONGRESSO BRASILEIRO DE GESTÃO DE DESENVOLVIMENTO DE PRODUTOS, 2, 2000, São Carlos. Anais... São Carlos: USP, 2000.

CHIEN, C. A portfolio evaluation framework for selecting R\&D projects. R\&D Management, v.32, n.4, p.359-368, 2002.

CLARK, K. B.; FUJIMOTO, T. Product development performance: strategy, organization, and management in the world auto industry. Boston, Mass.: Harvard Business School Press, 1991.

CLARK, K. B.; WHEELWRIGHT, S. C. Managing new product and process development. New York: The Free Press, 1993.

CLAUSING, D. Total Quality Development. New York: ASME Press, 1994.

COOPER, R. G.; EDGETT, S. J.; KLEINSCHMIDT, E. J. Benchmarking best NPD practices - II. Research Technology Management, v.47, n.3, p.50-59, 2004.

COOPER, R. G.; EDGETT, S. J.; KLEINSCHMIDT, E. J. Portfolio Management: fundamental for new product success. In: BELLIVEAU, P.; GRIFFIN, A.; SOMERMEYER, S. The PDMA Toolbook for new product development. New York: John Wiley \& Sons, 2002.

COOPER, R. G. Winning at new products. Cambridge, Massachusetts: Perseus Pub, 1993. 2ed.

COOPER, R. G. Winning at new products. Cambridge, Massachusetts: Perseus Pub, 2001. 3ed.

COOPER, R. G.; EDGETT, S. J.; KLEINSCHMIDT, E. J. Portfolio management for new products. Cambridge, Massachusetts: Perseus Books, 1998.

COOPER, R. G.; EDGETT, S. J.; KLEINSCHMIDT, E. J. Portfolio management for new products. Cambridge, Massachusetts: Perseus Books, 2001. 2ed.

CRAWFORD, M.; BENEDETTO, A. D. New Products Management. 8.ed. New York: McGraw-Hill//rwin, 2006. 
DANILEVICZ, A. M. F. Modelo para condução de decisões estratégicas associadas ao gerenciamento da inovação em produtos. 2006. Tese (Doutorado em Engenharia de Produção) - Programa de Pós-Graduação em Engenharia de Produção, UFRGS, Porto Alegre.

DAVIS, J. et al. Determining a project's probability of success. Research Technology Management, v.44, n.3, p.51-57, 2001.

GARCIA, M. L.; BRAY, O. H. Fundamentals of Technology Roadmapping. Sandia National Laboratories, 1997. Disponível em: < http://www.sandia.gov/PHMCOE/pdf/Sandia\%27sFundamentalsofTech.pdf >. Acessado em 1 julho 2008.

GIL, A. C. Métodos e técnicas de pesquisa social. São Paulo: Atlas, 1999.

GIL, B.; NELSON, B.; SPRING, S. Seven steps to strategic new product development. In: ROSENAU, M. D. The PDMA Handbook for new product development. New York: John Wiley \& Sons, 1996.

GRIFFIN, A. PDMA research on new product development practices: updating trends and benchmarking best practices. Journal of Product Innovation Management, v.14, n.6, p.429-458, 1997.

JETTER, A. Educating the guess: strategies, concepts and tools for the fuzzy front end of product development. In: PORTLAND INTERNATIONAL CONFERENCE ON MANAGEMENT OF ENGINEERING AND TECHNOLOGY, 2003, p.261-273.

KAPPEL, T. A. Perspectives on roadmaps: how organizations talk about the future. Journal of Product Innovation Management. v.18, n.1, p.39-50, 2001.

KOEN, P. A. et al. Fuzzy Front End: Effective Methods, Tools and Techniques. In: BELLIVEAU, P.; GRIFFIN, A.; SOMERMEYER, S. The PDMA Toolbook for new product development. New York: John Wiley \& Sons, 2002.

KOSTOFF, R.; SCHALLER, R. Science and technology roadmaps. IEEE Transactions on Engineering Management, v.48, n.2, p.132-143, 2001.

LEE, S.; KANG, S.; PARK, E.; PARK, Y. Applying technology road-maps in project selection and planning. International Journal of Quality \& Reliability Management, v.25, n.1, p.39-51, 2008. 2005.

LEVINE, H. A. Project portfolio management. San Francisco: Jossey-Bass,

MCDONOUGH III, E. F.; SPITAL, F. C. Managing project portfolios. Research Technology Management, v.46, n.3, p.40-46, 2003.

OLIVEIRA, M. G.; ROZENFELD, H. Desenvolvimento de um modelo para priorizar projetos de desenvolvimento de produtos. In: CONGRESSO BRASILEIRO DE GESTÃO DE DESENVOLVIMENTO DE PRODUTOS, 6, 2007. Anais... Belo Horizonte: UFMG, 2007.

OLIVEIRA, M. G; FONZI, W; AMARAL, D. C. Technology Roadmapping (TRM): barreiras para aplicação em uma pequena empresa. In: SIMPÓSIO DE ENGENHARIA DE PRODUÇÃO, 14, 2007. Anais... Bauru: UNESP, 2007.

PHAAL, R. Technology roadmapping - A planning framework for evolution and revolution. Technological Forecasting and Social Change, v.71, n.1-2, p.5-26, 2004. 
PHAAL, R.; FARRUKH, C.; PROBERT, D. T-Plan: fast start to technology roadmapping. UK: Cambridge University - Institute of Manufacturing, 2001.

PHAAL, R.; FARRUKH, C.; PROBERT, D. Developing a technology roadmapping system. In: PORTLAND INTERNATIONAL CONFERENCE ON MANAGEMENT OF ENGINEERING AND TECHNOLOGY, 2005, p.99-111.

PRASAD, B. Concurrent engineering fundamentals. Upper Sadle River: Prentice Hall, 1996.

PROBERT, D.; RADNOR, M. Technology roadmapping: Frontier experiences from industry-academia consortia. Research Technology Management, v.46, n.2, p.27-30, 2003.

REBELATTO, D. Projeto de investimento. Barueri: Manole, 2004.

ROSA, C. A. Como elaborar um plano de negócios. Brasília: SEBRAE, 2007.

ROZENFELD, $H$. et al. Gestão de desenvolvimento de produtos: uma referência para a melhoria do processo. São Paulo: Saraiva, 2006.

SEBRAE. Comece certo: consultoria. São Paulo: SEBRAE, 2005.

SILVA, E. L.; MENEZES, E. M. Metodologia da pesquisa e elaboração de Dissertação. Florianópolis: UFSC, 2005. Disponível em: <http://www.ufsc.br>. Acesso em: 18 mar. 2007.

STRAUSS, J. D.; RADNOR, M. Roadmapping for dynamic and uncertain environments. Research Technology Management, v.47, n.2, p.51-57, 2004.

VOSS, C.; TSIKRIKTSIS, N.; FROHLICH, M. Case research in operations management. International Journal of Operations \& Production Management, v.22, n.2, p.195-219, 2002.

YIN, R. K. Estudo de caso: planejamento e métodos. Porto Alegre: Bookman, 2005. 3ed.

WILLYARD, C. H.; MCCLEES, C. W. Motorola's Technology Roadmap Process. Research Management, v.30, n.5, p.13-19, 1987. 


\section{Apêndice}

\subsection{Roteiro da entrevista inicial}

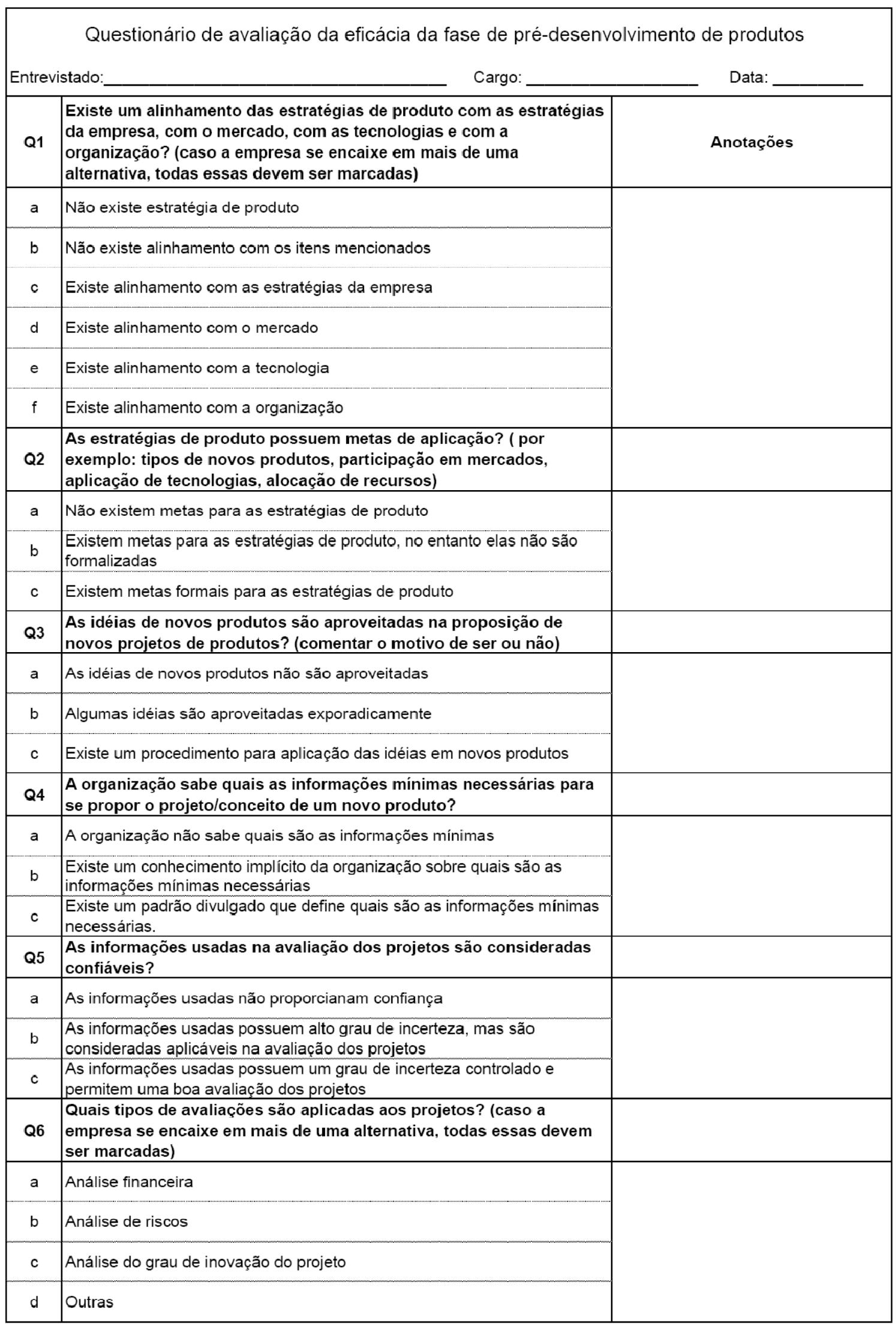




\begin{tabular}{|c|c|}
\hline Q7 & $\begin{array}{l}\text { Existe um procedimento para definição do portfólio de projetos de } \\
\text { produto? }\end{array}$ \\
\hline a & Não existe um procedimento \\
\hline b & Existe um procedimento informal \\
\hline c & Existe um procedimento formal \\
\hline Q8 & $\begin{array}{l}\text { Quais objetivos são buscados na definição do portfólio de projetos de } \\
\text { produto? (caso a empresa se encaixe em mais de uma alternativa, } \\
\text { todas essas devem ser marcadas) }\end{array}$ \\
\hline a & Maximização do valor do portfólio \\
\hline b & Equilíbrio dos projetos do portfólio \\
\hline c & Alinhamento com as estratégias de produto \\
\hline$d$ & Alocação eficiente de recursos \\
\hline e & Outros \\
\hline Q9 & $\begin{array}{l}\text { Qual a expectativa da organização sobre a taxa de sucesso comercial } \\
\text { dos projetos de produto? }\end{array}$ \\
\hline a & Baixa expectativa (até $10 \%$ dos projetos) \\
\hline b & Moderada expectativa (de $11 \%$ a $40 \%$ ) \\
\hline c & Boa expectativa (de $41 \%$ a $70 \%$ ) \\
\hline$d$ & Alta expectativa (acima de $71 \%$ ). \\
\hline Q10 & $\begin{array}{l}\text { Qual a expectativa da organização sobre a taxa de sucesso técnico } \\
\text { dos projetos de produto? }\end{array}$ \\
\hline a & Baixa expectativa (até $10 \%$ dos projetos) \\
\hline b & Moderada expectativa (de $11 \%$ a $40 \%$ ) \\
\hline c & Boa expectativa (de $41 \%$ a $70 \%$ ) \\
\hline$d$ & Alta expectativa (acima de $71 \%$ ). \\
\hline Q11 & Existe a comunicação das estratégias de produto para a organização? \\
\hline a & As estratégias de produto não são comunicadas \\
\hline b & As estratégias de produtos são comunicadas parcialmente \\
\hline c & As estratégias de produtos são totalmente comunicadas \\
\hline
\end{tabular}




\subsection{Roteiro da entrevista final}

\section{Roteiro para entrevista Projeto ITG Nanox}

\section{I) Avaliação da contribuição dos métodos para o pré-desenvolvimento}

1. A figura 1 apresenta as principais atividades da macro-fase de pré-desenvolvimento, segundo o modelo de Crawford e Benedetto (2006). Qual a contribuição dos métodos aplicados no estudo de caso para a realização de cada atividade? Marque, seguindo a escala abaixo, as respostas no campo reservado ao lado das atividades. Explique o porquê das respostas escolhidas. Legenda: GPf = gestão de portfólio.

(a) contribui claramente; (b) contribui indiretamente; (c) não contribui.

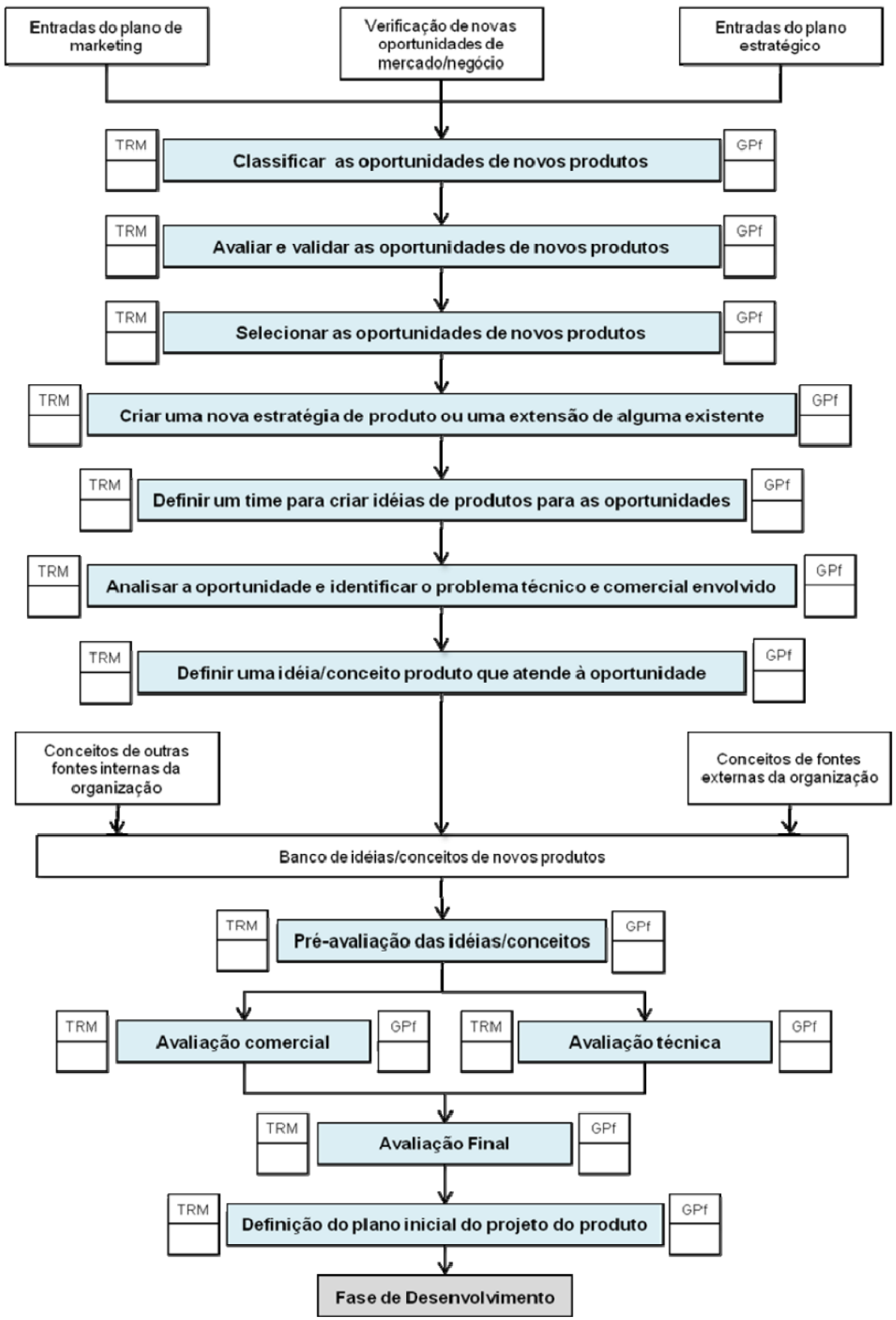

Figura 1 - Atividades da macro-fase de pré-desenvolvimento (adaptado de Crawford e Benedetto (2006)) 
2. Os métodos aplicados no estudo de caso aumentaram ou reduziram o tempo padrão da empresa na realização das atividades do pré-desenvolvimento? Por quê?
a) Aumentaram bastante;
b) aumentaram pouco;
c) não aumentaram;
d) reduziram pouco;
e) reduziram bastante

3. Os métodos aplicados no estudo de caso aumentaram ou reduziram o custo padrão da empresa na realização das atividades do pré-desenvolvimento? Por quê?

a) Aumentaram bastante; b) aumentaram pouco; c) não aumentaram; d) reduziram pouco; e) reduziram bastante

4. Os métodos aplicados no estudo de caso aumentaram ou reduziram a qualidade da empresa na realização das atividades do pré-desenvolvimento? Por quê?

a) Aumentaram bastante; b) aumentaram pouco; c) não aumentaram; d) reduziram pouco; e) reduziram bastante

5. Os métodos aplicados no estudo de caso aumentaram ou reduziram a integração das áreas funcionais na realização das atividades do pré-desenvolvimento? Por quê?

a) Aumentaram bastante; b) aumentaram pouco; c) não aumentaram; d) reduziram pouco; e) reduziram bastante

6. Os métodos aplicados no estudo de caso aumentaram ou reduziram o alinhamento dos novos projetos de produto com as estratégias do negócio na realização das atividades do pré-desenvolvimento? Por quê?

a) Aumentaram bastante; b) aumentaram pouco; c) não aumentaram; d) reduziram pouco; e) reduziram bastante

7. Os métodos aplicados no estudo de caso aumentaram ou reduziram a sistematização da tomada de decisão nas atividades do pré-desenvolvimento? Por quê?
a) Aumentaram bastante; b) aumentaram pouco;
c) não aumentaram;
d) reduziram pouco;
e) reduziram bastante 


\section{II) Avaliação das mudanças da empresa durante o estudo de caso}

8. O estudo de caso causou alguma mudança em como a empresa define as estratégias (caminhos) para os seus novos produtos? Se sim, qual a mudança? Se não, a empresa vê possibilidades para aproveitar os conhecimentos aplicados?

9. O estudo de caso causou alguma mudança em como a empresa trata a criacão e gerenciamento das idéias/conceitos de novos produtos? Se sim, qual a mudança? Se não, a empresa vê possibilidades para aproveitar os conhecimentos aplicados?

10. O estudo de caso causou alguma mudança em como a empresa gerencia a introdução de projetos de nov produtos no portfólio de projetos em andamento? Se sim, qual a mudança? Se não, a empresa vê possibilidades para aproveitar os conhecimentos aplicados?

\section{III) Avaliação dos resultados do estudo de caso}

11. Quais foram os pontos fortes e fracos identificados com relação aos métodos (atividades e ferramentas) usados no estudo de caso?

12. Quais foram os principais benefícios do estudo de caso para a organização e quais foram as principais dificuldades enfrentadas para sua realização? 


\subsection{Modelo detalhado do Método ITG em BPMN}

No modelo, o símbolo de objeto de dados representa as informações de entrada e de saída das atividades (em verde), sendo que as informações de entrada (em amarelo) estão localizadas sempre acima das atividades e as informações de saída (em azul) sempre abaixo. As ferramentas usadas no método são indicadas o símbolo de anotação e todo o método está contido em uma única piscina que simboliza o time envolvido na aplicação. 
Time de aplicação do Método ITG

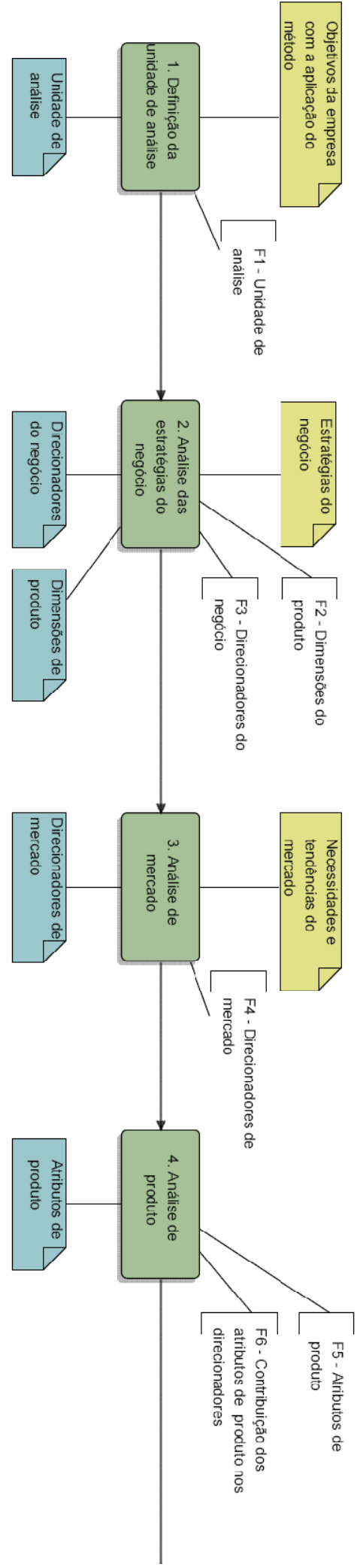




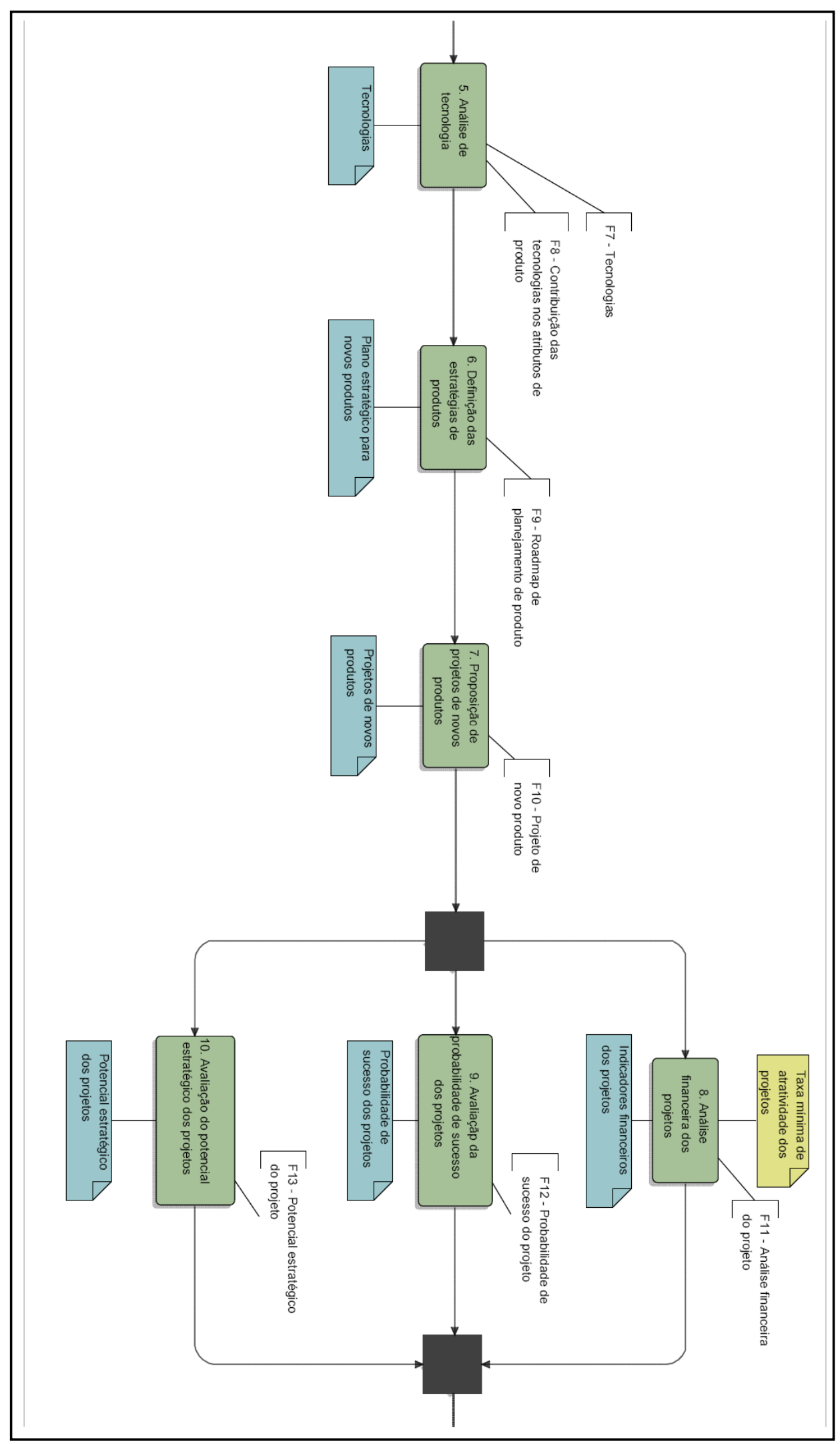




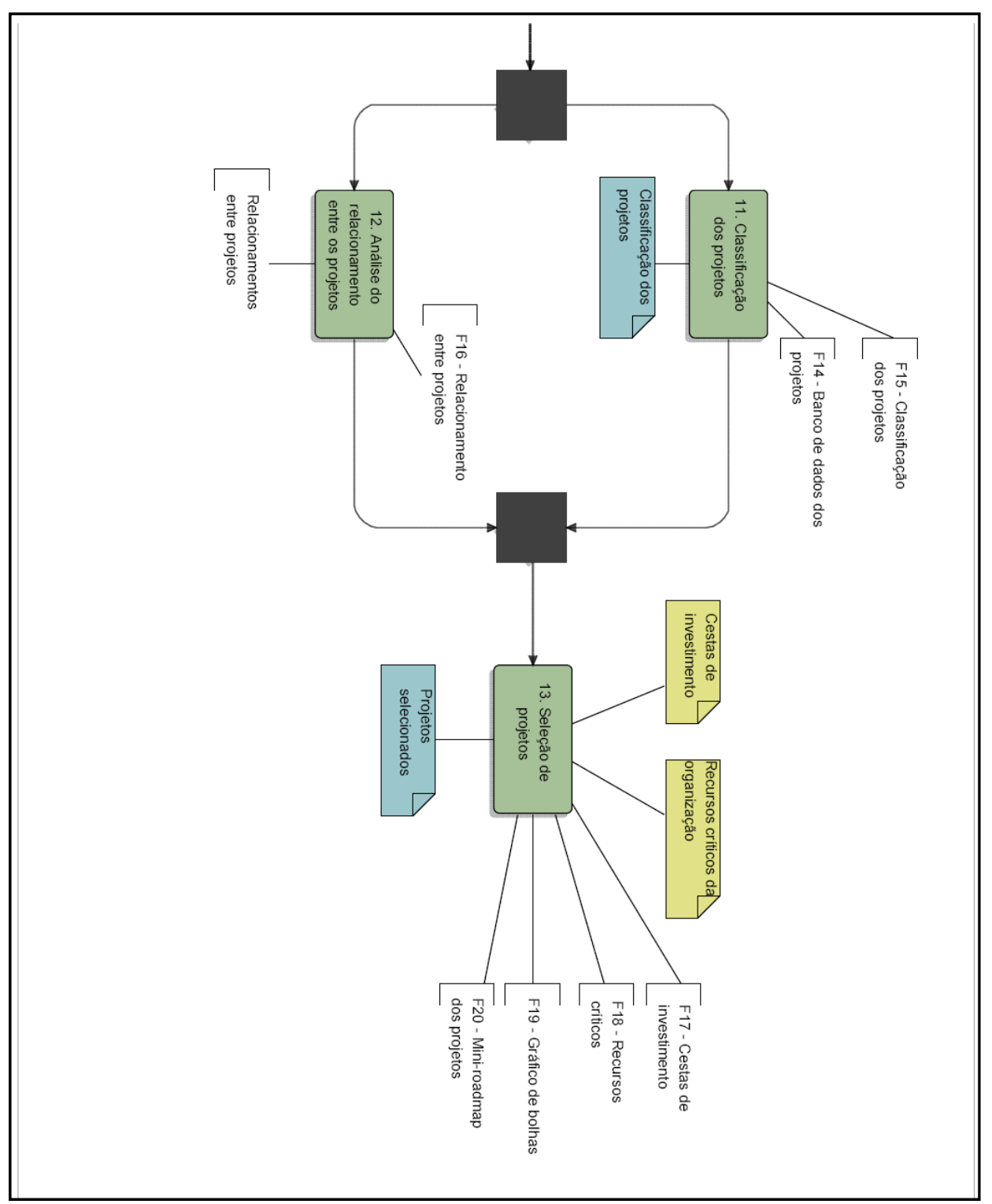

